\title{
Players' Responses to and Primary Caregivers' Perceptions of Authoritarian and Authoritative Coaching in the Inner-City
}

Renee Brown

Follow this and additional works at: https://researchrepository.wvu.edu/etd

\section{Recommended Citation}

Brown, Renee, "Players' Responses to and Primary Caregivers' Perceptions of Authoritarian and Authoritative Coaching in the Inner-City" (2017). Graduate Theses, Dissertations, and Problem Reports. 5269.

https://researchrepository.wvu.edu/etd/5269

This Dissertation is protected by copyright and/or related rights. It has been brought to you by the The Research Repository @ WVU with permission from the rights-holder(s). You are free to use this Dissertation in any way that is permitted by the copyright and related rights legislation that applies to your use. For other uses you must obtain permission from the rights-holder(s) directly, unless additional rights are indicated by a Creative Commons license in the record and/ or on the work itself. This Dissertation has been accepted for inclusion in WVU Graduate Theses, Dissertations, and Problem Reports collection by an authorized administrator of The Research Repository @ WVU.

For more information, please contact researchrepository@mail.wvu.edu. 
Players' Responses to and Primary Caregivers' Perceptions of Authoritarian and Authoritative Coaching in the Inner-City

\author{
Reneé Brown
}

Dissertation submitted to the College of Physical Activity and Sport Sciences at West Virginia University

in Partial fulfillment of the requirements for the degree of Doctor of Philosophy in Coaching and Teaching Studies/ Positive Youth Dynamics

\author{
Ryan Flett, Ph.D., Chair \\ Sean Bulger, Ph.D. \\ Andrea Taliaferro, Ph.D. \\ Suzanne Hartman, Ph.D.
}

Department of Coaching and Teaching Studies

Morgantown, West Virginia

2017

Keywords: Positive youth development, inner-city, coaching styles, coaching

Copyright 2017 Reneé Brown 


\begin{abstract}
Players' Responses to and Primary Caregivers' Perceptions of Authoritarian and

Authoritative Coaching in the Inner-City
\end{abstract}

Reneé Brown

An abundance of research in sport-based positive youth development (PYD) indicates that coaches should be positive, promote autonomy-supportive and authoritative coaching styles, and caution the use of authoritarian leadership, while too often ignoring elements of authoritarian leadership such as discipline and structure. However, most of the studies conducted targeted middle-upper socioeconomic status (SES) suburban, White populations, with little emphasis on the inner-city underserved context. Parenting and teaching literature provides strong support for authoritarian styles in the underserved setting (Hartman \& Manfa, 2015; Smetana, 2011). Similarly, the few studies conducted in the underserved sport settings show support of authoritarian styles (Brown et al., in preparation; Cowan et al., 2012; Flett et al., 2012; Flett et al., 2013; Richardson, 2012). The purpose of this study is to extend the previous year's season-long qualitative study of a single girl's basketball team (Brown et al., in preparation) to include perspectives from parents of that team and quantitative surveys from players across the league.

Participants included five head coaches with 14.2 years of experience and 80 players from the five teams in the league. The study incorporated interviews with six parental/primary caregivers from Team C; and quantitative surveys for players in the league. An abductive approach was used to develop thematic categories from the interview data (Miles, Huberman, \& Saldana, 2014).

Quantitative results revealed that players are improving life skill development over time. Additionally, in order for coaches to have the biggest impact, they must use authoritative coaching styles and foster a caring and mastery climate. More importantly, results indicated that authoritarian coaching was a unique predictor of life skills development, however, it did not affect life skill development in a negative or positive manner. Qualitative results revealed that parents/primary caregivers relied on the coach as a unique source of support and guidance to supplement, complement or compensate their adolescent's home life. Additionally, parents/primary caregivers strongly preferred authoritarian coaching combined with authoritative components to instill values and positively influence life skill development. 


\section{Acknowledgements}

First and foremost, I would like to give the praise, honor and glory to God for allowing me this opportunity to grow as a person, mentally, physically, spiritually, emotionally, and giving me the strength to endure through all odds. I am forever grateful and thankful for my advisor, Dr. Ryan Flett, because without your commitment, intuitive feedback, and immeasurable help, I would not have been able to complete this process without you. Throughout the years, you have been in my corner supporting me with everything whether it was academics, personal life, and exposed me to different opportunities to help develop me into the person that I am today. Dr. Flett, I want you to know that I sincerely appreciate and respect all that you do, because you go above and beyond the traditional role of a chair and I think more professors should strive to be more student-centered like you. To Dr. Hartman, I am so grateful that you were a part of the entire process. Your positive reinforcement, encouragement, and open-door policy helped motivate me through my dark times. I will forever remember the words you said to me, "If it was easy, then everyone would do it." To Dr. Taliaferro, I am so happy that you were willing to be a part of the committee because the thing I valued most was that you were straight-forward and did not sugar coat anything and it was from a place of love, which reminded me of my mother. To Dr. Bulger, thank you for having a listening ear and reminding me that everyone has breakdowns at one point in time, but the most important thing is that you get back up and little did you know; it was those very words that kept picking me up. I would also like to acknowledge Stephanie McWilliams for her assistance in the qualitative analysis and all participants in the study. I am grateful that 
you all allowed me your time to help me complete the study, given all the other tasks and responsibilities you had going on. Without you all, none of this would be possible.

There is an old African proverb which states "it takes a village to raise a child" little did you know, you were all that village and an extension of my family. If I could do everything over again, without changing one thing, I would; because I value each of you and because of your ideas and feedback made this a stronger dissertation.

To my parents, Cardell Nino Brown Sr., and Reneé Bernice Drummond-Brown, WVU has made me understand without a shadow of a doubt that none of my accomplishments would have been possible without parents like you. Your patience, trainings and beliefs helped shaped me into the person I am today. I know it has been rough over the years, and we did not always see eye to eye, but you never gave up on me because you both seen something greater in my future. Thank you for making sacrifices that you did and I hope that I have made you proud.

To my grandfather, Peter Charles Drummond, thank you pap-pap for loving me unconditionally, and being present at all of my presentations.

To my siblings, Cardell Nino Brown Jr. and Raven Chardell Brown, although, you could not be there at times physically, because of jobs and travel; you were always there with me in spirit.

To Anthony Antonelli and Family, thank you for the love, support and kindness you have shown me throughout the years. The Antonelli family will forever hold a special place in my heart. 
To my late grandmother, Barbara Ann Drummond, this degree is for you. I cannot thank you enough because it was you and mom who both challenged and inspired me to pursue a PhD. While at WVU as you both requested, I held on to this scripture, 2Timothy 2:15 "Study to shew thyself approved unto God, a workman that needeth not to be ashamed rightly dividing the word of truth," I hope I made you proud! I love you!

To all my extended family and supportive friends (too numerous to mention) please know, that I am grateful for your love, support and prayers throughout the education process, you also hold a special place in my heart. To God be the glory for the things He has done in my life. 


\section{Table of Contents}

Acknowledgements.............................................................................................................

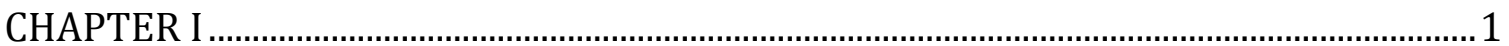

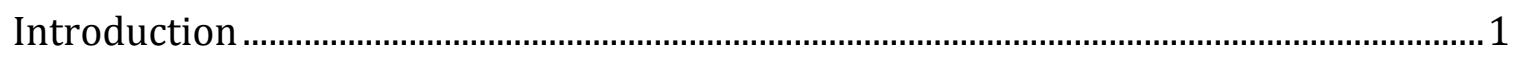

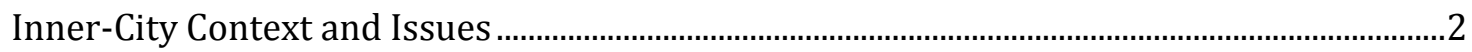

PYD, Sport, and Underserved Inner-City Youth.......................................................................

The Coach's Role in Inner-City Underserved Settings .................................................................5

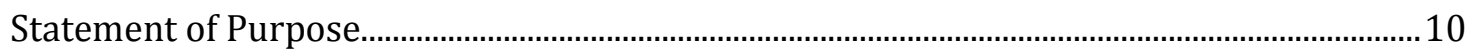

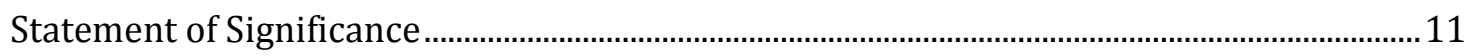

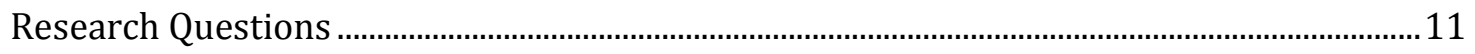

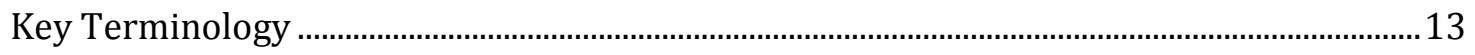

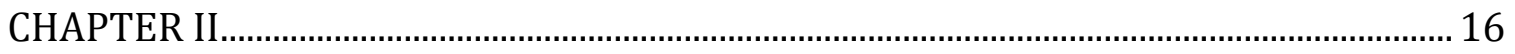

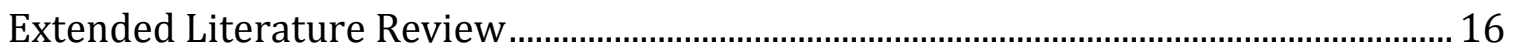

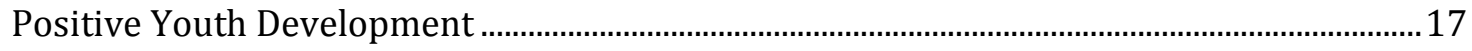

Framing Key Literature in Theory

Effective Coaching, Mentorship, and Sport Issues ...........................................................................

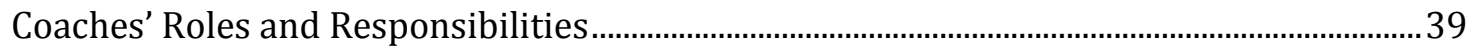

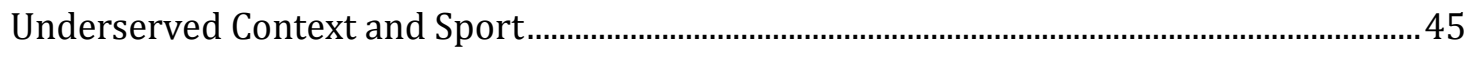

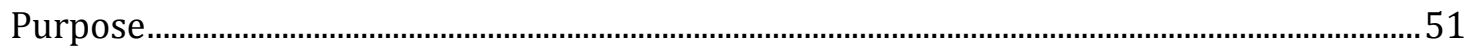

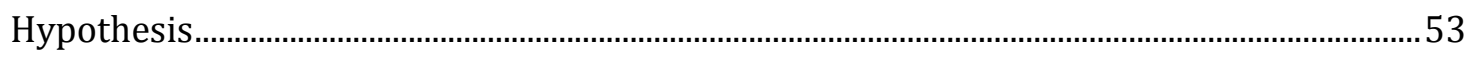

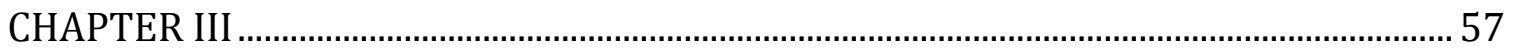

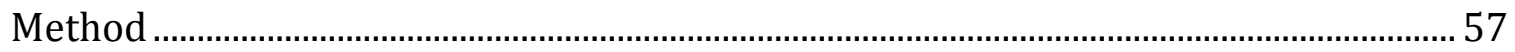




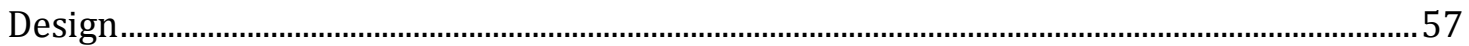

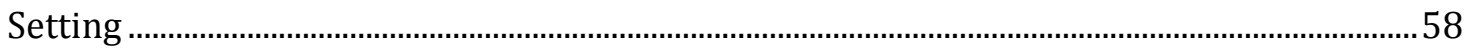

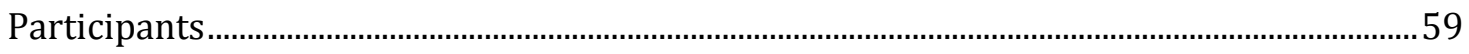

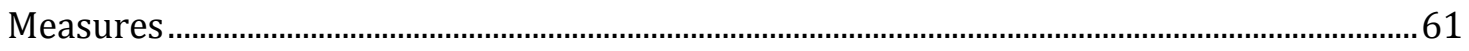

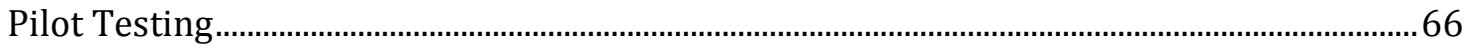

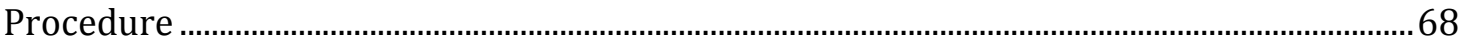

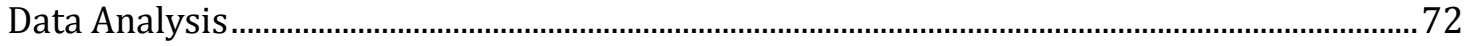

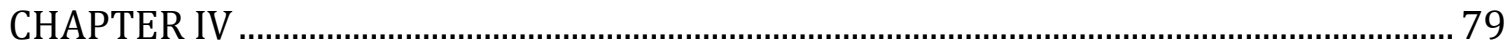

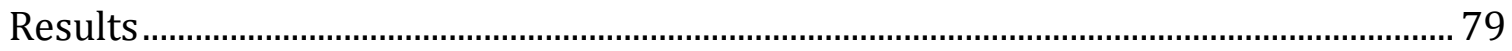

Participant Numbers, Measurement Reliabilities, and Assumptions .......................................79

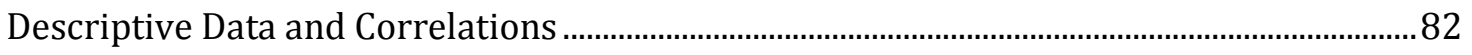

Research Question 1: Developmental Outcomes and Related Factors .................................... 85

Research Questions 2: Common and Comparison of Coaching Style in Context ..................92

Research Question 3: How Parents View Sport and/or Coaches ............................................. 93

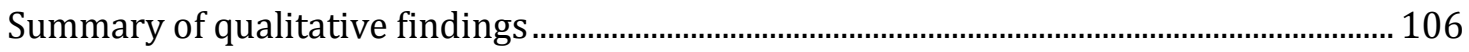

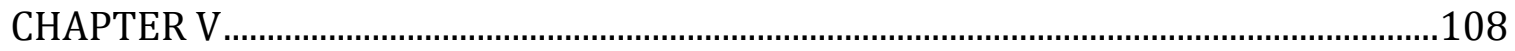

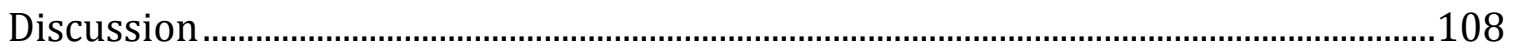

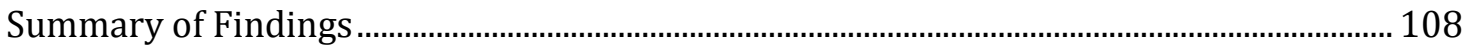

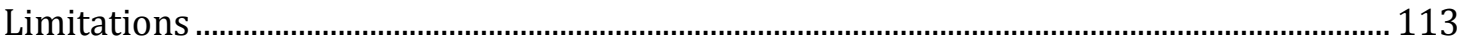

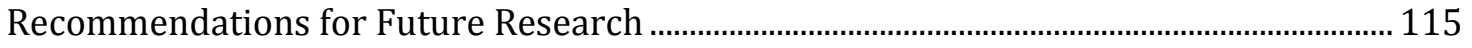

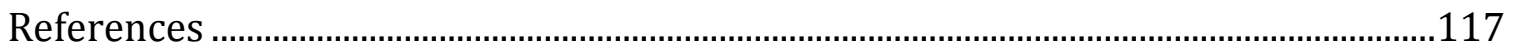

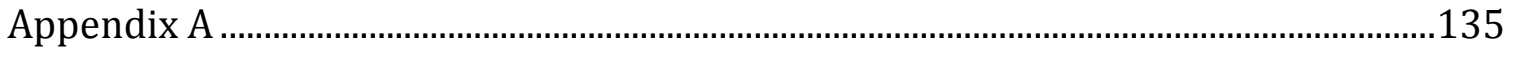




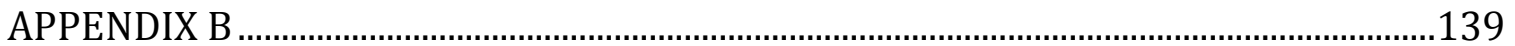

Appendix C

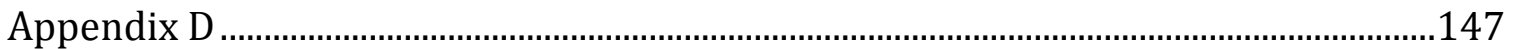

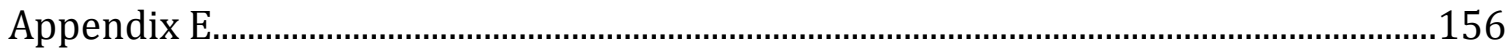




\section{CHAPTER I}

\section{Introduction}

The current dissertation is grounded in the ecological systems theory (EST) and expands Brown, Hayes, Goodson, Hartman, and Flett's (in preparation) season-long ethnography and interview study to include parental/primary caregiver perspectives and

the other high school girls' basketball teams within the same city league. The purpose of this study is four-fold. First, it will inform the reader of the coaching styles used in the underserved setting. Second, it will explore the impact of the coaching style and objectively track developmental outcomes throughout the season. Third, it will explore the use of authoritarian strategies in the underserved setting, which is under-represented in the sport literature. Lastly, it will investigate parental/primary caregivers' perceptions of the coaching style used in the underserved setting, the intentionality of the coach, whether life skills (LS) are transferred from the sport setting to other domains of life, and how the coach supplements or augments parental/primary caregivers' efforts in this context. In summary, the purpose of this study is to expand the previous year's seasonlong qualitative study of a single girls' basketball team to include perspectives from parents of that team and quantitative surveys from players across the league.

Positive youth development (PYD) is especially important in underserved communities because youth are less likely to have positive emotional, social, and cognitive developmental experiences (Flett, Gould, \& Lauer, 2013; Smetana, 2011). Sport is an avenue for youth to engage in PYD; however, PYD occurs from positive experiences and coaching, not from sport alone (Thomas-Fraser, Côté, \& Deakin, 2005). 
The sport-based PYD literature encourages coaches to create autonomy-supportive climates, be "positive" with their players, and cautions the use of authoritarian, controlling coaching styles (Cowan, Taylor, McEwan, \& Baker, 2012). PYD research typically focuses primarily on white, middle- to high-class populations with limited research on coaches in underserved urban settings. Based on strong support from parenting literature — and to a lesser extent, the teaching literature — authoritarian styles may be the most developmentally effective approach in underserved settings. This chapter will provide a basic overview of the literature and issues in inner-city contexts, PYD in sport, and the coach's role in the underserved setting, and will conclude with definitions of key terminology.

\section{Inner-City Context and Issues}

The underserved setting can be defined as those individuals that are provided with low levels of access, inadequate services (i.e. health services, low rates of insurance, etc.) and face a multitude of barriers in everyday life (Walsh, 2008). This context can be characterized by high-risk factors such as poverty, high crime rates, and lack of support. Youth who grow up in this setting are more likely to be at a developmental disadvantage socially, emotionally, and cognitively because they are not afforded the same opportunities as higher socioeconomic (SES) communities (Smetana, 2011). Underserved youth are more likely to face challenges such as broken homes, racism, poverty, lower quality health care, poor education, gang violence, crime, and limited extracurricular activities (Martinek \& Hellison, 1997; Martinek \& Schilling, 2003; Walsh, 2008). Experts have argued that youth living in the underserved settings are in the greatest need 
of PYD-support because they are more likely to lack developmental experiences and support systems (Flett et al. 2013; Walsh, 2008).

Parents and primary caregivers are responsible for socializing and teaching their children the socially desirable behaviors of the culture. However, parenting styles differ from home to home. Furthermore, Coakley (2002) indicated that upper-middle income, predominately White families place emphasis on upward mobility, as compared to an underserved minority family which emphasizes control and discipline. Research in parenting literature shows strong support for Coakley's claim and revealed that parents in the underserved setting are more likely to use authoritarian parenting styles because they are developmentally effective and serve as a protective factor to underserved youth (Eamon, 2002, Smetana, 2011). For example, Eamon's two-year longitudinal study with participants living in poverty found that the use of physical punishment prevented antisocial behavior. In a similar study, Dearing (2004) found that authoritarian parenting served as a protective factor for youth living in a neighborhood characterized by rape, robbery, burglary, larceny, and aggravated assault. The authors also found that the authoritarian parenting style had a positive effect on academic performance.

Research in teaching literature describes that the utilization of an authoritarian approach by staff and teachers toward youth living in poverty is associated with fewer child-behavior concerns (Hartman \& Manfra, 2015; Higgins \& Moule, 2009). For example, Hartman and Manfra conducted a year-long study to explore the relation between the quality of childcare and behavioral development with low-income underserved Latino children. The findings revealed that a controlling and strict (i.e. authoritarian) approach improved child behavior and decreased behavior concerns. In 
sum, some research indicates that authoritarian styles are developmentally effective for youth living in the underserved settings.

\section{PYD, Sport, and Underserved Inner-City Youth}

PYD is a holistic strength-based approach that focuses on enhancing pro-social norms and optimizing personal development, and engaging youth within their family, school, and community contexts. This leads to involvement in extracurricular activities and develops and refine youth skills (Coakley, 2011). Experts emphasize that organized sport participation could be beneficial and aid in PYD (Deakin, 2005).

Sport is considered the most popular and time-consuming activity in high schools (Hansen \& Larson, 2007), and is typically available to underserved populations. Many believe that sport is an appropriate activity for enabling PYD because it can serve as a protective factor, enhance personal and interpersonal development, and provide opportunities for youth to build rapport with adults, such as coaches (Cowan et al., 2012; Flett, Gould, Griffes, \& Lauer, 2012; Flett et al., 2013; Gould, Flett, \& Lauer, 2012; Richardson, 2012). Research shows that sport can have positive outcomes such as physical health (Côté \& Fraser-Thomas, 2007), teamwork/cooperation opportunities (Gould et al.), positive relationships with adults (Fry \& Gano-Overway, 2010) and positive self-esteem (Smith, Smoll, \& Curtis, 1979). However, other researchers found sport to have negative outcomes on youth such as increased stress (Merkel, 2013), emotional abuse (Stirling \& Kerr, 2013), poor cooperation, and negative peer influence (Dworking \& Larson, 2006). In other words, PYD does not occur from sport participation alone; other social contextual factors (i.e. coaches) contribute to the fostering of PYD (Petipas, Cornelius, Van Raalte \& Jones, 2005; Holt, 2008). 


\section{The Coach's Role in Inner-City Underserved Settings}

As stated earlier, PYD does not occur from sport alone; coaches play a pivotal role in player development through their coach-athlete relationship (Jowett \& Ntoumanis, 2004; Petipas et al., 2005; Smith \& Smoll, 2011) motivational climate, coaching style, and coaching behavior, especially in the underserved settings.

Coach-Athlete Relationship. In underserved settings, interpersonal relationships within non-familial adults (such as coaches) are important (Levine \& Munsch, 2016). The coach-athlete relationship is essential because coaches have the ability to become role models and mentors to their athletes due to the consistency and time spent in games, practices, and off-court activities (Jaime et al., 2015). Furthermore, research shows that athletes' perceptions of strong coach-athlete relationships are linked to positive developmental experiences (Jowett, 2008). Richardson's (2010) study in the underserved context of New York City showed that caring and trust was built between players and coaches through consistent interactions during practices and off-court activities. As a result, the coach was able to reduce risk, promote resiliency, and provide safety to players through mentorship. In addition, the coach kept players occupied with various activities and talked to players about their actions and choices. Experts emphasized the importance of the caring element when it comes to working with underserved youth.

Motivational Climate and Caring Climate. Another important factor that has a direct impact on player experience is the motivational climate. Coaches are responsible for creating and structuring an environment that is beneficial to PYD. Research strongly supports the idea of using a mastery climate because success is based on personal improvement, effort, helping others, learning through cooperation, and hard work (Cox, 
2002). Furthermore, studies have shown that mastery climates increased positive attitudes towards sport and coach (Fry \& Newton, 2003), decreased burnout (Vitali et al., 2015), decreased athlete anxiety (Fry \& Newton, 2003), and increased personal and social development. Gould et al. (2012) found that a mastery-oriented climate has the most positive impact on underserved youth.

However, Gould et al. (2012) also found that "kids don't care what you know, unless they know you care," (p.86) and hypothesized that the caring climate defined by Newton et al. (2007, p.70) as "the extent to which individuals perceive a particular setting to be interpersonally inviting, safe, supportive, and capable of providing the experience of being valued and respected" is more important than a motivational climate and is more likely to influence PYD. The caring climate is an important factor in PYD because if players perceive the feelings of being cared for (feelings of support, safety, value, and respect) then they are more likely to value the perspective of their coach (Gano-Overway et al., 2009). In other words, coaches who create a caring climate can impact their players' beliefs and foster prosocial behaviors. Similar to Richardson's (2010) study, Gould et al. found that building rapport, caring, and supporting the athletes allowed the coach to be more effective in their personal and social development (e.g. teamwork, physical skills, initiative, cooperation). Additionally, Fry and Gano-Overway (2010) found that players who perceived a caring climate reported having higher enjoyment and more positive attitudes towards the coach and teammates.

Coaching style. Coaches in urban, underserved settings are believed to be more authoritarian, controlling and militaristic towards their athletes because they want to protect and prepare their players for the ways of the world as opposed to creating an 
autonomy-supportive climate (Flett et al., 2013). For example, Flett et al. (2012) conducted a qualitative comparison study in inner-city Detroit with 12 youth coaches from six different sports. The authors used ethnographic methods and interviews to observe the coaches 14 times in practice and game settings before conducting in-depth interviews with each coach. Findings indicated that coaches who utilized an authoritarian, militaristic coaching style were invested in their athletes lives and knew the personal struggles the athletes faced (e.g. gang violence, crime, abuse, uninvolved parents, dangerous neighborhoods, etc.). Furthermore, coaches wanted to prepare players for the ways of the world with "tough-love." The coaches who utilized this approach disciplined the players out of love and went to the extremes to protect their athletes from negative outcomes. In addition, the authors found that discipline may be effective in the urban underserved settings, which is consistent with the parental literature.

However, the same sample of coaches tended to use authoritarian styles in overly harsh, ineffective ways. Discipline and toughness used by these coaches were understandable and justified, but extreme anger, harsh verbal attacks and emotional manipulations were unjustifiable. The study did not investigate the coaches' behavior over a long period of time, did not interview parents, and this particular study did not incorporate quantitative measures or a more generalizable sample size.

Cowan et al. (2012) conducted a case study in the underserved setting of Scotland to explore coaching behaviors and the common assumption that autonomy-supportive coaching is adaptive, versus controlling coaching which is considered to be maladaptive. The sample included two male head coaches and 18 athletes from two teams between the ages of 16 to 19 years. The authors found that the coaches were considered to be 
controlling and militaristic. However, the coach used humor to help buffer the negative outcomes associated with his authoritarian, controlling coaching style. In addition, the authors found that the provision of choice to the players was maladaptive in this setting because players lacked confidence and self-esteem. The study was limited because the authors were not immersed into the culture of the team but instead relied on nonparticipant observations. This underserved setting may also differ from North American high school sport. Although the context may differ, the fact remains that an authoritarian coaching style was effectively used in an underserved setting. Based on the few studies published about underserved sport-based PYD, results suggest that authoritarian coaching styles play a significant role in underserved PYD (Cowan et al., 2012; Flett et al., 2012; Flett et al., 2013; Gould et al., 2012; Richardson, 2012).

Brown et al. (in preparation) conducted a season-long in-depth ethnographic study to observe a coach's style and impact on players in the underserved setting. In addition, the study included interviews to assess the coach and players' perceptions of the developmental environment, the coach's perceived role/responsibilities, and the rationale for coaching style/strategies. In an effort to address multiple gaps in the literature, this study focused on a high school girls' basketball team, was conducted over an entire year, and the primary investigator was embedded within the team as a volunteer coach (and had already coached with that team for a full season before this research study). As such, the data collected in this dissertation represents the author's third year with the team and second year researching them and the city-league.

The results of Brown et al. (in preparation) indicated that the coach was characterized as highly authoritarian and controlling, but also highly caring and sensitive 
to the needs of the players. Together, these attributes are indicative of what the authors term a "tough-love" approach: caring, understanding, and supportive, yet disciplined, demanding, and lacking autonomy support. The coach consumed and controlled much of the player's time in order to develop academics, life skills, and character while keeping them from threats in the community. Player and coach-interviews revealed that the coach had high expectations for the players and disciplined them out of love. The coach used physical tactics such as Charlie Horsing (light jabs in the arm), "popping" (i.e. slapping players in the head), and "socking" (i.e. punching) to get players back on task, to motivate, and to keep their attention. All players believed the coach used physical contact in a positive and humorous manner, never in a negative manner, because the coach cared for the players. Critical to the literature, results indicated that players generally supported the coach's use of an authoritarian approach, and expressed a desire for even more disciplinary, controlling, and strict leadership (in order to manage newer and more unruly girls). However, the study was limited in its design because the authors focused on one team in the league and did not make comparisons to other teams. In addition, they did not obtain quantitative assessments of developmental outcomes or perceived coaching style. Parents of the players also expressed an interest in being interviewed so that they could share their perspectives on the coach, context, and their daughter's development.

What works for one context may be maladaptive in another context. Authoritarian styles used in underserved, high-crime/-violence, and disadvantaged settings are more likely to facilitate resilience and positive outcomes in youth (Cowan et al., 2012; Flett et al., 2012; Flett et al., 2013; Gould et al., 2012; Hartman \& Manfra, 2015; Richardson, 2012). Additionally, authoritative styles in these settings may be considered harmful and 
maladaptive. Coaching styles should be context-specific and focus on players' needs (Flett et al., 2016).

After reviewing the foundational articles related to coaching in the underserved settings, future research needs to explore parental/caregiver views on the coaching style and how it impacts child development, the transfer of life skills, and the use of authoritarian strategies. The current sport-PYD literature is not representative of the underserved context and the unique challenges they face in everyday life. As stated earlier, parenting literature and to an extent, some teaching literature shows strong support for authoritarian (controlling, monitoring, and strict) styles in the underserved setting. However, coaching literature typically cautions the use of authoritarian styles and supports the use of positive, choice-based, autonomy-supportive (i.e. authoritative) styles for PYD— but may be overgeneralizing their findings.

Furthermore, the current sport-PYD literature needs to expand and become more culturally and socioeconomically diverse. Additionally, the literature must progress and change from streamlining and stating that the use of authoritarian coaching and parenting is wrong. More importantly, the most valuable question that needs to be answered is: How can authoritarian styles of coaching be used most effectively, especially in the underserved settings?

\section{Statement of Purpose}

In summary, the purpose of this dissertation will address the lack of underserved PYD research; address the need for more longitudinal mixed-method studies; objectively measure and track developmental outcomes throughout a season; and better understand coaching styles used and how they impact PYD in the underserved setting (Cowan et al. 
2012; Flett et al. 2012 and 2013). In addition, the dissertation will answer the question "what combination of coaching style factors has the strongest influence for PYD in the underserved setting?" Lastly, it will look at parental/caregiver perceptions and preferences of coaching styles, the intentionality of the coach, and transferable life skills.

\section{Statement of Significance}

The following dissertation contributes to the existing sport-based PYD literature by exploring a multitude of coaching styles used in the underserved settings of the innercity. To the knowledge of the primary investigator (PI), this study is the first to objectively measure authoritarian and authoritative coaching in sport (in the underserved or any other setting). Additionally, the current study will assess life skill outcomes at two time periods, which differs from the current sport-based literature utilizing one time of data collection. This study is informed by not only the sport literature but also parental and teaching literature.

\section{Research Questions}

This study will use quantitative measures to survey teams across the city league located in an urban underserved setting in the North East United States, and in-depth interviews with parents/primary caregivers from one team (Team C) within this league. The research questions and sub-questions guiding the study are as follows:

1. Do life skills (LS) improve from participation, and what coaching style factors influence those LS outcomes?

1.1 Do quantitative measures of life skills show improvement for players across the season (Do scores change over time)? 
1.2 Do quantitative measures of coaching style change over the basketball season (between Time 1 and Time 2)?

1.3 Are certain coaching styles greater for LS development (i.e. authoritarian, authoritative, caring, mastery, ego)?

1.4 If you were to combine all coaching style factors, which have the strongest influence on LS?

1.5 What influence does authoritarian coaching have on LS when combined with each of the other three coaching style factors (i.e. caring, mastery, ego), one at a time (i.e. authoritarian + caring; authoritarian + mastery; and authoritarian + ego).

1.6 What influence does authoritative coaching have on LS when combined with each of the other three coaching style factors (i.e. caring, mastery, ego), one at a time (i.e. authoritative + caring; authoritative + mastery; and authoritative + ego).

2. What is the common style of coaching in the city league?

2.1 What is the common coaching style in the city league?

2.2 How does Coach DD's (Team C) style compare to other coaches' styles in the city league?

3. Is this coach (Coach DD, Team C) developing LS through basketball, and if so, what skills and how does she develop them?

3.1 What developmental outcomes do parents think occur from participation with this coach and team (i.e. life skills development, intentionality, and transferability)? 
3.2 Does the coach foster youth development intentionally? If so, how does she intentionally develop LS?

3.3 Do parents feel they can provide concrete examples of transferrable LS? If so, how are they being transferred?

3.4 Do parents think the sport or coach supplement psychosocial development in the players' home lives? If so, how does the coach or sport supplement psychosocial development in the players' home lives?

\section{Key Terminology}

Adolescents. Youth who are in the transitional stage concerning childhood and adulthood between the ages of 13 to 19 years.

Authoritarian. A person who is characterized as highly demanding, less responsive, controlling, and rarely provide rationales (Baumrind, 2013). Authoritarians tend to create a disciplined environment with clear rules, and monitor behaviors, and activities of youth (Holt, Tamminen, Black, Mandigo \& Fox, 2009).

Authoritative. A person who is characterized as highly demanding, responsive, consistent, and provides rationales (Baumrind, 2013). In addition, authoritative people are assertive, and use supportive rather than disciplinary actions (Holt et al. 2009).

Autonomy-supportive. "A style that actively supports self-initiated strivings and creates conditions for athletes to experience a sense of volition, choice, and selfendorsement (Bartholomew, Ntoumanis, Thøgersen-Ntoumani 2010)." In addition, an autonomy-supportive style allows youth to feel that they initiate their actions rather than feeling coerced to act in a certain manner (Grolnick, 2003). 
Caring climate. "The extent to which individuals perceive a particular setting to be interpersonally inviting, safe, supportive and capable of providing the experience of being valued and respected" (Newton et al., p.70).

Positive youth development. A holistic intentional approach that engages youth in all contexts (i.e. school, home, work, etc.) while enhancing pro-social norms and helping youth reach their full potential (Holt, 2008; U.S. Department of Health and Human Services, 2007).

Sport. Structured physical activity governed by a set of rules and facilitated by a coach or instructor that is implemented in an individual or group setting.

Tough-love. A formal, established definition for this term is not available from the literature, but because the term is frequently used in this dissertation, it is important to provide clarity it. The term has emerged from research by Flett et al. (2013) and Brown et al. (in preparation). Tough-love is meant to describe a highly caring and respectful approach to authoritarian, or more controlling, coaching. Such an approach would not be "entirely" authoritarian in that there could be elements of autonomy-supportive and authoritative behaviors. Finally, based on Flett et al.'s work, it is important to clarify that a tough-love approach is not angry, unregulated, out of control coaching. A tough-love coach is able to model life skills and positive psychosocial attributes.

Underserved. According to the American Journal of Managed Care (2013), underserved populations are defined as vulnerable populations that include the economically disadvantaged, racial and ethnic minorities, the uninsured, low-income children, the elderly, the homeless, those with human immunodeficiency virus (HIV), and those with other chronic health conditions, including severe mental illness. It may also 
include individuals who often encounter barriers to accessing healthcare services. The vulnerability of these individuals is enhanced by race, ethnicity, age, sex, and factors such as income, insurance coverage (or lack thereof), and absence of a usual source of care. Their health and healthcare problems intersect with social factors, including housing, poverty, and inadequate education. For the purpose of the dissertation, underserved will be characterized as those who are socially disadvantaged, living in poverty, and face many unique challenges such as racial discrimination, gang violence, substance abuse, and cultural barriers (see, Flett, Gould, \& Lauer, 2013; Richardson, 2012; Walsh, 2008). 


\section{CHAPTER II}

\section{Extended Literature Review}

This dissertation addresses the need for research on sport coaches and positive youth development (PYD) in the underserved setting. The study will explore inner-city coaching styles throughout the season and their impact on developmental outcomes. In addition, the study will examine parents'/primary caregivers' perceptions of the coaching style in the city league, and intentionality and transferability of life skills.

While an authoritative style and positive coaching strategies (e.g., autonomy support) are staples of a PYD approach to coaching, authoritarian parenting and teaching styles are more developmentally effective in underserved settings. Bartholomew, Ntoumanis, and Thøgersen-Ntoumani (2010) argued that coaches can use a mixture of both autonomy-supportive and controlling strategies simultaneously and still be considered adaptive. Youth from underserved settings are in the greatest need of PYD because of the unique challenges they face in their everyday life (Walsh, 2008). Researchers believe that underserved youth may also be less likely to have positive developmental experiences in sport (Flett, Gould \& Lauer, 2012; Flett, Gould, Griffes, \& Lauer 2013; Richardson, 2012). Sport is a popular activity in high school and many perceive it to be an effective activity to enhance personal development and serve as a protective factor for underserved youth (Coakley, 2011). Sport provides underserved youth the opportunity to develop interpersonal relationships and build rapport with peers and non-familial adults, such as coaches. 
The purpose of this chapter is to explain the importance of PYD and how it relates to this study. Additionally, this chapter will discuss the context needed for PYD to occur in sport and explain the importance of girls' participation in sport. The chapter will then focus on the ecological systems theory (EST), which will help explain the importance of interpersonal relationships throughout different contexts, and how they play an enormous role in player psychosocial development. Furthermore, it will then focus in depth on effective coaches, with specific emphasis on the coaches' role, style, and the created motivational and caring climate. Lastly, the chapter will review the scant literature in sport and the underserved setting, address gaps, and discuss future directions.

\section{Positive Youth Development}

In the past, traditional youth development was reactive and focused on minimizing and reducing problems such as teen pregnancy, sexual involvement, substance abuse, problem behaviors and delinquency during adolescence in targeted populations (Holt, 2008). This traditional approach provided intervention programming and treated youth as beneficiaries as opposed critical resources and solutions. Pittman et al. (2011) noted that problem-free youth are not fully prepared to be productive members of society. Larson (2000) argued that healthy development involves more than reducing and minimizing problem behaviors. In addition, Holt (2008) and others argued that a comprehensive, holistic approach is more beneficial and would achieve long lasting results for youth. As a result, a shift has been made from a traditional deficit reduction approach to a humanistic positive youth development approach.

PYD is a holistic, strength-based approach that engages all youth within their families, school, and community context. PYD has no singular definition. It concentrates 
on enhancing pro-social norms, helping youth reach their full potential (U.S Department of Health and Human Services, 2007), fostering positive relationships (Strachan, Côté, \& Deakin, 2009), and viewing youth as contributing members of society and critical resources to be developed as opposed to problems to be solved (Holt, 2008; Roth \& Brooks-Gunn, 2003).

Within the PYD field, several researchers have outlined key components needed for optimal development. Larson (2000) believed that there needs to be a match between experiences of adolescents and requirements of the adult word. He argued that youth need three important characteristics to function as healthy adults: initiative, empowerment and leadership opportunities. Damon (2009) believed youth need to have a "purpose" in life, which, in turn, helps adolescents cope and allow them to be optimistic no matter the situation. The Five C's Model of PYD created by Lerner and colleagues (2005) address psychological, behavioral, and social characteristics in youth including: competence, confidence, connection, character and caring. Youth who acquire the Five C's are considered to be thriving and will develop a sixth C, described as contribution to self, family, and community (Zarrett \& Lerner, 2008).

Similarly, the Search Institute identified 40 developmental assets, also known as "building blocks" for human development. These assets help youth to become more healthy, caring, and responsible adults. The developmental assets are organized into two components, internal assets and external assets, with eight domains. Internal Assets are sets of skills, links to the personal development, competencies, and values within a person and are grouped into four categories: 1) positive identity, 2) positive values, 3) social competencies, and 4) commitment to learning (Benson et al., 2011). External 
assets describe the environmental, contextual and relational assets (formation of strong bonds and relationships with the developing person), and are likewise grouped into four categories: 1) empowerment, 2) support, 3) constructive use of time, and 4) boundaries and expectations (Benson et al., 2011; Brofenbrenner, 2009). In order to develop these assets, youth must positively and effectively interact within various contexts (family, school, and community) to build important relationships and foster opportunities to enhance their skills (Strachan et al., 2009). Research shows that adolescents who acquire multiple assets have a greater chance of developing in a healthy manner (Benson et al., 2006; Strachan, Fraser-Thomas, \& Nelson-Ferguson, 2016). Fraser-Thomas, Côté and Deakin (2005) implied that organized sport participation could benefit youth and help them grow into caring and responsible adults.

Sport and PYD. PYD engages youth through multiple contexts (family, school, and community) and provides youth the opportunity to get involved in various extracurricular activities, like sport, to develop and refine their skills. In almost every school, sport is the most popular and time-consuming activity (Hansen \& Larson, 2007). In the United States, approximately 21.5 million youth between the ages of 6 to 17 participate in organized team sports annually (Kelley \& Carchia, 2013). The late Nelson Mandela stated:

Sport has the power to change the world. It has the power to inspire, it has the power to unit people in a way that little else does. It speaks to youth in a language they understand. Sport can create hope, where once there was only despair (Laureus World Sports Awards, Monaco 2000). 
Organized sport enhances personal development more so than informal activities such as hanging out with friends (Mahoney \& Stattin, 2000), or hanging out at the mall (Osgood \& Anderson, 2004). According to Perkins et al. (2007), "Time spent in youth programs is the most consistent predictor of youth thriving," and research supports that youth participating in organized sport are more likely to experience positive developmental outcomes in comparison to those who do not participate in organized sport (Larson, 2000). Empirical findings have shown that organized sport can lead to healthy social, psychological, and physical developmental outcomes such as an increase in physical health (Bailey, 2006; Côté \& Fraser-Thomas, 2007), self-esteem (Bailey, 2006; Smith, Smoll \& Curtis, 1979), decreased stress (Smith, Smoll, \& Cumming, 2007), leadership opportunities (Gould \& Carson, 2008), teamwork/cooperation opportunities (Gould et al., 2012), increased academic achievement (Bailey), character development (Donnelly \& Coakley, 2007; Gould, Collins, Lauer, \& Chung, 2007), responsibility (Hellison \& Cutforth, 1997) and the establishment of positive relationships with adults (Fry \& Gano-Overway, 2010; Strachan et. al, 2009).

The cultural and structural context of sport influences personal and social development (Theokas, Danish, Forneris, Hodge, \& Heke, 2008). Factors such as personal characteristics of the athletes and coach (Peterson, 2004), actions of the coaches (Smith\& Smoll, 2002), and the environmental context (Fry \& Gano-Overway, 2010; Holt, Sehn, Spence, Newton \& Ball, 2012; Martinek \& Hellison, 1997) play a role in developmental outcomes in sport. Larson, Hansen, and Montea (2006) contend that positive outcomes of sport will likely occur when it is intentional, structured, and systematic because sport is more likely to enhance external and internal assets in 
adolescents (Hodge, 1989; Petipas, Cornelius, Van Raalte, \& Jones, 2005). However, sport participation alone is not the "magic ingredient" to enhance PYD.

Negative outcomes and best-practices. Although many studies show that sport can be beneficial to PYD, negative outcomes can occur if PYD is not intentional. If sport is not conducted in the right manner, it has the potential to deter youth from personal and social development and result in eating disorders (Reel, SooHoo, Petrie, Greenleaf, \& Carter, 2010), elevated use of alcohol (Lisha, Crano, \& Delucchi, 2014; Veliz, Boyd, \& McCable, 2015), sport injuries (Vitali, Bortoli, Bertinato, Robazza, \& Schena, 2015), decrease in self-esteem and confidence (Stirling \& Kerr, 2013), athlete burnout (Vitali et al.), increased stress (Gould \& Carson, 2010), poor sportsmanship (LaVoi, \& Stellino, 2008), emotional abuse (Stirling \& Kerr), and/or poor cooperation and negative peer influence (Dworkin \& Larson, 2006). These negative outcomes are believed to occur because of parents, youth, and coaches placing too much emphasis on sport outcomes (i.e. winning, losing, and playing time), lack of formal education for coaches, and sport susceptibility to adult domination (Gould \& Carson, 2008).

The research presented shows empirical support for both positive and negative outcomes that may result from sport participation. As stated earlier, sport participation alone is not the "magic ingredient" to enhance PYD. Coakley (2011) argued that, "By itself, the act of sport participation among young people leads to no regularly identifiable developmental outcomes" (p. 309).

In an effort to reduce negative experiences, Petipas et al. (2005) created a PYD sport framework grounded in research findings and best practices in the field of youth development (Larson, 2000; Smith \& Smoll, 2002). Petipas et al. indicated that PYD will 
occur when youth a) are engaged in a desired activity within the appropriate context, b) are surrounded by positive, caring external assets, and c) have the opportunity to learn and acquire internal assets. In addition, Lerner and Lerner (2006) indicated that structure and physical/psychological safety of athletes are critical factors to instilling PYD. In the teaching personal and social responsibility (TPSR) framework, Martinek and Hellison (1997) suggested that youth development programs should develop a sense of values, purpose, and empowerment; respect diversity; promote safety; and develop resiliency. In other words, youth programs need to create and maintain a physically, psychologically, emotionally, and socially safe setting where coaches provide opportunities to teach youth the necessary skills and instill positive values needed for sport and other domains (i.e. school life, home life, and work life). The current study looks at how coaching styles, sport participation, and intentionality of the coach may promote PYD.

Girls in sport. This study will look at PYD in the context of high school girls' basketball teams. A generation ago, sport literature focused primarily on male involvement because girls participating in sport were not culturally accepted nor acknowledged. Within the past 40 years, there has been an increase in girls participating in sports in America due to Title IX of the Educational Act of 1972, which prohibits gender discrimination in any federally funded education program or activity (Paule-Koba, Harris, \& Freysinger, 2013). Title IX states, "No person in the United States shall, on the basis of sex, be excluded from participation in, be denied the benefits of, or be subjected to discrimination under any education program or activity receiving financial assistance" (Title IX and Sex Discrimination, 2015). As a result, Title IX increased athletic opportunities for girls and women. Women participating in sports has become more 
culturally accepted and celebrated (Cooky, 2010). Research shows that sport and physical activity positively impact the physical and psychosocial well-being of girls and women (Staurowksy et al. 2009). Sport can potentially increase girls' self-confidence, prevent eating disorders, and enhance their physical health (Kane et al., 2007). In addition, sport participation is associated with a positive body image (Hausenblas \& Fallon, 2006; Huang et al. 2007), an increase in educational achievement (Coakley, 2011), and a decrease in teen pregnancy and substance abuse (Staurowsky et al.). Allen (2003) implies that a sense of belongingness and enjoyment is the motivator for girls in sport. Furthermore, Allen (2003) also provided support that girls prefer social, "fun" activities, and opportunities to learn concepts and skills as motivators for their participation (Passmore \& French, 2001; Perkins et al., 2007).

Despite Title IX and increased athletic opportunities, sport participation gaps for underserved African American girls still exist in urban and rural communities (Sabo \& Veliz, 2008). Sabo (2009) suggested that the lack of participation in urban and rural communities can be explained by multiple contextual factors that include family income, race and ethnicity, and the type of community. Sport may be helpful to achieve PYD for underserved girls, but as stated earlier it is not the only ingredient (Coakley, 2011; Hartmann \& Kwauk 2011). Coakley (2011) argued that other factors within and outside the sport program help to foster developmental benefits.

\section{Framing Key Literature in Theory}

Multiple theories have been used in sport PYD literature to explain the positive and negative outcomes of sport. Due to the pragmatic approach for this dissertation, the theory used for the current study is grounded in the ecological systems theory (EST). The 
current study uses the EST (Brofenbrenner, 2009) to organize the review of literature and as the rationale for including parents and other teams from this league as participants in this study. EST allows the researcher to look at a broader picture of how an inner-city girls' basketball team functions in relation to the entire league and the parents'/primary caregivers' point of view.

Ecological System Theory. Brofenbrenner's (1977; 2009) EST suggests that human development and human behavior occur from person to context interactions. EST provides a framework to understand the significance of social interactions within and between various contexts, such as the home, school, and work environments. EST has been used across several research domains (e.g. sport, public health, psychology, child development, sport, etc.) to understand the bidirectional influence between youth and their context (Lerner et al., 2011).

Within the EST framework, the ecological systems model is organized into four nested systems that include: microsystem, mesosystem, exosystem and macrosystem. The microsystem represents one's immediate context that directly impacts development (e.g. home, school, church, team). The mesosystem represents regular social interactions and interconnectedness between the microsystems (i.e. the relationship between a coach and player). The exosystem represents the relation between a social setting and one's immediate context, which the individual does not have an active role in (i.e. the coach's relationship with the player's parents). Lastly, the macrosystem represents the cultural context, such where one lives (e.g., neighborhood), SES, poverty and ethnicity. EST is relevant to the sport domain because it takes into account the bidirectional influence of individual, environmental, and program characteristics, rather than studying the 
individual in isolation. Integrating EST into the design of this study reinforces the PYD perspective, because PYD is grounded in an ecological systems approach to youth development (Holt, 2008). The family, school, and community contexts of PYD are considered below.

Family context. Within the family context (microsystem), parenting strategies and techniques are used to socialize and teach their children appropriate behaviors of the culture. Parenting styles differ throughout cultures and vary from home to home. Coakley (2002) emphasized that upper- middle income, predominantly White families have different ideas about PYD and believe that outcomes should emphasize achievement and upward mobility, in comparison to underserved minority families who emphasize control and discipline.

Baumrind (2013) created a typology that described four different parenting styles grounded in research findings: authoritarian, authoritative, permissive and disengaged. For the purpose of this paper, authoritarian and authoritative parenting styles will be defined and emphasized as they relate to coaching in the inner-city. Authoritarian parenting styles are described as highly structured with clear stated rules, high control, and militaristic with the use of physical discipline such as spanking (Deater-Deckard, Lansford, Dodge, Pettit \& Bates, 2003; McLoyd, Kaplan, Hardaway \& Wood, 2007). Parents who utilize this style are considered to be high in demand and low in acceptance and responsiveness to their child. These types of parents often have a large number of rules that they expect their children to obey and rarely provide rationales for their rules and expectations. On the other hand, authoritative parenting styles are described as parents being highly demanding and highly accepting/responsive to their children. Unlike 
authoritarian parenting styles, authoritative parents tend to provide rationales for their rules/expectations and listen to their child more (Baumrind, 2013). Experts suggest that authoritative parenting styles are linked to positive PYD outcomes; however, these findings may not be generalizable to other contexts because the majority of these studies examined white, middle-class populations.

Coll and Pachter (2002) advised researchers studying African American or other minority populations to use a historical and cultural lens to try to account for their experiences (i.e. slavery, racism, and poverty). Similar to EST, sociocultural theorist Vygotsky believed "development occurs over time within the context of the culture" (Gardiner \& Kosmitzki, 2008, p. 302). In other words, learning and development occurs through context and social events, and cannot be separated from cultural, historical, and social contexts in which they are situated (Wang, Bruce, \& Hughes, 2011). This paradigm looks at how social interaction and participation in organized activity play a role in psychological development (Scott \& Palinscar, 2009). According to Thompson (2004), "African Americans in urban communities are socialized very differently from Whites from middle-class communities" (p. 72). Research has shown that authoritarian parenting practices used in low-income families correlate with lower levels of child behavior problems. For example, Eamon (2002) conducted a two-year longitudinal study with a sample of 963 participants between the ages 10 to 12 years old. Results showed that poverty was strongly related to neighborhood problems more than parental and peer influences. In addition, Eamon found that authoritarian parenting styles and the use of physical punishment for kids living in poverty buffered anti-social behavior. Similarly, Dearing (2004) conducted a longitudinal study in Massachusetts with three ethnic groups 
(i.e. African American, Latino American, and European American) living in an underserved setting plagued by rape, robbery, burglary, larceny, and aggravated assault. The purpose of the study was to examine how neighborhood characteristics moderated associations between parenting and child outcomes. Results showed that restrictive/controlling (authoritarian) parenting styles were a protective factor and had a positive effect on academic performance for African American and Latino American children, but had a negative effect on European American children. Furthermore, research shows that minority parents living in dangerous and impoverished neighborhoods are typically more controlling and use authoritarian parenting styles because this style protects and buffers their children from dangers of the context (Kelley, Sanchez-Hucles, \& Walker, 1993; Smetana, 2011).

Experts believe that the same parenting behavior may have different effects on children in different context or racial/ethnic groups (Deater-Deckard \& Dodge, 1997); whereas authoritarian parenting styles may be beneficial and adaptive to poor minority youth, the same may not be true for middle to high SES populations. Furstenberg (1993) indicated that the most adaptive parenting style for underserved youth is one where parents devote "enormous personal time to monitoring, supervising, and controlling children's behavior (p. 239). Authoritarian parenting styles used in underserved, dangerous, and disadvantaged settings may be more likely to facilitate resiliency and positive outcomes (i.e. behavior and academics); whereas authoritative parenting styles in an underserved context maybe considered maladaptive (Eamon, 2002). Experts believe that authoritarian parenting does not limit risky behaviors; instead it may even aid in higher rates of delinquency. For example, Hoeve and colleagues (2009) conducted a 
meta-analysis with 161 published and unpublished articles to conclude whether the relationship between parenting and high rates of delinquency exists. Results showed that authoritarian (i.e. controlling, monitoring, and restrictive) parenting styles made up 11\% of the variance in delinquency. However, majority of the studies were cross-sectional, and categorized majority of the samples as "ethnic minorities," as opposed to specific populations (i.e. African American, Latino American, Asian Pacific, etc.).

School context. Another important developmental context is the school setting because youth spend at least six to seven hours in school each day during the academic year (Juster, Ono, \& Stafford, 2004). The school context plays a deliberate role in socialemotional and cognitive development by providing academic learning opportunities (e.g. reading, math, etc.), socializing, and preparing youth for adulthood (Larson, 2000). According to Delpit (1995), teachers in African-American communities are expected to show that they care about their students by:

Controlling the class; exhibiting personal power; establishing meaningful interpersonal relationships; displaying emotion to garner respect; demonstrating the belief that all students can learn; establishing a standard of achievement and 'pushing' students to achieve the standard; and holding the attention of the students by incorporating African-American interactional styles in their teaching. Teachers who do not exhibit these behaviors may be viewed by community members as ineffectual, boring, or uncaring. (p. 142)

Similar to parenting literature, staff, and teachers working with children who live in poverty use authoritarian practices to manage the classroom, discipline, and decrease behavioral issues (Hartman \& Manfra, 2015). For example, Higgins and Moule (2009) 
conducted a study to understand classroom management strategies used in a predominately African-American elementary urban inner-city school setting. The participants included 13 pre-service teachers and eight mentor teachers over a three-week period. Through participant observations, interviews with classroom management instructor, and analyzed journal entries of pre-service teachers, results indicated that classroom management in urban inner-city schools should be assertive, authoritarian, controlling and to show students that their teachers care for them (Parsons, 2005).

Community context. Socioeconomic status and neighborhood quality play a significant role in research studies pertaining to youth development. The community context impacts the lives of youth because they may offer opportunities and resources for youth to get involved in positive, productive activities (i.e. after school programs, extracurricular activities, and support services) as opposed to negative activities (i.e. gang violence and crime). Leventhal and Brooks-Gunn (2000) suggested that neighborhood settings are associated with youth achievement and social-emotional functioning. In other words, wealthy neighborhoods are related to positive development and neighborhoods characterized as underserved/disadvantaged rarely provide the necessary tools or resources for adolescent development (Furstenberg \& Kaplan, 2004; Harding, 2008; Martinek \& Hellison, 1997, Richardson, 2012; Walsh, 2008). Parents who live in dangerous and impoverished neighborhoods have been found to be more likely to use authoritarian parenting styles on their children (Hill \& Herman- Stahl, 2002), increasing academic achievement and protecting their children from high-risk environments by providing the necessary structure and safeguards (Dearing, 2004). 
The PYD framework incorporates EST and recognizes that there is a bidirectional influence between a person and their context. In addition, experts believe that when schools, communities, and family contexts are responsive and provide opportunities for youth to be involved in positive, productive activities, youth are more likely to achieve optimal development (Lerner et al., 2005; Lerner et al., 2011).

\section{Effective Coaching, Mentorship, and Sport Issues}

In this section, the definition of an effective coach, and appropriate developmental strategies for youth coaches will be reviewed, with specific emphasis on the coach's role as a mentor.

Effective coaching. Côté and Gilbert (2009) offered an integrated definition of an effective coach as defined as, "the consistent application of integrated professional, interpersonal, and intrapersonal knowledge to improve athletes' competence, confidence, connection, and character in specific coaching contexts" (p. 316). Effective coaches focus primarily on the athlete/learners' outcomes through the successful application of professional, interpersonal, and intrapersonal knowledge (Côté \& Gilbert). Trudel and Gilbert (2006) organized coaching by three typologies: a) early recreation sport-contexts for children; b) developmental sport-contexts for adolescents; and c) elite sport (adult populations). For the purpose of this study, emphasis will be placed on the developmental sport-contexts for adolescents.

Effective coaching for adolescents should take a holistic approach and focus on developing the physical, mental, emotional, and possibly spiritual aspects of individual players. Coaches should not only provide opportunities for athletes to learn sport-specific skills (Gilbert \& Trudel, 2004), but to also enhance personal growth within their athletes. 
Flett et al. (in press) suggested that in order for coaches to be developmentally effective, they should focus on athletes' holistic development, have a clear coaching philosophy, and an openness to learn. In addition, coaches should: (a) focus on effort and persistence; (b) facilitate challenge; (c) promote the value of failure; (d) define success as effort; (e) promote learning in a mastery-climate; and (f) provide high expectations (Vella, Cliff, Okely, Weintraub, \& Robinson, 2014). It is clear from this definition and from recent reviews of the literature (e.g., Flett et al., 2016) that effective coaching is contextspecific, holistic, and must be individualized to meet the needs and expectations of players.

Over the past thirty years of research, the majority of the studies conducted on coaching effectiveness have examined the coaching characteristics, actions, leadership style, and behaviors that are most effective and have a direct impact on adolescent development (Smith \& Smoll, 2011; Smoll \& Smith, 2002). However, much is still unknown because researchers have yet to examine underserved, urban sport in great detail with a line of related studies (Cowan et al., 2012; Fry \& Gano-Overway, 2010; Flett et al., 2012; Flett et al., 2013). Furthermore, studies have focused more on coaching behaviors and styles, and have not explored coaches' rationale for their styles and athlete perceptions of coaching style.

This section will review PYD preferred coaching styles/behaviors in developing autonomy-supportive, motivational, and caring climates; coach-athlete relationships and mentorship; and what effects coaches' behaviors have on athlete's development. In addition, the coach's role in athlete psychosocial development will be examined, and importance of mentorship and coach athlete's relationship will be discussed. 
Coaching style and behaviors. The coaching literature emphasizes the use of an autonomy-supportive style "that actively supports self-initiated strivings and creates conditions for athletes to experience a sense of volition, choice, and self-endorsement" (Bartholomew et al., p. 194). An autonomy-supportive coaching style is linked to several positive outcomes personally, socially, and cognitively. Autonomy-supportive coaching is grounded in the self-determination theory and is described as coaches being authoritative (e.g. coaches providing a rationale for tasks, acknowledging athletes' feelings, allowing athletes to make their own decisions, and non-controlling). A considerable amount of research shows that PYD experts supports autonomy-supportive coaching style because this type of coaching relates to positive developmental experiences within youth such as goal setting, increased self-esteem, satisfaction, initiative, and positive affect (Amorose \& Anderson-Butcher, 2015; Coatsworth \& Conroy, 2009; Hodge, Danish, \& Martin, 2013).

For example, Amorose and Anderson-Butcher (2015) conducted a study to examine adolescent perceptions on motivational response to autonomy-supportive and controlling coaching behaviors. The participants included 301 male and female athletes from both individual and team sports. Eighty-five percent of the athletes identified themselves as Caucasian, and 8\% identified as African American. Findings revealed that perceptions of motivational outcomes were positively linked to autonomy-supportive coaching styles.

Similarly, Coatsworth and Conroy (2009) examined youth perceptions of coaching climates, coaching behaviors, and developmental outcomes. The participants included 119 male and female swimmers from a community recreational league. Eighty- 
eight participants identified as Caucasian, and 1\% identified as African American.

Results showed that autonomy-supportive coaching behavior predicted levels of satisfaction. As a result, the levels of satisfaction predicted youth perceptions, which had a positive effect on developmental outcomes. The studies were both cross-sectional in nature and emphasized the importance of autonomy-supportive coaching; however, the demographics of both studies showed that Caucasian participants made up more than $85 \%$ of the sample size. Much of the studies in the sport literature that focus on autonomy-supportive (authoritative) coaching styles are context-specific and focus on predominately White participants from middle to high-SES populations. More research is needed to examine coaching styles in an underserved setting with participants from middle to low-SES populations.

Although researchers have examined coaches' behaviors, and found that coaching actions are linked to personal and social development in individual athletes such as goal setting (Coatsworth \& Conroy, 2009), leadership opportunities (Gould \& Carson, 2008), teamwork and initiative (Gould et al., 2012), behaviors and actions alone do not determine PYD (Fry \& Gano-Overway, 2010; Smith, Smoll \& Cumming, 2007). Another factor that contributes to adolescent development is the coaching or team climate (e.g., motivation, caring, etc.).

Motivational climate. Coaches have the responsibility of creating and structuring an environment that is beneficial to PYD. Two types of motivational climates include mastery-oriented and performance (ego-involving) climates. Cox (2002, p. 39) defined a mastery climate as, "one in which athletes receive positive reinforcement from the coach when they work hard, demonstrate improvement, help others, learn through cooperation, 
and believe that each player's contribution is important." Athletes participating in this type of climate are inclined to judge their success based on personal improvement and effort. On the other end of the spectrum, a performance-/ego-climate is defined as, "one in which athletes perceive that poor performance and mistakes will be punished, highability athletes will receive the most attention and recognition and competition between team members is encouraged by the coach" (p. 39). In this type of climate, coaches are more likely to foster negative social comparison and intra-team competition.

The coaching literature shows that a motivational climate has a direct effect on the player's experience. Numerous studies have identified a mastery climate as the key element to promote adaptive psychological behaviors, achievement, and motivation within individuals. For example, Smith, Smoll, and Cumming, (2007) conducted an intervention study with 37 coaches and 216 athletes between the ages 10 to 14 years old. Results revealed that the experimental coaches who utilized a mastery approach decreased athlete anxiety, while (control group) athletes' anxiety increased. Similarly, Fry and Newton (2003) conducted a study with 168 low socioeconomic urban youth between the ages of 12 to 19 years old from 10 programs in five states. Forty-seven percent of the participants identified themselves as African American. Fry and Newton (2003) found that athletes involved in a mastery climate had positive attitudes towards the sport and coach. Similarly, Gould, Flett, and Lauer, (2012) found that a masteryoriented climate should be developed for coaches to have the most impact on undeserved youth.

Vitali et al. (2015) conducted a study with 87 adolescent basketball and volleyball players to examine youth perceptions on the role of personal factors and motivational 
climate on burn out. Similar to the above studies, Vitali et al. found that a mastery climate was positively linked with resilience and perceived competence, whereas a performance climate was positively related to athlete burnout. In summary of these studies, it seems that a mastery climate is appropriate for youth sport because it may increase personal and social development and minimize performance anxiety and decrease athlete burnout. However, Gould et al. (2012) argued that the motivational climate is not as important as the caring climate, because "kids don't care what you know, until they know you care" (p. 86).

Caring climate. In addition to a mastery-oriented climate, Gould et al. (2012) hypothesized that a caring climate created by the coach is likely to influence PYD (Brofenbrenner, 2009; Petipas et al., 2005; Hellison, 2000; Hirschi, 1969). Gould et al. surveyed 239 underserved middle- and high school baseball/softball players in Detroit to examine their perceptions of the sport climate created by coaches. Seventy-two percent of the participants were Black, and $64 \%$ were male. The authors utilized the caring climate Scale (CCS; Newton, Fry, et al., 2007) and Motivational Climate scale for youth sports (MCSYS; Smith, Cumming, \& Smoll, 2008) to assess youths' perceptions of the team climate; Youth Experiences Survey-2.0 (YES-2; Hansen \& Larson, 2005) to assess positive and negative developmental experiences; and coaching behavior life skill items (CBLS; Gould et al., 2007) to assess coaching factors related to life skill development in athletes. Gould et al. (2012) found that building rapport, caring, and supporting the athletes will allow the coach to be more effective in their personal and social development (e.g. teamwork, physical skills, initiative, and cooperation). Negative team 
climates were associated with negative youth outcomes, and mixed climates (positive and negative) had mixed outcomes with limited positive development.

Similarly, Fry and Gano-Overway (2010) conducted a study using the CCS to examine the relationship between athletes' enjoyment, attitudes, and behaviors toward their coach, teammates, and commitment to their sport in a summer camp setting. The participants included 184 high school and middle school soccer players between the ages of $10-17$ years. Of the 184 participants, 165 identified as Caucasian American, 5 identified as Asian American, 4 identified as Hispanic American, and 3 identified as African American. Results revealed that athletes who perceived a caring climate reported having higher enjoyment and more positive attitudes toward coaches and teammates. Gano-Overway et al. (2009) argued that future studies need to examine the caring climate and its impact on developmental assets using mixed-methodology.

Coach-athlete relationship. In the sport and non-sport PYD literature, emphasis has been placed on the promotion of interpersonal relationships with non-familial adults (Camiré, Trudel, \& Forneris, 2009; Cowan et al., 2012; Eby et al., 2008; Flett et al. 2013; Fry and Gano-Overway, 2010; Petipas et al., 2005; Richardson, 2012;). The formation of personal relationships between youth and non-familial adults is an important feature of adolescent development, especially for African American youth and those living in underserved settings (Jarett et al., 2005; Levin \& Munsch, 2016; Richardson, 2012). These non-familial relationships with adults should complement or augment the relationship that children have with their parents (Levin \& Munsch). However, in underserved settings, coaches typically compensate for a lack of support in youths' lives 
(support that should come from within the family), rather than add to or augment parents' support and role modeling (Richardson).

In a recent review of literature describing the antecedents and outcomes of effective coaching, Flett et al. (2016) acknowledged the link between coach-athlete relationships and positive consequences such as confidence, team commitment, motivation, low anxiety, better practices, and learning (Cowan et al., 2012; Flett et al., 2013; Fry \& Gano-Overway, 2010; Fry \& Newton, 2003; Gould et al., 2012; Richardson, 2012; Smith et al., 2007; Whitley, Bean, \& Gould 2013). Jowett and Shanmugam (2016) suggested that the coach-athlete relationship is at the heart of interpersonal sport coaching and the bond between the two "supplies coaches with the key to opening the door to their athlete's capabilities, capacities, and potential" (p.2).

Jowett and Ntoumanis (2004) created the Coach-Athlete Relationship Questionnaire (CART-Q) grounded in qualitative case studies with high-level athletes to measure the affective, cognitive, and behavioral aspects of the coach-athlete relationship through three constructs known as the $3 \mathrm{C}$ 's: closeness, co-orientation, and complementarity. Closeness represents respect, care and the emotional bond between the coach and athlete. Co-orientation represents the commonalities and shared perspectives (goals and values) between the coach and athlete. Complementarity represents the cooperative interactions between the coach and athlete. In addition to the $3 \mathrm{C}$ 's, another construct was added, known as commitment. Commitment represents the coach's intentions to maintain a close long-term bond with the athlete. These constructs are known as the $3+1 \mathrm{C}$ 's of the coach-athlete relationship. Jowett and Poczwardowski 
(2007) suggested that relationships that acquire these four components will thrive and promote psychological wellbeing within the athletes.

For example, Vella et al. (2013) conducted a study in Australia to examine athletes' perceptions of the coach-athlete relationship, team success, and positive developmental experiences. The sample included 455 soccer athletes between the ages of 11 to 18 years who were described as having a medium to high SES. The authors identified that athletes' perceptions of a quality coach-athlete relationship were linked to positive developmental experiences such as athlete performance, personal development, wellbeing, satisfaction, and motivation (Jowett, 2008; Jowett \& Nezlek, 2012; Sagar \& Jowett, 2012).

Perceptions and expectations. Perceptions and expectations are a big part of determining effective coaching and athlete satisfaction. The context and the characteristics of the coach and athletes dictate the appropriate leadership behavior (Chelladurai \& Saleh, 1980). Research shows that athlete perceptions may vary within each athlete (e.g. one athlete may want a disciplinarian hard-core coach, whereas another wants a comforting coach). Furthermore, the fit of the coach-athlete interpersonal relationship plays a large role in determining athlete satisfaction and effective coaching (Bennie \& O'Connor, 2012). This fit between coach and athlete supports the importance of EST. Coaches can enhance the coach-athlete relationship by personalizing their coaching style and being mindful of players' preferences while being true to themselves (Bennie \& O’Connor). Additionally, coaches need to be flexible and adjust their coaching style to be effective. Regardless of their style, coaches are more likely to develop 
psychosocial assets and skills in youth if players perceive coaches to be caring and genuine in their actions.

\section{Coaches' Roles and Responsibilities}

In general, the coach's responsibility is to maximize athletes' performance through technical and interpersonal components (Fletcher \& Roberts, 2013). Coaches should focus on developing athletes, building skills (assets), enhancing strengths, and personal resources (Côté \& Gilbert, 2009; Fraser-Thomas, Côté \& Deakin, 2005), similar to the PYD literature. It is critical for coaches to understand youth development and have the necessary skills to become effective, expert coaches. Côté and Gilbert (2009) described an effective coach as, "those who demonstrate the ability to apply and align their coaching expertise to particular athletes and situations in order to maximize athlete learning outcomes" (p. 316). In other words, effective coaches focus primarily on athlete/learner outcomes, and as such, the attributes of an effective coach are contextspecific (if not team specific); the coach's role may vary due to athletes' age, gender, and competitive level (Flett et al., 2016).

Several studies illustrate that coaches believe that they are responsible for providing opportunities and experiences for adolescents to develop appropriately. For example, Vella, Oades, and Crowe (2011) conducted a qualitative study with 22 male and female "participation" coaches in Australia to better understand how coaches perceived their role. The sport context was defined by a medium- to high-SES and did not emphasize performance/competition. The sports included netball, soccer, softball, cricket, and basketball. The athletes were between the ages of 11 to 19 years. The athletes practiced 2 to 6 hours per week. The authors conducted a seven question semi-structured 
interview with the participant coaches and found that coaches saw themselves as responsible for fostering competence, confidence, connection and character within their players, as well as life skills. In a similar study, Trottier and Robitaille (2014) found that coaches utilized a holistic approach to promote life skills based on athletes' needs in their personal and sport development.

Gould et al. (2007) conducted a qualitative study of 10 American football coaches with an average 30 years of coaching experience, who held bachelor's degrees and were certified to teach. The participants believed their main priority was to emphasize personal development within their athletes. Results revealed that coaches used specific strategies to instill life skills (e.g. treating players with respect, building relationships with athletes, team unity night per week, and goal setting), enhance personal development, and foster athlete performance. The authors suggested that further research should examine coaches of high school female athletes to determine if "tough love" is perceived to be effective. Although many coaches believe it is their responsibility and primary role to provide opportunities for adolescents to develop appropriately, many emphasize winning and losing outcomes rather than aiding in youth development in a positive manner (Côté \& Gilbert, 2009; Gould \& Carson, 2008) due to the lack of formal training programs and experience.

Coaching is a dynamic, diverse, and complex activity due to the varying levels of experience and education of coaches (Camiré, Trudel \& Forneris, 2014). Many coaches in youth sport are volunteers, recent graduates, or former collegiate athletes with limited experience and training in coaching. Research indicates that experience and education are two variables that can help explain the differences that occur between 
intentional coaches who implement PYD and those who do not (Camiré et al.). For example, Flett, Gould, Griffes, and Lauer (2012) conducted a study in Detroit to better understand the behaviors and beliefs of inexperienced (averaging 3.3 years) and highly experienced (average of 8 years) volunteer coaches in an underserved setting. Flett et al. found that the volunteer coaches described a lack of support from parents, rarely acknowledged the importance of administrative responsibilities, and rarely provided rationales for their coaching strategies. Similar to Gould et al. (2007), results indicated that more experienced coaches were open to formal coaching education programs, and had well-developed beliefs with specific strategies to enhance PYD in comparison to less experienced coaches. Limited studies hone in on the strategies utilized by coaches of female athletes to determine if the same strategies (i.e. tough-love) are perceived to be effective.

Mentorship. Coaches not only have a significant influence on adolescent development through their coaching style, motivational climate, and coach-athlete relationship (Petipas et al., 2005; Smith, Smoll \& Curtis, 1979), but also through their mentorship. Mentoring is associated with a wide scope of positive behavioral, healthrelated, social, motivational, and career outcomes for youth (Eby, Allen, Evans, Ng, \& DuBois, 2008), though many studies have found no impact and even negative effects when mentoring is done incorrectly (Eby et al.). Mentoring is a common intervention strategy that has been used across education, juvenile justice, public health, and other domains. According to Eby, Rhodes, and Allen (2007), mentoring is an emotional bond and unique relationship between a mentor and mentee. Practitioners use mentorship strategies to help guide mentees in the right direction and provide them with new 
experiences. The mentor literature refers to three distinct streams of mentoring: youth mentoring, academic mentoring, and workplace mentoring. For the purpose of this study, emphasis will be given to youth mentoring in sport.

The mentor-mentee relationship relates to Brofenbrenner's (1977) hypothesis that "the development of the child is enhanced through her increased involvement, from childhood on, in responsible, task-oriented activities outside the home that bring her into contact with adults other than her parents" (p. 282). According to Rhodes (2005), youth mentoring literature emphasizes the importance of supportive relationships with adults, and fostering personal, emotional, cognitive and psychological growth (e.g., learning how to avoid peer pressure, developing relationships with adult figures, increasing confidence, etc.). Typically, mentored youth are considered to be "at-risk" for delinquency, problematic behaviors, academic, or social difficulties due to the low SES context they are raised in. Research shows that in underserved areas, a supportive and close relationship between youth and a non-familial adult (i.e. coach) can serve as a protective factor against negative developmental outcomes and enhance PYD (Eby et al., 2008; Dubois \& Silverthorn, 2005; Higginbotham, MacArtuhur, \& Dart, 2010).

Mentorship Factors. The duration of the mentorship relationship is a key element of effectiveness. Mentors spending quality time, commitment to and keeping in regular contact with youth is crucial for positive relationship outcomes to occur (Maldonado, Quarles, Lacey, \& Thompson 2008). Research indicates that longer relationships lead to better outcomes within youth. For example, Maldonado et al. conducted a study with atrisk adolescent girls over a three-year period to better understand the impact of mentoring relationships. Results revealed that mentors had influenced the social, emotional and 
academic development of their mentees. Another study conducted by Herrera et al. (2000) found that positive relationship experiences were linked to the number of hours' youth spent with their mentors.

However, Rhodes and Lowe (2008) asserted that duration alone is not sufficient; mentors need to keep in regular contact with mentees and not meet sporadically. In sport, coaches consistently spend time and interact with their athletes throughout the season, whether it is during practice, games or tournaments. Coaches can become role models (Jaime et al., 2015) and develop a close, natural mentoring relationship with athletes (DuBois \& Silverthorn, 2005). Research shows that natural mentoring relationships that occur over years have the strongest effects in youth (DuBois \& Silverthorn).

Mentorship in sport. As stated earlier, mentorship offers various positive outcomes such as opportunities to foster positive relationships, avoiding risky behaviors, achievement of academic success, and enhancing youth development (Eby et al., 2008; Higginbotham, et al., 2010; Maldonado et al. 2008). Youth sport coaches are mentors and role models to their athletes because the duration of the coach-athlete relationship is consistent (e.g. games, practices, off-court activities; Jaime et al., 2015). In addition, the coaches must acknowledge the diversity of athletes (e.g. age, the level of competition, socioeconomic status), and be confident in themselves to develop the athlete's personal and athletic skills. These mentoring relationships in the underserved setting can buffer youth involvement in gangs violence, and crime (Jarett et al. 2005; Larson, 2006).

For example, Richardson (2012) conducted a three-year ethnographic and autoethnographic study in a high-risk urban setting. The purpose was to understand the coachathlete relationship, with specific intentions of understanding how coaches reduce risk 
and promote resilience off the field in a predominately poor neighborhood in New York City. The sample included 15 Black male middle-school students who were on the basketball team, the school's honor roll, and who participated in the school's Dropout Prevention program. Eighty-percent of the participants came from a single-parent home, and $100 \%$ were eligible for free school lunch. Through participation, observations, and annual interviews, the author found that mutual trust between the coach and athletes were strengthened through consistent interactions in structured and unstructured settings (e.g. after hours in the gym and violence prevention workshops) As a result of this mutual trust, coaches were a form of social control and were able to reduce delinquency and violence, corresponding with social control theory (Hirschi, 1969). Richardson argued that limited literature explores the relationship between coaches and athletes both on and off the field. In addition, the author argued that ethnographic methodology is suitable for exploring and gaining an in-depth understanding of the mentoring role coaches have with their players.

Findings indicate that coaches, as mentors, play a crucial role in urban underserved settings. Like most parents, coaches will go to the extreme measures to provide safety (Richardson, 2012), protect their athletes from negative outcomes, and prepare them for the harshness of the real world (Flett et al., 2012; 2013). With respect to the current study, it is important to extend this literature and examine the coaches' role in a different context with underserved female athletes on and off the court from a parental/primary caregiver perspective. 


\section{Underserved Context and Sport}

This section will review the characteristics of an urban underserved context. In addition, the importance of perceptions and expectations, and how they relate to the underserved context, will be discussed.

Smetana (2011) argued that underserved youth living in high-risk environmental settings (e.g. poverty and neighborhood violence) are not afforded the same opportunities as middle-class populations and lack the resources to develop socially, emotionally, and cognitively due to numerous challenges they face including poverty, racism, substance abuse, teen pregnancy, family issues, lower quality health care, and violence (Martinek \& Hellison, 1997; Martinek \& Schilling, 2003; Walsh, 2008). Experts argue that underserved youth are in the greatest need of PYD (Walsh, 2008) because underserved neighborhoods rarely provide opportunities for youth to build rapport with adults, which can hinder PYD. These environmental factors can result in a dysfunctional lifestyle, with little to no support or guidance from adult figures. Experts argue that the mixture of low socioeconomic status, at-risk behavior, and lack of adult-structured activities are a recipe for disaster (Flynn, 2008).

Some studies suggest that underserved youth are limited to developmental opportunities and various sports (i.e. football, basketball, and soccer) due to their socioeconomic status, race, and environmental setting (Fraser-Thomas, Côté \& Deakin, 2005; Mohan, 2014). Sport can serve as a protective factor and buffers some of the unique challenges faced by underserved youth (Gould \& Carson, 2008; Walsh, 2008). Martinek and Hellison (1997) believed that structured physical activity programs combat the negative effects of the underserved setting and play a significant role in providing 
opportunities for youth to "get off the streets" and be involved in extracurricular activities that will provide a balance for youth's hoped-for- selves ("what we would like to become") and feared-selves ("what we are afraid of becoming"; Martinek \& Schilling, 2003; Walsh, 2008). Coakley (2011) referred to sport participation as "car wash effect," for at-risk youth because, "it cleanses character and washes away personal defects so that young people can become acceptable to those in mainstream society" (p. 308). Research supports Coakley's claim and has found that minority youth who engaged in after school programs had fewer behavioral problems.

Perkins et al. (2007) conducted a study with 77 minority youth to examine the contextual and cultural influence that youth sport has and found that sport provided a means for youth to stay off the streets, learn new skills, avoid boredom, and participate in fun and enjoyable activities. However, Perkins et al. found that some participants did not participate in sport because of parental influence and others they viewed the program as "boring."

In another study, Holt, Kingsley, Tink, and Scherer (2011) examined the perceptions of 35 low SES parents and children's beliefs about the benefits and challenges associated with youth sport. Results indicated that both parents and children reported a range of personal and social developmental benefits; however, parents reported that numerous barriers restricted their children from participation including time management and scheduling demands, financial barriers, and maintaining children's participation as they improve in sport. Limited studies have examined urban youth and the factors that motivate sport participants, the benefits, constraints, and the perceived barriers (Flett et al. 2012; Flett et al. 2013; Holt, Scherer \& Koch, 2013). 
Coaching in underserved inner-city contexts. Coaches have a direct impact on adolescent development through their coaching style and behaviors, especially in the underserved urban setting (Smith \& Smoll, 2007; Richardson, 2012). As reviewed earlier, effective coaching varies from context to context. Flett et al. (2013) indicated that "contextual demands should have a strong influence on how coaches develop their players" (p.326). Underserved youth are characterized as lacking confidence, structure, and self-esteem (Cowan et al., 2012), and as a result, coaches are forced to play multiple roles as a mentor, parental figure, disciplinarian, supporter, and friend (Camiré et al., 2009; Cowan et al., 2012; Flett et al. 2012 \& 2013; Olushola et al., 2013; Stodolska, 2014; Richardson, 2012). Coaches in urban, underserved settings are believed to be more authoritarian, militaristic, and controlling towards the athletes because they are trying to protect and prepare their players for the ways of the world as opposed to creating an autonomy-supportive climate (Flett et al., 2013).

In exploring coaching styles in underserved contexts, Cowan et al. (2012) conducted a case study in Scotland to explore the common assumption that autonomysupportive coaching is adaptive versus controlling coaching, which is maladaptive. The study described coaching styles and behaviors used in an underserved setting with soccer players. The sample included two male head coaches and 18 athletes from two teams between the ages of 16 to 19 years old. Through non-participant observations, field notes, video footage, and semi-structured interviews, the authors found that provision of choice to the athletes can be maladaptive because athletes in this setting typically lacked confidence and self-esteem. In addition, the authors found that coaches who held national qualifications and were trained to work with underserved youth were considered 
to be controlling. However, one coach used humor and rapport with the athletes to buffer the negative effects of the controlling coaching style. This study used multiple sources of data to investigate coaching styles and behaviors, but the context was not representative of North American high school sport programs and non-participant observations did not allow the authors to fully immerse and embed themselves in the day and life of an athlete or coach in this setting. Furthermore, underserved urban communities in America not only suffer from poverty but may differ from underserved communities in other countries in terms of violence and drug use. Cowan et al. suggested that further research should examine coaches' justifications and rationale behind their coaching behaviors.

In an effort to study coaching behaviors in underserved settings, and coaches' rationales for their actions, Flett et al. (2013) conducted a qualitative comparison study in inner-city Detroit. Participants included 12 youth coaches from six different sports that were categorized into two groups: effective and ineffective based on their ability to foster PYD. The authors used ethnographic methods to observe the coaches 14 times in practice and game settings before conducting in-depth $(1 \mathrm{hr} 23 \mathrm{~min})$ interviews with each coach. The authors found that the "less effective" coaches utilized more militaristic, authoritarian coaching styles to prepare youth for the harshness of the world. Flett et al. found that "less effective" coaches believed that a "soft" approach would jeopardize the athletes because the coaches knew the personal struggles the athletes faced (e.g. gang violence, crime, abuse, uninvolved parents, dangerous neighborhoods, etc.). In addition, the authors found that discipline may be effective in urban underserved settings, which is consistent with the parental literature. 
Cowan et al. (2012) argued that researchers and practitioners should consider cultural context and situation-specific factors before endorsing autonomy-supportive coaching styles or cautioning the use of a controlling-coaching style. Similar to the parenting literature, what is adaptive for one context may be maladaptive to another-and vice-versa. While Flett and colleague's work addresses an important gap in underserved, sport-based PYD and coaching research, the design provided a relatively limited investigation into the actions, effects, and rationale of the 12 coaches. Therefore, there is a need for more longitudinal qualitative studies that will not only provide more reliable data, but more in-depth data resulting from a closer rapport with the participants, and data over a longer time frame that is more sensitive to developmental, season-long changes in coaching behaviors or impact on players. In addition, Flett et al. (2013) indicated that future studies should answer the question, "what is an effective coaching style for developing underserved youth?"

Coaching in the inner-city. Brown, Hayes, Goodson, and Flett (in preparation), conducted a four-month ethnography study to observe an experienced coach's style and impact on her players, and assessed the coach's perceptions of the players' developmental environment, the coach's perceived role/responsibility, and the rationale for coaching style/strategies. In addition, the study examined the players' perceptions of the coach's approach, and their understanding of the coach's rationale. The sample was purposefully selected and included one coach and 10 female high school athletes. The coach had 29 years of coaching experience at the high school level, received formal education, and was trained to work with youth. Seven players were new to the team and to the coach. 
The primary researcher participated in games, practices, and off-court activities with the team for a total of 34 events/sessions that lasted on average 7 hours (approximately 238 total hours spent with coach and team). In addition to field notes and participant observation, semi-structured interviews were conducted twice with the coach (before and after the athlete interviews) and once with each player.

Results showed that the coach used a tough-love approach, with more emphasis on being authoritarian, strict, and controlling with players. The coach interview revealed that the coach utilized a more authoritarian style based on personal and coaching experience. In addition, both player and coach interviews revealed that the coach had high expectations for the players and disciplined them out of love. The coach used physical tactics to get players back on task, motivate players' and keep their attention.

All of the players believed the coach used physical contact in a positive and humorous manner, never in a negative manner, because the coach cared for the players. The players believed the coach played multiple roles in their lives, including a motherly figure, disciplinarian, therapist, and mentor. This study should be replicated because of 1) the scant research in underserved sport-based PYD research, 2) the rarity of multi-year sport-based PYD studies, and 3) the need to extend the design to provide a more complete picture of the coach's actions and player experiences. The study can be extended by taking an ecological systems theory approach by including parental/primary caregiver perceptions, and quantitative measures to assess developmental outcomes of players within the league throughout the season. This EST approach would allow to triangulate the findings and provide more context for qualitative data. 


\section{Purpose}

The goal of this dissertation is not to attack autonomy-supportive, authoritative, positive coaching styles, nor to endorse authoritarian, controlling coaching styles. The objective is to provide examples of why coaching styles should be context-specific and explain how and why some authoritarian styles can foster PYD in underserved areas. Coaches have a significant impact on adolescent development (Petitpas et al., 2005; Smith, Smoll \& Curtis, 1979) through their coaching style and the climate they create. The element of caring may be one of the most important factors in PYD, independent of the coaching style.

Therefore, the purpose of this dissertation will extend the season-long ethnography and interview study of Brown et al. (in preparation) by including parental/primary caregiver perspectives and incorporate all teams within the city league. Additionally, the dissertation will attempt to address multiple gaps in the literature. First, it will examine the coaching styles used in the underserved setting. Second, it will explore the impact of the coaching style on life skill development throughout the season (Cowan et al., 2012; Flett et al. 2012 and 2013). Fourth, it will answer the question "what combination of coaching style factors have the strongest influence for PYD in the underserved setting?” (Flett et al., 2013). Lastly, it will explore parental/primary caregivers' perceptions of the coaching style used in the underserved setting, the intentionality of the coach, and whether life skills transferred from the sport setting to other domains of life. Furthermore, parents/primary caregivers provided in-depth information of how the coach supplements or augment home life within this context (Flett et al. 2013; Richardson, 2012). 


\section{Statement of Purpose}

The purpose of this study is to explore coaching styles in the underserved setting, to objectively assess developmental outcomes throughout the season, and gain a better understanding of the coaches' role, intentionality, and transferable life skills from parental/primary caregiver perspectives.

The three research questions and sub-questions guiding this study incorporate both quantitative and qualitative components. The questions are as follows:

1. Do life skills (LS) improve from participation, and what coaching style factors influence those LS outcomes?

1.1 Do quantitative measures of life skills show improvement for players across the season (Do scores change over time)?

1.2 Do quantitative measures of coaching style change over the basketball season (between Time 1 and Time 2)?

1.3 Are certain coaching styles greater for LS development (i.e. authoritarian, authoritative, caring, mastery, ego)?

1.4 If you were to combine all coaching style factors, which have the strongest influence on LS?

1.5 What influence does authoritarian coaching have on LS when combined with each of the other three coaching style factors (i.e. caring, mastery, ego), one at a time (i.e. authoritarian + caring; authoritarian + mastery; and authoritarian + ego).

1.6 What influence does authoritative coaching have on LS when combined with each of the other three coaching style factors (i.e. caring, mastery, ego), one at 
a time (i.e. authoritative + caring; authoritative + mastery; and authoritative + ego).

2. What is the common style of coaching in the city league?

2.1 What is the common coaching style in the city league?

2.2 How does Coach DD's (Team C) style compare to other coaches' styles in the city league?

3. Is this coach (Coach DD, Team C) developing LS through basketball, and if so, what skills and how does she develop them?

3.1 What developmental outcomes do parents think occur from participation with this coach and team (i.e. life skills development, intentionality, and transferability)?

3.2 Does the coach foster youth development intentionally? If so, how does she intentionally develop LS?

3.3 Do parents feel they can provide concrete examples of transferrable LS? If so, how are they being transferred?

3.4 Do parents think the sport or coach supplement psychosocial development in the players' home lives? If so, how does the coach or sport supplement psychosocial development in the players' home lives?

\section{Hypothesis}

Not all of the research questions warrant hypotheses. Some of the qualitative questions, for example, are exploratory. However, because this dissertation is an extension of previous research performed by the primary author and other researchers, and not an exploratory study overall, it is necessary to propose hypotheses. Each 
hypothesis described below is based on its corresponding research question; and null hypotheses are provided with each (alternative) hypothesis.

Research Question 1.1. Do quantitative measures of life skills show improvement for players across the season (Do scores change over time)?

- Hypothesis: Although there is a short interval of only three months between LS tests in this study, life skills will improve over time.

Research Question 1.2. Do quantitative measures of coaching style change over the basketball season (between Time 1 and Time 2)?

- Hypothesis: Coaches will become more authoritarian and decrease in mastery climates between Time 1 and Time 2 .

Research Question 1.3. Are certain coaching styles greater for LS development (i.e. authoritarian, authoritative, caring, mastery, ego)?

- LS changes will be greater for caring climates.

Research Question 1.4. If you were to combine all coaching style factors, which have the strongest influence on LS?

- Caring climate will have the strongest influence on developmental outcomes.

Research Question 1.5. What influence does authoritarian coaching have on LS when combined with each of the other three coaching style factors (i.e. caring, mastery, ego), one at a time (i.e. authoritarian + caring; authoritarian + mastery; and authoritarian + ego).

- The combination of authoritarian and caring will positively impact life skill development. 
Research Question 1.6. What influence does authoritative coaching have on LS when combined with each of the other three coaching style factors (i.e. caring, mastery, ego), one at a time (i.e. authoritarian + caring; authoritarian + mastery; and authoritarian + ego).

- The combination of authoritative and caring impacts life skill development.

Research Question 2.1. What is the common coaching style in the league?

- Coaches in the inner-city will use a tough-love approach (high levels of authoritarian and high levels of caring)

Research Question 2.2. How does Coach DD's (Team C) style compare to other coaches' style in the city league?

- Coach DD is the most authoritarian coach in the league, with some components of authoritative coaching

Research Question 3.2. Does the coach foster youth development intentionally? If so, how does she intentionally develop LS?

- Yes, parents will be able to answer the intentionality of the coach. The coach fosters youth development intentionally with various off-court strategies used with the team.

Research Question 3.3. Do parents feel they can provide concrete examples of transferrable LS? If so, how are they being transferred?

- Parents will be able to provide concrete examples of transferrable life skills.

Research Question 3.4. Do parents think the sport or coach supplement psychosocial development in the players' home lives? If so, how does the coach or sport supplement psychosocial development in the players' home lives? 
- Parents will be able to provide concrete examples of how the coach supplements home life. 


\title{
CHAPTER III
}

\begin{abstract}
Method
Petipas et al. (2005) argued that conducting a true experimental design in a youth sport program is not feasible because it is difficult to isolate variables and make cause and effect conclusions. As a result, mixed-methodology was used to allow the researcher to gain a more in-depth and complete understanding of coaching styles in the inner-city. The proposed method for this dissertation includes quantitative surveys of five teams (at two time points in the season) and interviews with parents of players on one specific team.

\section{Design}

The study was conducted over a full season and used mixed-methodology with quantitative data collected from all players in the league and from qualitative interviews with parents of the student-athletes from one specific team in this league studied the previous year (Brown et al., in preparation). The quantitative surveys enhanced objectivity and generalized findings by providing a range of perspectives on the primary team and the league it plays in. The parental/caregiver interviews provided information about the community, cultural and parental values; how the coaching style developed life skills in their daughters (granddaughters/niece); and whether the coaching style complemented or conflicted with their parenting style. Figure one (below) provides an overview of the timeline for each participant group.
\end{abstract}




\begin{tabular}{|c|c|c|c|c|}
\hline \multirow[b]{2}{*}{ Methods } & \multicolumn{4}{|c|}{ Participants } \\
\hline & $\begin{array}{l}\text { Primary } \\
\text { Caregiver }\end{array}$ & Coach & Team & League \\
\hline $\begin{array}{l}\text { Quantitative } \\
\text { Surveys }\end{array}$ & N/A & $\mathrm{N} / \mathrm{A}$ & $\begin{array}{l}\text { December } \\
\text { March }\end{array}$ & $\begin{array}{l}\text { December } \\
\text { March }\end{array}$ \\
\hline Interviews & January & N/A & N/A & N/A \\
\hline
\end{tabular}

Figure 1. The figure includes an overview of the design, including the methods components used with each participant in the study.

\section{Setting}

All participants, methods, and findings should be understood within the environmental context of the study. "Brownie High School" (pseudonym) is in an underserved inner-city environment in the North East United States. "Brownie High School" is in a predominately black neighborhood and approximately $45 \%$ of residents live below the poverty line (Neighborhood and Community Information System, 2011). The neighborhood suffers from high crime rates according to the Department of Public Safety (2010), and it is considered the most dangerous neighborhood in the city because $68.4 \%$ of homicides occur between this neighborhood and two other adjacent neighborhoods.

"Brownie High School" is a Title I school, and provides financial assistance to children from low-income families. It is currently one of the lowest-performing schools pertaining to the Keystone exams in the district due to financial factors, staff retention, 
and student dropout rates. Graduation rates for the school are approximately $72 \%$, which is lower than the state average of $85 \%$. The school has approximately 700 students from grades $6^{\text {th }}$ to $12^{\text {th }}$. Of those students, $97 \%$ identify as African American, $2 \%$ identify as Multi-Racial, and 1\% identify as Caucasian. "Brownie High School" offers temporary assistance for families in need, and food assistance for $81 \%$ of their students. The school has various extracurricular activities available to the students, however they have limited school-sponsored transportation (e.g., school bus and school vans), meaning that participants must find their own way home if they wish to participate in extracurricular activities. This can be problematic for most students living in this neighborhood because of the high crime rates (Department of Public Safety, 2010).

\section{Participants}

League coaches. The City Basketball League consists of six teams within the city limits. Five teams participated in the study. The fifth team (Team E) provided limited Time 2 surveys, which will be described in more detail in the procedure. The league was chosen because of the relationship that the primary researcher has with the team/community. In addition, the players from the five teams described the exemplar coaching style used in this underserved context. The league teams allowed the researcher to observe what coaching style is used, and how coach in the target team (Coach DD) compared to the other five coaches' in the city league. In addition, the quantitative data from the league allowed the researcher to see if coaching style impacted developmental outcomes in athletes throughout the season. The six coaches ranged from 32 to 52 years old $(M=38.40, S D=8.02)$. The three female coaches were African American, and the 
two male coaches were Caucasian. Coaches averaged 14.20 years of general coaching experience that ranged from seven to 32 years $(S D=10.47)$.

League players. The player sample consisted of players from five teams within the city league and alphabetized from A to E. The participants included 80 female players between the ages of 12 to 18 years $(M=15.68, S D=1.37)$. Among the participants, 68.4\% identified as African American, 20.3\% identified as Caucasian, $1.3 \%$ identified as Asian, and 7.6\% identified as other. Each player was a female and attended a high school located in the underserved inner-city community.

Participants from Team A had played basketball for their coach for eight months $(M=1.95, S D=2.31)$ to five years $(M=2.15, S D=1.69)$. Participants from Team B had played basketball for their coach for 10 months $(M=3.07, S D=3.65)$ to four years $(M=$ 1.38, $S D=1.26)$. Participants from Team $\mathrm{C}$ had played basketball for their coach for nine months $(M=5.86, S D=3.37)$ to five years $(M=1.00, S D=1.62)$. Participants from Team D had played basketball for their coach for eight months $(M=4.75, S D=1.98)$ to one year $(M=.19, S D=.40)$. Participants from Team $\mathrm{E}$ had played basketball for their coach for eight months $(M=1.27, S D=2.25)$ to six years $(M=2.40, S D=1.77)$.

Team C/Coach DD. Coach DD has 30 years of coaching experience in the high school and underserved settings. She has won multiple championships and is known in the city league for her strict, controlling, and structured coaching style (Brown et al. preparation). The coach helped numerous former players obtain full athletic scholarships to various colleges and universities - "a lot of players" in her description, but she could not provide a specific number. The selection criteria used for the coach included: (a) at least three years of coaching at a public school in the inner-city and (b) must be the head 
coach. Coach DD and her team was used to expand the previous longitudinal multi-year study of Brown et al. (in preparation).

Team C parents/primary caregivers. The selection criteria used for guardians included: (a) must have an adolescent on Coach DD's team; and (b) must be either the parent or primary caregiver raising the player. All the parents/primary caregivers from Team $\mathrm{C}$ were invited to participate in the study. Team C included 14 players and the parental/primary caregiver sample included six participants who ranged from 22 to 68 years old $(M=43.00, S D=15.07)$. The sample consisted of three mothers, one father, one grandfather, and one uncle. All participants identified as African American. Three participants identified as single, two identified as married or living with partner, and one identified as widowed. In terms of education, three participants identified as having some college/junior college degree, and three identified as having a college degree.

\section{Measures}

Parent/primary caregiver interview guide. The parent/primary caregiver semistructured interview guide (Appendix B1) explored themes related to the coaching style used in the city league, developmental outcomes, intentionality of the coach, transferable life skills and the coach as a supplement to home life. The interview guide was composed of four sections: a) introductory; b) perceived environment/context; c) impact of coach and sport; and d) coaching style. The following Table 3.1 provides the five major sections of the interview guide and the corresponding questions. The interview guide was grounded in research findings from the underserved parental and sport-based PYD literature. The guide was developed by the researcher with help from her doctoral advisor (an expert in the underserved sport-PYD field) and piloted twice. 
Table 3.1. Interview Questions that Correspond to Specific Category Category Question

\begin{tabular}{ll}
\hline Coach Style & $\begin{array}{l}\text { How would you describe the style of coaching style in } \\
\text { the city league? }\end{array}$ \\
& $\begin{array}{l}\text { How would you describe the style of coaching } \\
\text { implemented by Coach DD? }\end{array}$ \\
& What coaching style do you prefer for your daughter? \\
Developmental Outcomes & $\begin{array}{l}\text { List the life skills your daughter (niece/granddaughter) } \\
\text { has learned from the coach, team, and sport. }\end{array}$ \\
\hline Intentionality & $\begin{array}{l}\text { For the life skills that your daughter learned from the } \\
\text { coach, do you think coach fostered these life skills } \\
\text { intentionally? }\end{array}$ \\
\hline Life Skills Transfer & $\begin{array}{l}\text { For each skill that you just circled, have you actually } \\
\text { seen these things transfer to life? }\end{array}$ \\
& $\begin{array}{l}\text { Are there skills or lessons that you haven't seen } \\
\text { transferred yet, but believe will transfer? }\end{array}$ \\
\hline Coach Supplement & $\begin{array}{l}\text { Does the coach really deserve credit? Is there } \\
\text { something the coach does that your daughter can't } \\
\text { experience elsewhere? }\end{array}$ \\
Do you believe this coaching style complements or \\
conflicts with your parenting style?
\end{tabular}

Quantitative measures. The quantitative measures used included a demographic survey, the Caring Climate Scale (13-items; Newton et al. 2007), Motivational Climate Scale for Youth Sport (12-items; Smith et al., 2008), Parenting- Practice Questionnaire (27-items; Robinson et al., 1995), and Life Skills Scale for Sport (43-items; Cronin, 
Allen, \& Dimeo, 2016). Reliability scores for each measure and subscale based on this sample/study will be provided in the opening section of the Results.

Demographic Surveys. Players on the five teams completed questions about age, race, home life, total playing experience, years with the coach, and similar items (Appendix C2). Coaches and parents of Team C completed similar questions (Appendix C1 \& C3). This data was used to describe the sample, and give readers a better understanding of the participants, environment, and sport/coaching experience.

Caring Climate Scale (CCS). The CCS was used to measure "the extent to which individuals perceive a particular setting to be interpersonally inviting, safe, supportive, and able to provide the experience of being valued and respected" (Newton et al., 2007, p. 70; see Appendix D1). The CCS is a 13-item self-report Likert scale that measures the perceived caring climate in a physical activity setting. The test-retest reliability of the CSC was assessed among a sample of 395 participants in a National Youth Sport Program by Newton et al. The CCS had acceptable internal reliability between the ranges of $\alpha=.83$ to .92 . Recent literature using the CCS in the underserved setting in an innercity includes Gould et al. (2012).

In the analysis for this dissertation, CCS scores at Time 1, Time 2, and an aggregate of the two time-period scores were modeled. Ultimately, most of the analysis utilized Average Caring scores (the aggregated value of Time 1 and Time 2).

Motivational climate scale for youth sports (MCSYS). The MCSYS was used to assess athletes' perceptions of the mastery oriented versus ego oriented sport environment created by their coach (Smith, Cumming \& Smoll, 2008; see Appendix D2). The MCSYS is a 12-item self-report 5-point Likert scale with anchors of 1 (Not at all 
true); 3 ("Somewhat true"); and 5 ("Very true"). The MCSYS consists of six masteryorientation questions and six ego-orientation questions. The variables measured include achievement goal-orientations, intrinsic motivation, enjoyment, perceived success, persistence through adversity, perceived ability, and emotional responses (e.g. anxiety). The test-retest reliability of the MCSYS was assessed among 992 athletes between the ages of 9 to 16 years by Smith et al. (2008). Results showed that the subscales of the MCSYS was internally consistent exceeding acceptability $\alpha=.70$. In addition, the testretest reliability was shown to be sufficient with $\alpha=.84$ for mastery items and $\alpha=.76$ for ego items. Recent literature that utilized the MCSYS includes Gould et al. (2012), and Smith, Smoll and Cumming (2009).

In this analysis, the ego climate and mastery climate subscales were used as both independent and dependent variables. In keeping with previous research, they were not combined into a single motivation value (by adding, subtracting, averaging, or through any other manipulation). Like caring climate and all other coaching style predictor variables, ego and mastery climate were also represented by an average (Time 1 and Time 2) score.

Parenting Styles Dimensions Questionnaire (PSDQ). The PSDQ was used to assess specific parenting behaviors and practices consistent with Baumrind's (2013) three global typologies: authoritarian, authoritative, and permissive (Robinson et al., 1995; see Appendix D3). The shortened PSDQ is a five-point scale ranging from 1 (never) to 5 (always), and is comprised of 27-items across the three typology components. The authoritative scale contains questions that relates to warmth and involvement, reasoning/induction; democratic participation, and good natured/easy going. The 
authoritarian scale contains questions that relate to verbal hostility, corporal punishment, non-reasoning/punitive strategies and directiveness. The test- retest reliability of the PSDQ was assed among 1,251 volunteer parents who were predominately Caucasian from two-parent families with a median family income estimated around $\$ 30,000$ by Robinson et al. Results were shown to be sufficient for the authoritative items with a $\alpha$ of .91 , the authoritarian items with a $\alpha$ of .86 , and the permissive items with a $\alpha$ of .75 .

Based on the review of the literature and communication with the PSDQ's primary author, no previous study in the sport literature had used the PSDQ (R. Clyde, personal communication, October 25, 2016). For this dissertation, the phrasing was adapted and applied to coaching rather than parenting (i.e. "parents" would change to "coaches" and "child/children" would change to "players"). Additionally, the permissive subscale was omitted. In recognition of these sport-specific modifications and the fact that the scale was only minimally revised from the original form (see Appendix E1), the revised scale was referred to as the Coach-PSDQ (or C-PSDQ; see Appendix D3).

In the analysis for this dissertation, average authoritarian, average authoritative, and average aa-difference scores (authoritative minus authoritarian difference) are the Time 1, Time 2, and an aggregate of the two time-period scores were modeled. Ultimately, most of the analysis utilized average authoritarian, average authoritative, and average aa-difference (the aggregated value of Time 1 and Time 2).

Life Skills Sport Scale (LSSS). The LSSS was used to assess the degree to which youth are learning and developing life skills through sport (Cronin et al., 2016; see Appendix D4). The LSSS is a five-point scale ranging from 1 (not at all) to 5 (very much), and is comprised of 43-items with eight life skill subscales, which include: 
teamwork, goal setting time management, emotional skills, interpersonal communication, social skills, leadership, and problem solving and decision making.

Cronin et al. (2016) assessed the internal consistency and test-retest reliability of the LSSS with 37 British youth sports participants between the ages of 17 to 21 years with an average of 8.47 years of playing experience. Results showed that the subscales of the LSSS was internally consistent surpassing acceptability $\alpha=.70$. In addition, the testretest reliability was shown to be sufficient with .93 for teamwork, .93 for goal setting, .92 for time management, .87 for emotional skills, .89 for interpersonal communications, .86 for social skills, .93 for leadership, and .82 for problem solving and decision-making. In this analysis, Total LS and each subscale were all modeled with emphasis placed on total aggregated subscales because, the dissertation focuses more on coaching style than on LS change. Additionally, running too many analyses would increase Type I error and potentially result in mixed results that cannot be interpreted.

\section{Pilot Testing}

Prior to data collection, pilot tests were conducted to help improve the interview guides and quantitative surveys.

Quantitative pilot test. Three sets of quantitative pilot tests occurred one month prior to Time 1 data collection. The first set of tests occurred with three participants (one doctoral student, one former collegiate athlete, and one undergraduate student) who were not comparable of the sample. The survey included 136-items and took approximately 45-minutes to complete. Feedback from participants included that the survey was too long and some of the questions were unclear. As a result, the researcher revised the questions that were not clear and deleted questions that were not applicable to the study. 
The second pilot test occurred with eight adolescent boys from a JV team in the underserved setting outside of the city league, who shared similar characteristics as the sample population. The survey included 127-items and took approximately 30 to 35 minutes to complete. After examining results, the researcher included two "test questions" to the surveys to make sure participants read each question (i.e. Circle both 2 $\& 4$ for this question).

The third pilot test occurred with five adolescent girls from a JV team in the underserved setting outside of the city league. The survey included 115-items and took approximately 25 to 35 minutes to complete. Based on feedback, the players felt that the length was appropriate and the questions were easy to understand.

These pilot test helped determine the time needed to complete the 115 -item survey battery, and assessed the likelihood of participants filling out the survey questionnaire without burnout. The feedback from each pilot test was used to improve the structure by revising and reducing the amount of questions.

Qualitative pilot test. One qualitative pilot test occurred in December after the first collection of quantitative surveys from the players. The pilot test involved two bracketing interviews with parents who had a teenage daughter participating on a sport team (one similar to the sample population, and the other living in a suburban setting). The interview examined parental perceptions of the coaching style, the strengths and weakness of this style, and how the coaching style relates to child development. The bracketing interviews improved phrasing, the order of questions, identified any leading questions, and estimated the duration of interviews (Creswell, 2007). As a result, the 
order of questions was revised to enhance the flow. Additionally, the pilot studies helped the researcher to determine which questions were redundant and needed to be excluded.

\section{Procedure}

An overview of the procedure is provided in Figure 3.2 below. Approval from the IRB of West Virginia University was obtained (see Appendix A1). In order to gain access to the teams, the researcher contacted and individually met with the five head coaches in the city league to explain the purpose of the study. In addition to the meetings, the coaches were read a recruitment script approved in the IRB protocol (Appendix A4). During the meetings, the researcher answered any questions the coaches had. Coaches who agreed to participate in the study completed an informed consent form and returned them to the researcher in person.

\begin{tabular}{|c|c|l|l|l|l|l|}
\hline Directives \& Tasks & Nov & Dec & Jan & Feb & Mar & Apr \\
\hline A) Obtain IRB & & & & & & \\
\hline$\bullet \quad$ Letter of Permission to principal & $\sqrt{ }$ & & & & & \\
\hline$\bullet \quad$ Recruit Participants & $\sqrt{ }$ & & & & & \\
\hline B) Pilot Instruments $\quad$ Pilot Surveys -Teams & & & & & & \\
\hline$\bullet \quad$ Pilot Interviews - Parents & $\sqrt{ }$ & $\sqrt{ }$ & & & & \\
\hline C) Procedure & & & & & & \\
\hline 1. Quantitative Surveys (Team \& League) & & & & & & \\
\hline$\bullet \quad$ Time 1 - 2 weeks & & $\sqrt{ }$ & & & & \\
\hline
\end{tabular}




\begin{tabular}{|c|c|c|c|c|c|c|}
\hline$\bullet \quad$ Time 2-2 weeks & & & & & $\sqrt{ }$ & \\
\hline 3. Interviews & & & & & & \\
\hline$\bullet$ Parents/Primary Caregiver & & & $\sqrt{ }$ & $\sqrt{ }$ & $\sqrt{ }$ & \\
\hline D) Proposed Analysis & & & & & & \\
\hline - Quantitative Analysis & & Entry & Plan & & Entry & $\sqrt{ }$ \\
\hline$\bullet \quad$ Qualitative Analysis & & & & Transcribe & $\sqrt{ }$ \\
\hline
\end{tabular}

Figure 2. The table includes a time line and visual representation of the design in relation to each participant.

Quantitative data collection. Parental/primary caregiver consent was waived by IRB. Parents/primary caregivers could remove players from study. After obtaining consent from each head coach, the researcher asked coaches to distribute parental information and youth assent forms to their players during practice. The researcher emphasized that if the participant does not feel comfortable, they can drop out at any time without consequences. Surveys were completed and returned to the coach prior to the scheduled meeting. The researcher scheduled two meetings with each team, through the head coach.

First scheduled meeting. The first meeting for each team was scheduled three weeks into the season in the month of December. The researcher met with each head coach and team in a quiet, private room to facilitate formal introductions and a description of the study. Due to IRB parental waivers for the study, the researcher only distributed youth assent forms to each participant. Prior to distributing surveys, the researcher provided verbal directions to the participants, and answered questions. The 
researcher then distributed surveys, clarified survey ambiguity, and waited for participant completion. The researcher viewed each survey, with special emphasis on the "test questions," to ensure the surveys were completely appropriately and truthfully. In the event "test questions" were missed the researcher guaranteed to participants that there was no right or wrong answer, and then kindly asked the participants to look over the section once more.

Second scheduled meeting. The second meeting for each team was scheduled three weeks after the regular season ended in the month of March. The researcher met with each head coach and team in a location that facilitated data collection. The researcher reminded each team the purpose of the study and distributed the surveys. All teams had quick response rates and the researcher collected data within three weeks after the season, apart from Team E. The researcher contacted the coach from Team E via email (four times), phone (e.g. left three messages with school secretary), and in person (e.g. left two messages with school secretary and security guard). However, the coach did not respond.

Parent interviews. The parents/primary caregivers from Coach DD's team were purposefully sampled to obtain a range of participants who varied in age, ethnicity, experience, gender, and perceptions, which resulted in a more comprehensive study, and provided the researcher with information-rich cases for study in-depth (Patton, 2002).

The researcher met with the seven parents/caregivers of the players during the parent conference hosted by Coach DD during pre-season in November. The parents/caregivers who attended the conference were made aware of the study with a recruitment brochure (see Appendix A4), and asked if they would like to participate in 
the semi-structured interviews. The researcher informed the parents/caregivers that the interviews would take approximately 45 - 60 minutes and would examine their perceptions of the coaching style in the inner city; the intentionality of the coach; transferrable life skills; and the coach as a supplement to home life. The researcher contacted the volunteer parents in mid-December to schedule interview times for the 2-3 weeks of January during regular season. Additionally, the researcher met the remainder parents/caregivers, who did not attend the parent-conference from transporting players home from practice, games, and off-court activities (i.e. church, community service, track meets, etc.). The researcher introduced herself and made the parents/primary caregivers aware of the study, and asked if they would like to participate. The researcher followed the same procedures as the parents who attended the parent-conference hosted by Coach DD.

In December, the researcher contacted parents/caregivers of Team C and attempted to schedule seven interviews in January at a convenient location were the participants felt most comfortable. The researcher struggled with scheduling interviews with parents/caregivers because of various reasons (e.g. participants were too busy; forgot about the interview; did not want to be a part of a research study; work; medical emergencies; etc.). Out of the seven parents/caregiver interviews, four were conducted as planned, whereas the other two (participant number 6, and potential participant number 7) rescheduled multiple times. In the end, the researcher conducted interviews with each of the six parent/primary caregiver participants. At the beginning of the interviews, the researcher spoke to the participant about confidentiality and asked if the participant had any questions, comments, or concerns about the interviews. After the participants asked 
their questions, the researcher made the participant aware that the interview would be audiotaped and transcribed verbatim, and that they could stop and quit the study at any time. After each interview, the researcher made participants aware that she would send the interviews after transcription as a member check to improve trustworthiness.

\section{Data Analysis}

Quantitative. All statistical analyses were performed using the statistical software tool IBM SPSS Version 21. To minimize Type I error, only results that indicated a $\mathrm{p}$ - value of .05 or less were considered statistically significant. Descriptive statistics are given as mean and 95\% Confidence Interval for quantitative variables.

\section{Hypothesis 1.1.}

- Null: There will be no difference in life skills over time.

- Alternative: Life skills will improve over time.

Analysis Plan: To examine the improvement of life skills through quantitative measures, two sets of within-subjects one-way ANOAVA (with repeated measures) was used. The first test examined the variable LS total, and then an additional 8 ANOVA on each of the eight subscales of LS. The second test examined the eight subscales of LS. Time was the predictor and the LSSS scale and subscales were the dependent variables.

\section{Hypothesis 1.2.}

- Null: There will be no difference in coaching styles between Time 1 and Time 2.

- Coaches will become more authoritarian and decrease in mastery climates between Time 1 and Time 2 . 
Analysis Plan: To examine coaching style change between Time 1 and Time 2, six separate within-subjects one-way ANOAVA (with repeated measures) was used. Time was the predictor and the coaching style (i.e. authoritarian, authoritative, caring, mastery-motivation, and ego motivation) were the dependent variables.

\section{Hypothesis 1.3.}

- Null: There will be no difference in life skill changes for caring climates.

$\circ$ LS changes are greater for caring climates

Analysis Plan: To examine life skill improvement for players across the season based on coaching style, three sets of analyses were used based on different representations of the outcome variable. The analyses included a) a regression analysis with changed scores; b) repeated measures ANOVA (Time 1 and Time 2); and c) a regression analysis with Time 2 scores.

\section{Hypothesis 1.4.}

- Null: The caring climate has no relationship on developmental outcomes.

- Caring climate has the strongest influence on developmental outcomes.

Analysis Plan: To examine which coaching style predictors had the strongest influence on developmental outcomes, a backwards regression of total LS scores (Time 2) was ran to assess which variable(s) had the greatest impact and strongest predictor of life skill scores.

\section{Hypothesis 1.5.}

- Null: The combination of authoritarian and other coaching style predictors do not impact life skill development. 
- The combination of authoritarian and caring impacts life skill development.

Analysis Plan: To examine the strength of the relationship between authoritarian and other coaching style predictor variables among life skill development, a two-way mixed ANOVA was used. Interaction effects tested whether relationships varied by high or low authoritarian coaching styles while simultaneously assessing the effects of other predictors.

\section{Hypothesis 1.6.}

- Null: The combination of authoritative and other coaching style predictors do not impact life skill development.

- The combination of authoritative and caring impacts life skill development.

Analysis Plan: To examine the strength of the relationship between authoritative and other coaching style predictor variables among life skill development, a two-way mixed ANOVA was used. Interaction effects tested whether relationships varied by high or low authoritative coaching styles while simultaneously assessing the effects of other predictors.

\section{Hypothesis 2.1.}

○ Null: Coaches in the inner-city will not use a tough-love approach.

- Coaches in the inner-city will use a tough-love approach (high levels of authoritarian and high levels of caring) 
Analysis Plan: To determine the rank order of coaches for both authoritarian, authoritative and other predictor variables, a Wilcoxon Signed-Rank test was used. This allowed for the researcher to statistically rank each coach in the league.

\section{Hypothesis 2.2.}

- Null: Coach DD is not the most authoritarian coach in the league, nor does she have authoritative components

- Coach DD is the most authoritarian coach in the league, with some components of authoritative coaching

Analysis Plan: To determine how Coach DD compares to other coaches in the league, one-way ANOVAs and Gabriel's pairwise comparison test was used to assess whether Coach DD significantly differed in terms of authoritarian (and other coaching style factors).

\section{Hypothesis 3.1.}

○ Null: Parents/primary caregivers will not provide examples of intentionality the coach

$\circ$ The coach fosters youth development intentionally with various off-court strategies used with the team.

Analysis Plan: To determine the intentionality of the coach, parents/primary caregivers were asked a set of interview questions that targeted the specific theme.

\section{Hypothesis 3.2.}

○ Null: Parents/primary caregivers will not be able to provide concrete examples of transferrable life skills. 
- Parents will be able to provide concrete examples of transferrable life skills.

Analysis Plan: To determine the transferability of life skills, parents/primary caregivers were asked a set of interview questions that targeted the specific theme.

Quantitative Validity. The researcher used various methods to aid improve and enhance internal and external validity. If the researcher was unable to locate answers within statistical analysis books, then the researcher sought guidance from her doctoral advisor and a committee member who have expertise with statistical analysis. If both the doctoral advisor and committee member were unavailable, the researcher sought guidance from the statistical consultation services created specifically for graduate students on West Virginia University's campus. Additionally, other techniques were used to enhance generalizability, which is described in more detail in Chapter 4.

Qualitative. The researcher reviewed the audio and transcribed each interview word for word for a total of 110 typed pages. Qualitative data was analyzed through abductive content analysis, which aided in finding emerging themes (according to question topics) that related to developmental outcomes, coaching style, intentionality, transferable life skills, and the coach as a supplement, by summarizing or understanding meanings and context (Lederman, 1991). The researcher used Microsoft Word to independently code each interview transcript and compared them to create common themes. The researcher organized data by creating categories according to the topic of the interview questions through open codes. The researcher utilized Excel to identify similar concepts and categories within the data. Any time a participant mentioned a theme related to other participants, the researcher would use different colored highlights to distinguish 
categories. The data was grouped both deductively and inductively into lower and higher order themes (Miles, Huberman, \& Saldana, 2014). The deductive approach was used in establishing categories that related to the five interview guide themes (Miles et al.). The inductive (bottom-up) approach allowed the researcher to find emergent raw themes from each semi-structured interview and compare them to create common themes (Brinkmann \& Kvale, 2009).

Trustworthiness and Authenticity. To ensure trustworthiness and authenticity, the researcher used various methods to aid in credibility and transferability. The focus of this study was shaped by personal experiences of the researcher, as a high school player during adolescent years and a current assistant coach within the inner-city league.

Prior to data collection, bracketing interviews with three parents were used to help the researcher reflect on biases, improve and refine the questions (Creswell, 2007). Throughout the qualitative analysis process, two critical friends were used. The first critical friend was a doctoral candidate and trained in qualitative research. This reviewer was not present during the interviews or coding analysis process. The reviewer viewed raw data codes in context to each transcript and provided detailed constructive feedback. Additionally, the reviewer provided feedback on the organization of codes and development of themes. After changes were made to the organization of codes and development of themes, the researcher met with the reviewer (via phone) to make sure lower, middle, and higher order themes reflected the purpose of the interview guide and the corresponding theme (developmental outcomes, intentionality, transferable life skills, coaching style, and coach as a supplement). 
The second critical friend was the doctoral advisor of the PI. He was not present during interviews, coding analysis process, or during the initial thematic analysis, but critiqued the completed analysis. The second reviewer required the researcher to provide more descriptive labels for higher order themes, and insisted that the PI focus solely on the purpose of the dissertation, when identifying, organizing, and presenting results (Long Pantaleon, Bruant, \& d'Arripe-Longueville, 2006). Additionally, the researcher met with the reviewer to outline qualitative results and receive guidance on how to tell a logical and complete story that centered around the purpose of the study.

As a result, the data was triangulated in two ways. The results were triangulated by methods and sources which reduced bias and provided a more holistic picture of coaching styles, context, and developmental outcomes in the underserved setting. In addition, member checking and peer debriefing was utilized to corroborate the researcher's descriptions and interpretations of the context, coaching style, and player outcomes (Long et al., 2006). In addition to the critical friends, member checking and triangulation of methods, the researcher utilized field notes and kept a journal throughout the interview process of the study. The journal included the researchers assumptions, expectations, and beliefs about the interviews and allowed her to reflect on her prejudices, and how she may have influenced the results. 


\section{CHAPTER IV}

\section{Results}

The results for this dissertation are described in five major sections: The first two provide foundational information before formal analyses, and the last three are arranged according to the research questions and corresponding hypotheses.

\section{Participant Numbers, Measurement Reliabilities, and Assumptions}

A total of 80 players completed the player surveys. Fifteen out of 80 players did not complete Time 1 survey because they were unavailable. Eighteen out of 80 players did not complete the Time 2 survey due to attrition or unavailability. This resulted in a final sample of 47 players who completed both Time 1 and Time 2 surveys. The data for time 1 and time 2 were screened for data entry errors. Forty cases were randomly chosen to confirm the data was entered correctly. No errors were detected during the screening process. Missing data was assessed through frequency tables. Reliability, normality, homogeneity of variance, linearity, and independence were also assessed prior to conducting statistical analysis.

After pre-screening the data, Cronbach's Alpha were calculated to assess the internal reliability and consistency of each coaching style factor and outcome scale and subscale (see Table 4.1). Specifically, each scale and subscale for authoritarian, authoritative, caring climate, mastery climate, ego climate, and life skills (LS) were assessed for Time 1 and Time 2 data separately. 
Table 4.1.

Descriptive and Reliabilities of Scales and Subscales for Coaching Style Factors and Life Skill Dependent Variables

\begin{tabular}{|c|c|c|c|c|c|c|c|c|}
\hline \multirow[b]{2}{*}{ Variable } & \multicolumn{4}{|c|}{ Time 1} & \multicolumn{4}{|c|}{ Time 2} \\
\hline & M (SD) & Skewness & Kurtosis & $\alpha$ & M (SD) & Skewness & Kurtosis & $\alpha$ \\
\hline Authoritarian & $2.30(.76)$ & .34 & -.82 & .80 & $2.21(.80)$ & .72 & -.40 & .84 \\
\hline Authoritative & $3.43(.77)$ & -.19 & -.67 & .87 & $3.56(.82)$ & -.53 & -.40 & .89 \\
\hline Caring Climate & $4.51(.52)$ & -.97 & .13 & .94 & $4.46(.49)$ & -.86 & .21 & .90 \\
\hline Mastery Climate & $4.57(.55)$ & -1.29 & .71 & .90 & $4.69(.40)$ & -1.30 & .71 & .84 \\
\hline Ego Climate & $2.71(.96)$ & 1.12 & .63 & .83 & $2.78(.82)$ & .72 & .84 & .73 \\
\hline LS Total & $4.05(.55)$ & -.47 & .20 & .96 & $4.11(.64)$ & -.97 & .89 & .97 \\
\hline Teamwork & $4.30(.61)$ & -1.15 & 1.83 & .88 & $4.32(.65)$ & -.94 & .59 & .90 \\
\hline Goal Setting & $4.29(.65)$ & -.74 & -.44 & .90 & $4.23(.78)$ & -1.42 & 2.35 & .92 \\
\hline Social & $4.03(.76)$ & -.85 & .58 & .84 & $4.00(.86)$ & -.85 & .84 & .88 \\
\hline Problem Solving & $3.77(.88)$ & -.39 & -.59 & .92 & $3.83(.86)$ & -.38 & -.66 & .91 \\
\hline Emotional & $3.83(.69)$ & -.05 & -.76 & .66 & $4.00(.83)$ & -.84 & .53 & .82 \\
\hline Leadership & $4.09(.68)$ & -.71 & .43 & .87 & $4.14(.72)$ & -1.14 & 1.58 & .92 \\
\hline Time Mgmt. & $4.04(.73)$ & -.78 & .56 & .77 & $4.04(.82)$ & -.80 & .17 & .87 \\
\hline Communication & $4.1(.68)$ & -.84 & 1.37 & .79 & $4.13(.72)$ & -.75 & -.29 & .82 \\
\hline
\end{tabular}


Time 1 Reliabilities. Cronbach's alpha reliability coefficients ranged from .80 to .94 for the coaching style factors variables (authoritarian, authoritative, caring, mastery climate, and ego climate) and from .66 to .96 for the LS outcome total and subscales (see Table 4.1). All coaching style factors, LS subscales and the total LS aggregate therefore had acceptable reliability based on the critical criterion of $r>.70$ (Pallant, 2013), apart from LS emotional subscale (.66), which was not used in the analysis (see Table 4.1).

Time 2 Reliabilities. Cronbach's alpha reliability coefficients ranged from .73 to .90 for the coaching style factors variables and from .82 to .97 for the LS outcome total and subscales. All coaching style factors, LS subscales and the total LS aggregate therefore had acceptable reliability based on the critical criterion of $r>.70$ (Pallant, 2013). Table 4.1 contains the Cronbach's alpha coefficients, mean, standard deviation, skewness and kurtosis obtained in this study for Time 1 and Time 2 (see Table 4.1).

Normality of distributions. To assess normality for the independent and dependent variables, descriptive statistics were used to examine skewness, kurtosis, scatter plots, histograms, and standard error coefficients. Results for the KolmogorovSmirnov statistics indicated two variables (i.e. mastery climate, and LS subscale goal setting) violated the assumption of normality. As a result, the researcher examined the data for potential outliers.

The researcher used three techniques to identify and detect potential outliers which included box plots, histograms and z-scores with an absolute value of $|3|$. If potential outliers exceeded criteria for any one of the three techniques, then the researcher made note of the case and the value was left unchanged. However, if potential outliers 
exceed all three techniques, then the outliers were removed. Only two cases exceeded the z-score with an absolute value of $|3|$ or higher.

One participant's scores did violate all three techniques specifically the changed score for goal setting. Prior to removal of participant number 33's data, the mean was .08 (Std. Error $=.06)$ and $5 \%$ trimmed mean of .08. In terms of statistics, the ratio of skewness to standard error was .90 , and kurtosis ratio was 3.23 . After removal of participant 33, the subscale had mean of $1.71($ Std. Error $=.04)$ and $5 \%$ trimmed mean of 0.05 . The new ratio of skewness to standard error was -.17 , and kurtosis ratio was .11 .

Additionally, the change scores for the "communication" subscale included an outlier. Prior to the removal of participant 33, the mean was .21 (Std. Error $=.11)$ and $5 \%$ trimmed mean of .18. The ratio of skewness to standard error was 1.25, and kurtosis ratio was 5.99. After removal of participant 33, the subscale had mean of $.14($ Std. Error $=.04)$ and $5 \%$ trimmed mean of .16. The new ratio of skewness to standard error was -.53 , and kurtosis ratio was .43 .

\section{Descriptive Data and Correlations}

The following section provides an overview of the descriptive statistics and correlations among the factor variables (i.e. coaching style factors) and dependent variable (i.e. life skill development outcome).

Factor (predictor) variables. The following section describes the means, standard deviations, and ranges of the factor variables used in the study (see Table 4.1). The range of all coaching style scores were between 1 and 5 on a 5-point scale. Average authoritarian scores at both Time 1 and Time 2 fell lower within the range (e.g. $M_{\text {Timel }}=$ 2.29, $S D_{\text {Timel }}=.77$ ), whereas average authoritative coaching style scores on at both Time 
1 and Time 2 fell within the middle of the range (e.g. $\left.M_{\text {Timel }}=3.43, S D_{\text {Timel }}=.77\right)$. The caring climate scores for Time 1 and Time 2 fell high within the range of 1 to 5 (e.g. $M_{\text {Timel }}=4.51, S D_{\text {Timel }}=.52$ ). Regarding motivational climates, mastery fell high within the range at both time points (e.g. $M_{\text {Timel }}=4.57, S D_{\text {Timel }}=.55$ ). In contrast, ego for Time 1 and Time 2 fell within a lower part of range (e.g. $M_{\text {Timel }}=2.71, S D_{\text {Timel }}=.96$ ). Statistical differences in Time 1 to Time 2 scores will be explored in the research question analyses below. The $S D$ for both caring climate and mastery climate was relatively small at Time 1 and Time $2(.40-.55)$, which resulted in little variability among participant responses. Authoritarian, authoritative, and ego climate had larger $S D$ (.76 - .96), and more variability among participant responses (see Table 4.1)

Dependent variables. The following section describes the means, standard deviation and ranges of the LS scale and subscale variables used in the study. The range of all variables fell between 1 and 5 on a 5-point scale. All scales and subscales for Time 1 and Time 2 (life skills total, teamwork, goal setting, social skills, emotional, leadership, time management, and communications) fell high within the range, with the exception of problem solving which fell within the middle of the range (e.g. $M_{\text {Timel }}=3.77, S D_{\text {Timel }}=$ .88 ; see Table 4.1). The $S D$ for goal setting, social skills, problem solving and time management were larger for both Time 1 and Time 2, whereas, emotional skills (e.g. $\left.M_{\text {Timel }}=3.83, S D_{\text {Timel }}=.69\right)$, leadership (e.g. $\left.M_{\text {Timel }}=4.09, S D_{\text {Timel }}=.68\right)$, and communications (e.g. $M_{\text {Timel }}=4.08, S D_{\text {Timel }}=.68$ ), were smaller and resulted from little variability among participant responses. Statistical differences in Time 1 to Time 2 life skills scores will be explored in the research question analyses below. 
Relationships among variables (correlations). Pearson correlations were calculated to determine relationships among the coaching style factors and among life skill dependent variables. A variable labeled aa-difference was calculated to capture the difference between authoritative and authoritarian scores (authoritative minus authoritarian difference, or aa-difference). The rationale behind aa-difference is to represent the interplay between players' perception of authoritarian and authoritative coaching. AA-difference is the difference between authoritative and authoritarian scores. Therefore, a positive score represents authoritative coaching, and a negative score represents authoritarian coaching.

Coaching style factors. At Time 1 and Time 2, authoritative coaching had a significant positive correlation with caring climate and mastery climate, and caring climate and mastery climate had a strong positively correlation (see Appendix E2). At Time 1, all remaining coaching style factors were not significantly correlated. At Time 2, authoritarian coaching was negatively correlated with aa-difference and positively correlated with ego-mastery. AA-difference was positively correlated with caring climate and mastery climate at Time 2.

Life skill outcomes. At Time 1, all life skill subscales and total scores had a moderate to strong positive correlation. At Time 2, all subscales had a moderate to strong positive correlation except for the emotional, social skills, and problem solving subscales, which had a small to moderate positive correlations. Based on the correlations, findings indicate that all subscales were collinear and designed to measure some aspect of life skill development (see Appendix E3). 


\section{Research Question 1: Developmental Outcomes and Related Factors}

Changes in life skills (outcomes) over time. This section was guided by Research Question 1.1: Do quantitative measures of life skills show improvement for players across the season. Two sets of separate one-way repeated measures ANOVA were conducted to compare the effects of each of the eight subscales within LS and the total LS score between Time 1 and Time 2 during the basketball season. A test of the eight subscales a priori hypothesis was conducted and used Bonferroni adjusted alpha levels of $0.006(.05 / 8)$. As such, the DV were the total (aggregated) LS score and each subscale scores, and Time was the within subjects' factors. Findings revealed that only overall life skill development total score improved over the season, $F(1,47)=6.49, p=.01$ (see Appendix E4).

Changes in coaching style (factors) over time. This section was guided by Research Question 1.2: Do quantitative measures of coaching style change between Time 1 and Time 2 of the basketball season? Six separate one-way repeated measures ANOVA were conducted to compare the scores of each of the coaching styles factors from Time 1 and Time 2. As such, the DVs were the six coaching style scores, examined separately, and Time was the within-subjects' factors. Findings revealed that there were no statistically significant differences among coaching styles across time (see Appendix E5). As a result, the average scores of Time 1 and Time 2 coaching style were used in the future statistical analysis to increase power.

Changes in life skills by coaching style. This section was guided by Research Question 1.3: Are certain coaching styles greater for LS development (i.e. authoritarian, authoritative, caring, mastery, ego)? Three sets of analyses based on different 
representations of the LS outcome variable were used which included 1) a regression analysis with change scores, 2) repeated measures ANOVA (Time 1 and Time 2) and 3) a regression analysis with Time 2 scores.

LS change score regressions. Six simple linear regressions were conducted to model the relationship between the coaching style factors (authoritarian, authoritative, aadifference, caring, mastery climate, and ego climate) and LS outcomes change scores. The independent variables (IV) were the six coaching style factors scores averaged across Time 1 and Time 2. The dependent variable (DV), LS outcomes scores, were the difference in scores over time (Time 2 - Time 1). The simple linear regressions found no significant relationship between any of the coaching style factors and LS change scores (see Table 4.6). As a result, the researcher conducted repeated measures ANOVA.

LS repeated measures ANOVA. Six separate two-way mixed ANOVAs were conducted to compare the effects of each of the six coaching style factors on life skill development between Time 1 and Time 2. As such, the DV was total LS scores, Time was the within subjects' factors, and each coaching style factor was the between-subjects' factors. Findings revealed that there was no statistical significance among each factor for change in LS scores. As a result, the LS Time 2 total score was examined (see Appendix E7).

LS Time 2 score regressions. Six simple linear regressions were conducted to model the relationship between the same coaching style factors as in the above with LS outcome scores at Time 2 at the dependent variable. As prior, the IV's (i.e. authoritarian, authoritative, aa-difference, caring climate, mastery climate, and ego climate) were the 
average score across Time 1 and Time 2, and the DV was LS total outcome score for Time 2.

Authoritarian coaching. The model examining the relationship between average authoritarian coaching style and Time 2 LS total scores was found to be non-significant, $F(1,60)=1.74, p<.13)$, with an $R^{2}$ of .03 . The results of the regression indicated that authoritarian coaching did not significantly predict LS scores for Time $2(\beta=-.17)$.

Authoritative coaching. The model examining the relationship between average authoritative coaching style and Time 2 LS total scores was found to be significant, $F(1$, $60)=38.95, p<.001)$, with an $R^{2}$ of .39. Participants LS total Time 2 scores increased .627 (on a 5-point scale) for each 1 point increase in authoritative coaching style. The results of the regression indicated that authoritative coaching significantly predicted LS scores for Time $2(\beta=.63)$.

AA-difference coaching. The model examining the relationship between average aa-difference coaching style and Time 2 LS total scores was found to be significant $F(1$, $60)=32.39, p<.001$ ), with an $R^{2}$ of .35. Participants LS total Time 2 scores increased .59 (on a 5-point scale) for each 1 point increase in aa-difference coaching style. The results of the regression indicated that the aa-difference significantly predicted LS scores for Time $2(\beta=.59)$.

Caring climate. The model examining the relationship between average caring climate coaching style factor and Time 2 LS total scores was found to be significant $F(1$, $60)=15.77, p<.001$ ), with an $R^{2}$ of .21 . Participants LS total Time 2 scores increased .46 (on a 5-point scale) for each 1 point increase in caring climate coaching style. The results 
of the regression indicated that the caring climate significantly predicted LS scores for Time $2(\beta=.46)$.

Mastery climate. The model examining the relationship between average mastery climate coaching style and Time 2 LS total scores was found to be significant $F(1,60)=$ $15.14, p<.001$ ), with an $R^{2}$ of .20. Participants LS total Time 2 scores increased .45 (on a 5-point scale) for each 1 point increase in motivational mastery climate. The results of the regression indicated that the mastery climate significantly predicted LS scores for Time 2 $(\beta=.45)$.

Ego climate. The model examining the relationship between average ego climate coaching style and Time $2 \mathrm{LS}$ total scores was found to be not significant $F(1,60)=2.24$, $p<.14$ ), with an $R^{2}$ of .04 .

Findings revealed a statistically significant Time 2 LS scores for authoritative, aadifference, caring, and mastery climate. As a result, LS Time 2 total scores were used in future statistical analysis to increase the sample size from 47 to 62 participants, which also increased statistical power (see Appendix E8).

Strength of coaching style factors on life skill development. This section was guided by Research Question 1.4: If you were to combine all coaching style factors, which have the strongest influence on LS? A backward regression was run to assess which variables had the greatest impact on life skill scores (total LS scores in Time 2 were the DV in the model). Overall, three models were run, with the first model including all five coaching style factors (i.e., authoritarian, authoritative, caring climate, mastery climate, and ego climates). The $R^{2}$ values for the three models were $.48, .48$, and .47 , showing that effect sizes were just below medium. The ego climate variable was the first 
to be removed $(B=.01, p=.94)$, indicating that ego climate was the weakest factor in life skill development. In the second model, the weakest factor was the perceived caring climate $(B=.13, p=.31)$ and it was removed accordingly. In the last model, mastery climate was not significant $(B=.20, p=.07)$. In the final model, authoritarian coaching style $(B=-.20, p=.04)$, and authoritative coaching style $(B=.55, p>.001)$ were found to be the strongest factors among the coaching style variables.

The difference between authoritative and authoritarian scores (authoritative minus authoritarian difference, or aa-difference) was a variable that was not included in the previous backward regression because it would violate multicollinearity within the model. In other words, the relationship to both the authoritative and authoritarian variables does not allow aa-difference to be included in the same model as either of the two variables that it is derived from. However, based on the final model described above, it is clear that authoritative and authoritarian coaching styles are very important to LS development (see Appendix E9).

Authoritarian and authoritative combined with other factors. This section were guided by Research Questions 1.5 and 1.6: What influence does authoritarian and or authoritative coaching have on LS when combined with each of the other three coaching style factors (i.e. caring, mastery, ego), one at a time (i.e. authoritarian + caring; authoritative + caring; etc.). Three sets of three separate two-way between-groups ANOVAs were conducted to explore the impact of the three primary coaching style IVs: authoritarian, authoritative, and aa-difference (average authoritative score - average authoritarian score), combined with other coaching style variables, on Time 2 LS total scores (see Table 4.10). 
Authoritarian and caring, mastery, ego climates. A two-way ANOVA was conducted that examined the effect of authoritarian coaching and caring climate on life skill development. The interaction effect between authoritarian coaching and caring climate on life skill development was non-significant, $F(1,57)=1.14, p=.29$. There was a no significant main effect for authoritarian coaching, $F(1,57)=.06, p<.81$. However, there was a statistically significant main effect for caring climate $F(1,57)=5.47, p<.02$. Players in low caring group $(M=3.91, S D=.62)$ statistically differed from players in high caring group $(M=4.29, S D=.63)$ on LS development.

A two-way ANOVA was conducted that examined the effect of authoritarian coaching style and mastery-motivation climate on life skill development. The interaction effect between authoritarian and mastery-motivation on life skill development was also not significant, $F(1,57)=.00, \mathrm{p}=.97$. There was a no significant main effect for effect for authoritarian, $F(1,57)=.21, p=.65$. Also, there was a no significant main effect for mastery climates, $F(1,57)=3.80, p=.06$.

A two-way ANOVA was conducted that examined the effect of authoritarian and ego climate on life skill development. The interaction effect between authoritarian and ego climate on life skill development was also not significant, $F(1,57)=.16, p=.69$. There was a no significant main effect for authoritarian $F(1,57)=.41, p=.53$. Also, there was no significant main effect for ego climate $F(1,57)=1.89, p=.18$.

Authoritative and caring, mastery, ego climates. A two-way ANOVA was conducted that examined the effect of authoritative and caring climate on life skill development. The interaction effect between authoritarian and caring climate on life skill development was also non-significant, $F(1,57)=.10, p=.75$. There was a statistically 
significant main effect for authoritative, $F(1,57)=9.18, p<.05$. Players in the high authoritative coaching group had significantly higher life skill scores $(M=4.37, S D=$ $.47)$ than players in the moderate authoritative coaching group $(M=3.83, S D=.70)$. There was no significant main effect for caring climate, $F(1,57)=2.55, p=.12$.

A two-way ANOVA was conducted that examined the effect of authoritative and mastery climate on life skill development. The interaction effect between authoritarian and mastery climate on life skill development was not significant, $F(1,57)=.02, p=.88$. Again, there was a statistically significant main effect for authoritative, $F(1,57)=8.60$, $p=.01$, with the same pattern and group means and standard deviations as reported above in the two-way ANOVA for authoritative coaching and caring climate. There was no significant main effect findings for mastery climate, $F(1,57)=.72, p=.40$.

A two-way ANOVA was conducted that examined the effect of authoritative and ego climate on life skill development. The interaction effect between authoritarian and ego climate on life skill development was non-significant, $F(1,57)=.00, p=.99$. Again, there was a statistically significant main effect for authoritative, $F(1,57)=11.44, p<$ .001 , with the same pattern and group means and standard deviations as reported above. There was no significant main effect findings for ego climate here, $F(1,57)=.91, p=.34$.

\section{AA-difference and caring, mastery, ego climates. A two-way ANOVA was} conducted that examined the effect of aa-difference and caring climate on life skill development. The interaction effect between aa-difference and caring on life skill development was non-significant, $F(1,57)=.30, p=.59$. There was a statistically main effect for aa-difference, $F(1,57)=7.70, p=.01$. Players in the high aa-difference groups ( $M=3.91, S D=.62)$, were statistically higher from players in the low aa-difference groups 
$(M=4.29, S D=.63)$. There was no significant main effect for caring, $F(1,57)=2.73, p=$ .10 .

A two-way ANOVA was conducted that examined the effect of aa-difference and mastery climate on life skill development. The interaction effect between aa-difference and mastery climate on life skill development was non-significant, $F(1,57)=.05, p=$ .82. There was a statistically significant main effect for aa-difference, $F(1,57)=7.87, p$ $=.01$, with the same pattern and group means and standard deviations as reported above. There was no significant main effect for mastery climate, $F(1,57)=1.23, p=.27$.

A two-way ANOVA was conducted that examined the effect of aa-difference and ego climate on life skill development. The interaction effect between aa-difference and ego climate on life skill development was non-significant, $F(1,57)=.00, p=.96$. There was a statistically significant main effect for aa-difference, $F(1,57)=8.95, p<.001$, with the same pattern and group means and standard deviations as reported above. There was no significant main effect for ego climate, $F(1,57)=.30, p=.58$.

Findings indicated that authoritarian coaching did not affect LS development, and the combination of other coaching styles did not statistically increase or decrease LS development. However, authoritative coaching affected LS development and was particularly impactful when combined with a mastery climate.

\section{Research Questions 2: Common and Comparison of Coaching Style in Context}

The section was guided by Research Questions 2.1 and 2.2: What is the common style in the city league? How does Coach DD's style compare to other coaches' style in the city league? The following section provides an overview of coaching styles and life 
skill development within the city league. In addition, the section compares Coach DD to other coaches in the league on these factors.

Coaching style factors. Six separate one-way ANOVAs were conducted to examine how Coach DD compared to other coaching styles in the league. The ANOVA for authoritarian coaching was significant, $F(4,74)=9.14, p<.001$. Post-hoc comparisons using Gabriel's test indicated that the mean score for Coach DD $(M=3.07$, $S D=.74$ ) was statistically higher than all other coaches in authoritarian coaching (see Table 4.11). The ANOVA for authoritative coaching was not significant, $F(4,74)=1.50$, $p=.21$. The ANOVA for aa-difference was significant, $F(4,74)=2.96, p<.03$. Post-hoc comparisons using Gabriel's test indicated that the mean aa-difference score for Coach $\mathrm{DD}(M=.68, S D=.86)$ was significantly lower than Team 4 's mean score $(M=1.83, S D$ $=1.46$; see Appendix E12). The ANOVA for caring climate was significant, $F(4,74)=$ $3.03, p=.02$. However, the post-hoc comparisons using Gabriel's test due to unequal variance did not reveal any significant team differences. The ANOVA for mastery climate was significant, $F(4,73)=2.61, p=.04$. However, the post-hoc comparisons using Gabriel's test due to unequal variance did not reveal any significant team differences. The ANOVA for ego climate was not significant, $F(4,73)=1.05, p=.39$.

LS Time 2. A one-way ANOVA was conducted to examine how Coach DD compared to other teams in the league in terms of LS development. There was no significant difference for LS Time 2 scores, $F(4,56)=.49, p=.74$.

\section{Research Question 3: How Parents View Sport and/or Coaches}

The section was guided by two sub-questions from Research Questions 2 and all of Question 3 (which includes three sub-questions). Questions were answered using semi- 
structured interviews. Five deductive categories emerged from the semi-structured interview guide: Coaching style, Developmental outcomes, Coach as a supplement, Intentionality of the coach, and Life skill transfer (see Table 3.1 in Method). Each of these categories are described below, along with relevant inductive subthemes and participant quotes (rich narrative data).

Coaching Style. This section describes the common coaching style used in the city league with emphasis on Team C's coach (Coach DD). In addition, the parents/primary caregiver's preferred coaching style for their daughter (niece/granddaughter) are described.

City league and Coach DD. This section examined Participant's perceptions of coaching styles, in terms of authoritarian, authoritative or a blend of the two. Results revealed that majority of participants were unsure of the coaching style implemented in the city league.

P1: I haven't really observed that much of the city league, other coaches outside of DD ... but just looking at a few games and a couple of things on tv, they [coaches] want to win. They have more of the authoritative kind of attitude. Whereas, Participant 5 felt that coaches, aside from Coach DD, are neither authoritarian nor authoritative, and are lacking in many areas. Although the majority of participants were uncertain of the coaching style in the league due to the lack of observation and/or involvement, they felt more comfortable assessing Coach DD (Team C) and the style she used with her players.

Coach DD is (mostly) authoritarian. According to parents and primary caregivers, Coach DD is an authoritarian who focuses on the development of her players. 
One participant believed that it is "her" way or no way. Another participant (P4) felt as though for Coach DD, it was more than just playing basketball; it was about academics and getting her players involved in different activities and developing them holistically: "She's more authoritarian .... It's more than just a game to her, it's like study hard. She does more with the kids. She helps them grow as a better person." In addition, two participants talked about the coach having high expectations and being demanding of her players both on and off the court. Of the six participants, one mother did not like the coach's controlling authoritarian style because she felt as though the coach took up too much time with practice, and did not stress the importance of education and having other goals or ambitions aside from basketball.

P2: I think it's a little too much practice and it's like I understand she wants them to play basketball, but I think she needs to show them another path, what if you don't make it in basketball then what else you good in...like education wise...Right now my daughter don't want to do nothing but basketball. She quit her job, I'm like okayyy, what is she gonna do now?

Authoritative components buffer authoritarian styles. In addition to most participant's descriptions that Coach DD was highly authoritarian, some participants also felt as though she had some authoritative components that buffered her authoritarian approach. This section examines the benefits of the authoritative components used with high authoritarian coaching styles. All participants characterized Coach DD as someone who genuinely cares, does not give up on her players, and demonstrates patience. They explained that these qualities are needed for players growing up in the inner-city due to the unique challenges they face in their lives. 
P4: I mean she cares about all those girls. I mean [chuckles] she really does. I'm not padding her, by nature that's how Coach DD is and it's good for us, plus my granddaughter being inner city, being a black girl, influences, everything around, people shooting, killing each other, drugs, everything...so she has it in her heart to be that way, Coach DD.

Preferred coaching style. This section describes the participants' preferred coaching style used in the inner-city context with their daughter (granddaughter/niece). Results revealed that almost all participants preferred an old school "traditional coach" that ingrains values and focuses on development rather than just winning.

P5: The "traditional role of a coach" to me isn't just 'we're just here to play this game and win.' I think traditional coach is basically, you're a life coach! You're a basketball coach... you play a big part in their lives, they listen to you, they look up to you. So, you should be telling them, your grades are important if you want to go to college these are what your grades need to be. They need to know that! You're not just coaching them for the championship game. Your coaching these girls to go to the next level, that to me as a coach should be your aspiration. How can I help these kids win a championship, feel good about themselves, and follow their dreams wherever they may be, whether you believe they are D2 player or not, or a D1 player or not?

In addition, participants believed that an old-school disciplined and controlling approach was beneficial to their daughters because it taught them values, which are different than the "new school" approach. One participant, who had two daughters on two teams in the city league, discussed her experience with Coach DD. She considered Coach DD to be an 
old school "traditional coach," compared to the other city league coaches, whom she considered to be "new school."

P5: I like how she [Coach DD] believes in the older traditional ways of coaching, like if you don't come to practice, you can't play and things like that. My other kids basketball, I was disappointed with their coaching ... it looks the like the difference is that Coach DD comes from that other generation and coach Jessica [pseudonym] has came from the new generation. Those kids wouldn't come to practice but then she (Jessica) would start them based on sometimes how cool she was with their parents or their parents influence on the team or just certain things. In addition to the old school "traditional coach" preference, participants want coaches to care for their daughters and place more emphasis on development rather than performance outcomes and winning.

Developmental outcomes. This second section describes participants' perceptions of the developmental outcomes that occur from the coach, team, sport, and/or natural maturation, with emphasis on the coach's influence. All participants believed that life skill development could occur from the coach, team, and or sport and provided examples. Some of the life skills listed overlapped in two or more categories. Table 4.13 include participant responses to life skills that occur from the coach, team, sport, and natural maturation, as well as from each source's unique contribution.

Table 4.13 Themes from Interview Responses: Life Skills that occur from Coach, Team, Sport, and/or Natural Maturation 
Life skills learned from: The Coach, Team, and Sport

Life skills learned from: The Coach

Life skills learned from: The Team

Life skills learned from: The Sport

Life skills learned from: Natural maturation and Life experiences
Social skills, goal setting, independence, perseverance, good listener, respect, and obedience.

Discipline, maturity, social skills, goal setting, leadership, openness, patience, dedication, time management, and resilience.

Teamwork, cooperation, selflessness, team effort, togetherness, and goal setting.

Teamwork, hard work, strength, how to accomplish a goal, obedience, and discipline.

Perseverance, decision-making skills, leadership, strength, and resilience.

Participants believed that the developmental outcomes that occur from the coach, team, and sport include character development, positive interpersonal relationships with others, goal setting and accomplishing goals. In addition, participants indicated that the inner-city context, combined with sport, coach, and team taught their daughters (granddaughter/niece) to be resilient and persevere in any situation. As a result, the coach, sport and team can positively aid in youth development and influence life skill development within players.

Coach influences $\mathbf{L S}$ development. This section describes participants' perceptions of the coach's direct influence on life skill development regardless of parental/primary caregiver involvement. In addition, parents/primary caregivers provided a list of attributes coaches should have to have the biggest influence in LS development. 
Two participants indicated that $75 \%$ or more life skills development occurs primarily from the coach. Whereas others strongly believed that if parents are involved, coaches should not receive all the credit for life skill development, but some.

P6: I don't think that the coach deserves all the credit, depends on the parent and skills of that parent. If you never interacted with your kid, then yeah, the coach should get all the credit, but if you're a parent that has interactions with ya kids then you go from there. You can't give all the credit to somebody when you're the one that's really raising your child. The coach is only with your child 3-4 hours out of a day, maybe let's say 20-25 hours a week. You can't get all the credit for raising a child with that little bit of time.

However, some participants stressed that if there is a good, positive, and caring influence, kids can learn life skills elsewhere outside of the coach, team, and sport.

P5: I wouldn't give coaches all the credit, especially when they are crap. I think if they are good coaches, then yeah, they get credit for that, but I do believe some things are learned elsewhere because I don't feel my other kids got any of that from their experience playing for their high school team. So, they had no choice but to get it someplace else. I feel you give credit where credit is due.

Additionally, participants also described characteristics and attributes they felt coaches need to have when developing life skills within players. Four participants emphasized that coaching style, patience, and consistency have the biggest influence in personal development within athletes.

P1: Just being influential, [coach] has called my granddaughter lots of times, has put up with my granddaughter dissing her at times. I'm like, I want a coach like 
that. She [the coach] has never wavered, Coach DD. Does she get frustrated? Probably, she's human, but she never showed. So, Coach DD has been an asset, just to be able to let them [the team] know you can persevere, to look at me [the coach].

Additionally, one participant felt as though the most important attributes are the coach's character, coach-athlete relationship, and individualized player strategies.

P6: I would say that's just a character of a coach because they're the ones that are dealing with ...okay you got 15 kids on your team, that's 15 different attitudes and different personalities...I just think it's something a coach is knowledgeable and knows what they are doing and how to take kids cause you know what kids you can push to do something and what kid you can try to push that just ain't gonna do it... You have to look at everybody differently, you can't look at everybody the same way because like I said, everybody is different. Nobody is the same. You may think people are the same, nah their characteristics are different.

Coach intentionally fosters LS development. This third section describes participants' perceptions of the coach's intentionality in developing life skills through different strategies. Participants believed Coach DD intentionally fostered psychosocial development beyond sport-settings. Half of the participants described the coach as being both covertly and overtly intentional with her coaching strategies. Some intentional strategies included the communication between coach, players, and parents/primary caregivers; holding players accountable for their actions; mandatory study halls, off-court activities; etc. One participant described the coach's intentionality as being covert. 
P3: I think the way she [coach] sets it up, you don't even realize that's what's going on with you. She's taking them to church and they're all together, then they go out to eat and they're altogether...and she says well were gonna do this...cause my daughter wouldn't have, but she [coach] made it like this is what were gonna do and I think definitely yea because without some of that she [daughter] probably wouldn't have friends [laughs].

Whereas two others described the intentionality of the coach as being overtly by having the same rules apply for everyone on the team and punishing those who did not follow them, which aided in responsibility and discipline.

P5: Just like showing and proving. When some of the kids didn't come to practice, she didn't put them in. So, my daughter is like, oh I got to make sure I'm at practice or she's not gonna play me or I got to get to practice on time or I'ma have to run or do this and do that.

Another participant described the coach's strategy of making players cheer for another aided in teamwork and togetherness amongst the team. Although most participants believed that the coach intentionally fostered psychosocial development beyond sport, two participants were unsure of how the coach fostered life skills.

LS transfer beyond sport settings. This fourth section includes participants' examples of transferrable life skills beyond the sport setting. Within this category, the analysis revealed that parents/primary caregivers believed that their daughters (niece/granddaughters) learned social skills and personal responsibility within the sport settings, and provided detailed stories of how these skills transferred to non-sport settings. 
Social and interpersonal skills. This section includes participant's' examples of their daughter (granddaughter/niece) transferring social and interpersonal skills learned from the sport setting into other domains of life. All six participants provided examples of how they have seen an improvement in transferrable life skills (e.g., teamwork, respect, communication skills, obedience, patience, and tolerance for others) outside of the sport setting. Three participants felt as though their daughter transferred teamwork and togetherness outside of the sport setting.

P3: I'm gonna say teamwork, she's much better at that... she's a lot more helpful when you're at birthday parties and stuff, she's [daughter] the one who rallies the kids together, plays the games, and she braids all their hair and just like that whole thing of togetherness and teamwork type thing...she's willing to do a lot for people.

Additionally, another participant felt as though her daughter was becoming more respectful with more self-control. However, this participant did not believe that her daughter is at the level of maturity that she needs to be for her age. Similarly, two participants noticed that their daughters (niece/granddaughter) were becoming more respectful.

P6: The respect issue. I think she's starting to respect other people's boundaries, and what somebody may be expected of her... You treat people the way you want to be treated, it is a part of the respect thing and my daughter does that...the ones she don't like, she'll tell you, I don't like you so just get away from me [laughs]. Growth in personal responsibility. This section includes participant's' examples of their daughter (granddaughter/niece) transferring personal responsibility skills learned 
from the sport setting into other domains of life. Participants also provided examples of how their daughter (niece/granddaughter) were becoming more autonomous, responsible, resilient, and obedient in multiple contexts outside of sport.

P5: I just know she's became more responsible with just her having to leave school, get on the bus for practice because this is a different place... there's no running here or there to get tennis shoes or shorts cause she forgot. So just like that, keeping up with her stuff and getting to practice on time and being where she needs to get, and knowing what she needs to do and where she needs to go.

One participant emphasized that his daughter was becoming more responsible and obedient with chores and homework. Another participant described the improvement of her daughter's time management skills for school.

P2: I used to have to get her up for school, but now she gets up on her own... [Laughs] I was a little surprised because I used to drop my mom off at the bus stop around 6:30am and I'll be like daughter are you up and she be like, yeah mom, I'm already up.

Coach as a supplement for parents and primary caregivers. This fifth section describes how the coach supplements or reinforces home life values, and beliefs within players living in the inner-city context. In addition, it examines the coach's role and strategies used to develop life skills within players. This section is organized into two high order themes which included: the coach reinforces or complements home life; and the coach goes "beyond" traditional role.

Coach reinforces and/or complements home life. This section describes the participants' perceptions of the coach as another adult figure who positively reinforces 
and or expanding what kids are learning at home. Of the six participants, four believed the coach aligned with parental beliefs in terms of value, expectations and development. P5: Yeah, I think her style complements perfectly, she's embracing everything that I would want, but she can only do so much, she's one person and she has all these girls, but to me she's doing a good job.

Similarly, another participant described how the authoritarian, demanding, and controlling coaching style complemented his parenting style.

P6: I'm definitely demanding and controlling because of what I ask my kids to do...if I wasn't demanding and controlling, my kids would be running doing the hell whatever they want to do, which ain't happening in my book. Nope! Not on my watch!

Beyond "traditional" role of coach. The section is related to the coach doing more than what is expected in terms of the off-court coach athlete relationship, and providing players with diverse opportunities and learning experiences that they may not receive experience if it was not for the coach.

Coach-athlete relationship. Parental/primary caregiver participants emphasized that the coach continuously communicated with players, and dedicated time and resources to get to know/ help her players however she can on and off the court.

P1: I'm not with her [coach] every day but from the outside looking at how she is, how she talks to the students, how she goes beyond the basketball court, that's what I'm talking about cause all coaches want to win. All coaches are $100 \%$ on the field, on the court, on the track team, or whatever. What do you do beyond 
that? Do you compromise with them [the team]?... The coach is there to help and has helped. I've been there, I've talked to her [the coach]. Another participant emphasized that if it was not for the coach-athlete relationship, her daughter would not have had the opportunity to play basketball for any other school because of her attitude and disrespect.

P3: I feel like if my daughter didn't play at her school, she wouldn't play at all because she is a very challenging kid, she's mouthy, she sometimes can be disrespectful and most coaches would be like I don't want to coach her, she's very hard to coach but Ms. DD for some reason is able to get into her and tell her there's bigger and better things out here and this is what...this can change your life, different things like that. I just feel like without her [coach] she wouldn't play ball at all because other coaches would be like, "bye, I got somebody else," and that's not how she [coach] was. I don't want her [daughter] to be me, we struggle and that's why you want more. I think that she [coach] shows the kids that you can have more, you can get more.

Furthermore, a participant described the coach as being a "life saver" and helping her family financially and emotionally.

Exposure to diverse opportunities and learning experiences. More than half of the participants described the coach providing learning opportunities, and hosting trips (i.e. charity, library, museums, out of state team camps) for her players to grow, obtain knowledge, and be successful in both sports and life.

P3: She is always willing to take them to church, and do activities with them. I've never heard of other coaches that does the things that she do. She takes them to 
her home, takes them out... I'm talking more of the nurturing part ...she [coach] is much more nurturing then you would get from another coach. What coach takes their kid to church? Very rarely, I mean some may but you know stuff like that and it makes her [daughter] grow up and then my daughter gets to see the different side. I don't have a college degree, you know I don't have this big house and different things, not saying that's really important but she sees those things in her [coach] as well.

One participant described another diverse learning experience the coach utilized for her players which included the use of informal volunteers (i.e. coaches and mentors) on and off- the court.

P4: I like how coach allows people like us to help them with basketball, or whatever it might be cause were older, we serve as a role model. I don't know how many other coaches do that but it shows where she is coming from, it shows that she's open.

\section{Summary of qualitative findings}

Results from semi-structured interviews revealed that parents/primary caregivers in the underserved settings were not always aware of the coaching style implemented by the coach due to little involvement, and or lack of resources. Participants were unsure of the coaching style in the league, but described Coach DD as being highly authoritarian, with authoritative and caring components. In addition, results revealed that parents/primary caregivers preferred an "old school" authoritarian coach who genuinely cares for players and focuses on holistic development, rather than performance outcomes 
because players living in this context are influenced by gangs, drugs, negative people and other unique challenges.

Results indicated that life skills development can occur from the coach, sport, team, and natural maturation/life experiences. Specifically, the coach has a direct and indirect influence on life skill outcomes regardless of parental/primary caregivers' involvement. Coaches in the underserved setting are capable of augmenting, and or supplementing the home life by reinforcing parenting styles. Additionally, coaches may compensate what youth are lacking in their home life by going above and beyond the "traditional" role of the coach, by strengthening the on and off court coach - athlete relationship, and exposing youth to diverse learning opportunities, which can aid in life skill development. However, parents/primary caregivers felt that coaches should not receive all credit for life skill development if parents are involved, and emphasized that people should give credit to where credit is due. For coaches to have the biggest impact on life skill development in the underserved setting, they must be caring, consistent, positive, patient and have a positive coach-athlete relationship. More importantly, the coach must be intentional, using both overt and covert strategies when fostering life skills.

As a result of the coaching style and intentionality, life skills such as social skills, interpersonal skills, and personal growth transferred from the sport settings into other domains of life. Therefore, coaches can provide a unique context for development because they are another perspective outside of the parent/primary caregiver. Additionally, the guidance and positive reinforcement of the coach is another source of support for the players which aided with academic achievement, personal development. 


\section{CHAPTER V}

\section{Discussion}

This chapter is organized into four sections which include (a) a summary of the current study's findings, (b) conclusions that connect the findings and present three big take-home points, (c) how the current study informs existing literature, and (d) limitations and future directions. The purpose of this chapter is to simplify the Results and describe how this study contributes to the sport-based coaching and PYD, particularly in underserved settings.

\section{Summary of Findings}

Players' in the league are improving life skills across the season between Time 1 and Time 2. Findings revealed that authoritative coaching, aa-difference, caring, and mastery climates were statistically significant and predicted higher life skills scores for Time 2. Additionally, data revealed that authoritarian and authoritative coaching styles were unique predictors of life skill development. However, authoritarian coaching styles combined with other factors were not significant. Also, the caring climate did not make authoritarian coaching more effective. While authoritarian coaching was not as strong a predictor of LS as previous qualitative studies would suggest, higher authoritarian coaching clearly did not negatively impact LS. However, authoritative coaching affected LS development and was particularly impactful when combined with a mastery climate. This was a surprising result because caring did not account for improvements in LS when examined with authoritative coaching. Authoritative coaching had strong psychometric properties (above $\alpha=.87$ for Time 1 and Time 2) and was a very strong predictor of higher LS. Quantitative data showed that players perceived coaches to be moderately-low 
in authoritarian coaching $(M=2.24 ; S D=.72)$, moderately-high in authoritative coaching $(M=3.46 ; S D=.78)$, high in caring climate $(M=4.47 ; S D=.52)$, high in mastery climate $(M=4.63 ; S D=.47)$, and low in ego climate $(M=2.77 ; S D=.90)$ on a 1 to 5-point scale. Coach DD ranked the highest in both authoritarian and authoritative scores. However, she consistently ranked low in all other predictor variables. Furthermore, Coach DD statistically differed from the other five coaches in the league in terms of authoritarian coaching. Surprisingly, all coaches were statistically equal in terms of LS development. Findings from this study indicated that high authoritarian coaching factors did not increase or decrease LS development.

From an EST point of view, the addition of parents/caregivers triangulated player perceptions and provided another perspective of the coaching style and life skill development. Qualitative data revealed that participants were unsure of the coaching style used in the league; however, they characterized Coach DD as being highly authoritarian with authoritative and caring components. Additionally, participants believed the life skills their daughters' (granddaughters'/nieces') developed resulted from the coach, sport, team and natural maturation. These findings are consistent with the current sport PYD because research indicates that positive outcomes can occur from sport (Fraser-Thomas et al., 2005; Gould \& Carson, 2008). However, sport alone does not automatically teach life skills. According to Gould and Carson (2008), coaches need to be intentional when teaching life skills. Regarding Coach DD's intentionality of fostering life skills, some participants believed the coach fostered youth development intentionally both covertly and overtly with different strategies which aided in the transference of life skills from the sport setting to other domains of life. Additionally, all parents/primary caregivers 
provided examples of transferrable life skills that related to a growth in personal responsibility, players' becoming more autonomous and responsible. Based on parental/primary caregiver perceptions, it seems as though players' are transferring life skills from the sport settings to non-sport settings (Gould \& Carson, 2008). Additionally, all participants emphasized that Coach DD either complemented, supplemented, or compensated players home lives (in terms of values, beliefs, and expectations).

Understanding the inner-city setting. A substantive amount of evidence indicates that the coach aids in LS development. This is no less true or important within the inner-city setting. Similar to previous research, youth living in the underserved setting are facing a multitude of unique challenges (Walsh, 2008) such as lack of support/disengaged parents (Flett et al. 2013), incarcerated parents/caregivers (Flett et al. 2013; Richardson, 2012), and gang violence (Flett et al. 2013), etc. As a result, parents/primary caregivers in this setting are not always aware of what is going on in their daughters (granddaughter/nieces') lives due to their lack of involvement at practices and games, and look to the coach as a unique source of support and guidance for their adolescents (Levine \& Munsch, 2016). These are not suburban helicopter parents because they rarely attended practices, games, off-court activities, parent - team meetings, due to various reasons (e.g. single parent home, parents/primary caregivers were too busy, had work, lack of transportation, or did not want to be involved). Consistent with Richardson's (2010) study, parents/caregivers looked at Coach DD as a form of social capital, role model, and mentor for her players. They relied heavily on Coach DD to reinforce, supplement, or even compensate for parental guidance in the players' home lives. Additionally, parents/ primary caregivers felt as though Coach DD was aware of 
players' home lives and utilized "old school" tough-love approach, which is similar to findings from Flett et al. (2013). According to Flett et al. (2013) the tough-love approach helped fostered resilience, perseverance, and prepared players for the harshness of the real world. Additionally, Coach DD would have been considered an effective coach in the underserved setting because she was intentional with trying to foster LS, she had high expectations, engaged in positive behaviors, and allowed players the opportunity to learn from mistakes (Brown et al., in prep...), which is consistent with Flett et al. (2016) description of effective coaches.

Typically, coaches in this setting are more authoritarian but need a balance with authoritative guidance to reduce negative outcomes associated with authoritarian styles (Brown et al. in preparation; Cowan et al. 2012; Flett et al. 2012; Flett et al. 2013). Parents/primary caregivers are in strong support of authoritarian coaching as long as there is an authoritative and caring foundation. This finding is consistent with the parenting literature and to some extent the teaching literature in the underserved settings because authoritarian styles serve as a protective factor for youth living in the underserved setting (Hartman \& Manfa, 2015; Smetana, 2011). However, coaches in the current study were not perceived as highly authoritarian but had some levels of authoritarian coaching style $(M=2.24, S D=.72)$ and structure with their teams. Players perceived their coaches to be moderately authoritative $(M=3.46, S D=.78)$, highly caring $(M=4.47, S D=.52)$, and utilized a mastery climate $(M=4.63, S D=.48)$ which aided in life skill development. The current study supports the literature showing that coaches in this setting were somewhat authoritarian and were capable of fostering LS development throughout the season. 
Coaching style. Within the underserved setting, coaches need to create a disciplinary structure and take a positive approach to coaching. Based on the results, the biggest impact on LS development occurred from an authoritative coaching style, with a foundation of disciplined authoritarian structure, and high mastery and caring climates. However, authoritative coaching styles overlapped with mastery and caring climates and accounted for more of the variance in LS outcomes than all other measures in the study. Furthermore, the current literature shows strong support for mastery climates (Gould et al. 2012; Vitali et al., 2015) and caring climates (Fry \& Gano-Overway, 2010; Gould et al. 2012) and emphasizes their importance of instilling LS. However, to the knowledge of the PI, no other study in the underserved sport-based PYD literature has quantitatively measured authoritative coaching. Based on the current findings of this study, it seems that the authoritative instrument/measure could potentially be a better predictor than mastery and caring climate measures. Nonetheless, based on previous literature, mastery and caring climates are important to instilling LS. The data from the current study supports previous literature and indicate the importance of mastery and caring climates in underserved settings. However, results from this study indicate that if coaches want to have a bigger impact on life skill development in the underserved setting, they must be authoritative and implement a mastery and caring climate.

One interesting finding was that the authoritarian style was shown to be a unique predictor of life skill development. Although authoritarian coaching did not facilitate LS, it did not have a positive or negative relationship with high LS scores. Results from the current study did not indicate that there was a significant positive or negative linear relationship between authoritarian coaching and LS. This finding is interesting because 
the current sport literature indicates high authoritarian coaching is detrimental to life skill development (Holt et al., 2009). However, the current findings support the argument that what works in one context may be maladaptive to another, and shows that authoritarian style may be beneficial for youth living in the underserved setting (Cowan et al. 2012; Dearing, 2004; Flett 2013; Smetana, 2011).

\section{Limitations}

The current study had five notable limitations. First, the relatively small sample size likely limited the range of perceptions of coaching style because the data was limited to players from five teams within the city league. As a result, the range of coaching styles were limited, and may not be representative of all coaching styles in the underserved setting. The potential lack of variability on coaching style perceptions may have limited the analysis and conclusions that were possible. Additionally, the study was limited to high school girls' basketball and not inclusive of males, various sports, and SES.

Second, the limited variance on some scales (i.e. caring and mastery climate) likely reflected a lack of range in data (i.e., player perceptions), whereas a larger sample size and variety of coaching styles may have provided different results. There were very few if any players who, for example, perceived their coaches to be low in caring, mastery, or authoritative styles as well as few, if any, very high authoritarian ratings. As a result, a true comparison of low caring- and high caring-authoritarian coaches was not possible. Furthermore, without actual data from which to model the extreme ends of the authoritarian continuum (i.e., very low and very high authoritarian ratings), it is unclear how such extremes interact with other coaching styles and impact the development of LS. 
The third limitation was that the parent/primary caregiver interviews occurred with six participants and did not represent every player on the selected team. Although parents/primary caregivers provided data on the preferred coaching style in the underserved setting and attributes coaches need to have to foster PYD, these individual experiences may not be generalizable to other underserved settings or other teams. More participants would have been beneficial in generalizing these findings to the larger population, and would have added more information to the limited research in underserved sport-PYD. In particular, the opinions of the parents/primary caregivers who did not participate in the study may have been unique from those who did. Such parents may have been even more removed from the actions of the coach and culture of the league.

The fourth limitation was the use of self-report measures. Due to the reliance on player responses, the researcher depended on players' ability to provide accurate responses of their feelings towards the coaching style factors and LS development. Responses could be a result of social desirability, which is a consistent limitation with any self-report measure. Some players, for instance, may have felt that low ratings could get their coach in trouble, or even get them in trouble with the coach-in spite of assurances of confidentiality and other methodological precautions.

The final limitation included the researcher's personal bias. Due to the researcher's prior relationship with the league, and previous study conducted with Coach DD and Team C, a cultural and confirmation bias may have occurred. Additionally, based on the researcher's own experience with tough-love approach from her family and former coaches', she firmly believes that some levels of authoritarian in the underserved setting 
aids in positive youth development. However, the researcher took steps to reduce bias and enhance trustworthiness and generalizability of the study, as described in Chapter 3.

\section{Recommendations for Future Research}

Due to limited research related to sport based PYD in the underserved setting, future studies should replicate the current study to include various sports and male teams because some research suggest that coaches are more willing to implement harsher coaching styles with males than girls (Flett et al., 2012). This would allow for a larger and more varied sample (perceived lack of caring, low authoritarian, high authoritarian, low mastery, etc.), and potentially a bigger range of scores for coaching style factors (i.e. authoritarian, authoritative, caring climate, mastery climate, and ego climate). Additionally, future studies should include an urban and suburban sample to see how coaching styles compare and differ in terms of life skills development.

In terms of the PSDQ scale, the current findings suggested that both authoritarian and authoritative coaching styles were the strongest predictors of coaching styles. However, the permissive scale was omitted due to the purpose of this study. Future research should include the permissive scale because it may account for some variance in predicting LS development. Additionally, future studies should aim to look at the phrasing of the authoritarian subscale because some items are extreme and may give off a negative connotation. As a solution, an instrument like the PSDQ for coaches in sport needs to be validated beyond reliability coefficients.

Lastly, the current study indicated few parents/primary caregivers were aware of what was going on and can provide valuable insight on the coaching style, intentionality of the coach, the coach as a supplement, and transfer of life skills. Future research should 
include parents/primary caregivers of multiple teams and see how they compare or contrast in terms of coaching style factors and their impact on LS development.

\section{Conclusion}

The current study is invaluable because it expanded the existing sport-based PYD literature and objectively and qualitatively explored authoritarian and authoritative coaching styles in the underserved settings of the inner-city. Additionally, the study objectively measured life skill development across two time periods which differs from the current sport literature. From an EST perspective, the inclusion of parents/primary caregivers informed the study that life skills are being transferred from the sport setting to other domains of life.

A practical implication for coaches is the knowledge that the use of an authoritative coaching style combined with caring and mastery climates is positively related to higher LS. Outcomes from this study showed that all coaches in the underserved setting had some levels of low-to-moderate authoritarian coaching style and were still able to foster LS development within their players. The findings from this study have the potential to inform sport-based PYD in underserved setting and show that not all authoritarian coaching styles are detrimental, as long as they are done in a positive manner. Coaching is not one dimensional, nor should it be one style fits all; instead coaching should be based on the individual needs of the athletes. 


\section{References}

Anatomy of a neighborhood homewood in the $21^{\text {st }}$ century - UCSUR. (2011, March). Retrieved October 22, 2016, from http://ucsur.pitt.edu/wpcontent/uploads/2014/11/Homewood-Neighborhood-Report_UCSUR_March2011.pdf

Amorose, A. J., \& Anderson-Butcher, D. (2015). Exploring the independent and interactive effects of autonomy-supportive and controlling coaching behaviors on adolescent athletes' motivation for sport. Sport, Exercise, and Performance Psychology, 4, $206-218$.

Bartholomew, K., Ntoumanis, N., \& Thøgersen-Ntoumani, C. (2010). The controlling interpersonal style in a coaching context: Development and initial validation of a psychometric scale. Journal of Sport and Exercise Psychology, 32, 193-21.

Bailey, R. (2006). Physical education and sport in schools: A review of benefits and outcomes. Journal of school health, 76, 397-401.

Baumrind, D. (2013). Authoritative parenting revisited: History and current status. In R. E. Larzelere, A. Morris, \& A. W. Harrist (Eds.), Authoritative parenting: Synthesizing nurturance and discipline for optimal child development. Washington, DC: American Psychological Association.

Bennie, A., \& O'Connor, D. (2012). Coach-athlete relationships: A qualitative study of professional sport teams in Australia. International Journal of Sport and Health Science, 10(0), 58-64. 
Benson, P. L., Scales, P. C., Hamilton, S. F., Sesma Jr, A., Hong, K. L., \& Roehlkepartain, E. C. (2006). Positive youth development so far: Core hypotheses and their implications for policy and practice. Search Institute Insights \& Evidence, 3(1), 1-13.

Benson, P.L., Scales, P.C., Roehlkepartain, E.C., \& Leffert, N. (2011). A fragile foundation: The state of developmental assets among american youth ( $\left.2^{\text {nd }} \mathrm{ed}.\right)$. Minneapolis: Search Institute.

Brinkmann, S., \& Kvale, S. (2009). InterViews: Learning the craft of qualitative research interviewing ( $3^{\text {rd }}$ ed.). Thousand Oaks, CA: Sage Publications.

Bronfenbrenner, U. (1977). Toward an experimental ecology of human development. American psychologist, 32, 513-531.

Bronfenbrenner, U. (2009). The ecology of human development: Experiments by nature and design. Harvard university press.

Brown, R., Hayes, S., Goodson, A., Hartman, S., \& Flett, M.R. (Manuscript in preparation). Coaching inner-city girls: A season-long ethnography.

Camiré, M., Trudel, P., \& Forneris, T. (2009). High school athletes' perspectives on support, communication, negotiation and life skill development. Qualitative research in sport and exercise, $1(1), 72-88$.

Chelladurai, P., \& Saleh, S. D. (1980). Dimensions of leader behavior in sports: Development of a leadership scale. Journal of sport psychology, 2(1), 34-45. City of Pittsburgh Department of Public Safety Bureau of Police (2010). Retrieved October 22, 2016, from http://pittsburghpa.gov/police/files/annual_reports/10_Police_Annual_Report.pdf 
Coakley, J. (2011). Youth sports what counts as “positive development?". Journal of sport \& social issues, 35, 306-324.

Coatsworth, J. D., \& Conroy, D. E. (2009). The effects of autonomy-supportive coaching, need satisfaction, and self-perceptions on initiative and identity in youth swimmers. Developmental psychology, 45, 320-328.

Côté, J., \& Fraser-Thomas, J. (2010). Youth involvement and positive development in sport. In P. Crocker (Ed.). Sport psychology: A Canadian perspective, $\left(2^{\text {nd }}\right.$ edition). Toronto: Pearson.

Côté, J., \& Gilbert, W. (2009). An integrative definition of coaching effectiveness and expertise. International journal of sports science and coaching, 4, 307-323.

Coll, C. G., \& Pachter, L. M. (2002). Ethnic and minority parenting. Handbook of parenting: Social conditions and applied parenting, 4, 1-20.

Cowan, D. T., Taylor, I. M., McEwan, H. E., \& Baker, J. S. (2012). Bridging the gap between self-determination theory and coaching soccer to disadvantaged youth. Journal of Applied Sport Psychology, 24, 361-374.

Damon, W. (2009). The path to purpose: How young people find their calling in life. Simon and Schuster.

Dearing, E. (2004). The developmental implications of restrictive and supportive parenting across neighborhoods and ethnicities: Exceptions are the rule. Journal of Applied Developmental Psychology, 25, 555-575.

Deater-Deckard, K., Lansford, J. E., Dodge, K. A., Pettit, G. S., \& Bates, J. E. (2003). The development of attitudes about physical punishment: An 8-year longitudinal study. Journal of Family Psychology, 17, 351-360. 
Donnelly, P., \& Coakley, J. (2007). The use of sport to foster child and youth development and education. Literature Reviews on Sport for Development and Peace, 7.

DuBois, D. L., Holloway, B. E., Valentine, J. C., \& Cooper, H. (2002). Effectiveness of mentoring programs for youth: A meta-analytic review. American journal of community psychology, 30(2), 157-197.

DuBois, D. L., \& Silverthorn, N. (2005). Natural mentoring relationships and adolescent health: Evidence from a national study. American journal of public health, 95, $518-524$.

Dworkin, J., \& Larson, R. (2006). Adolescents' negative experiences in organized youth activities. Journal of youth development, 1(3), 1-19.

Eamon, M. K. (2002). Poverty, parenting, peer, and neighborhood influences on young adolescent antisocial behavior. Journal of Social Service Research, 28(1), 1-23.

Eby, L. T., Allen, T. D., Evans, S. C., Ng, T., \& DuBois, D. L. (2008). Does mentoring matter? A multidisciplinary meta-analysis comparing mentored and non-mentored individuals. Journal of vocational behavior, 72, 254-267.

Eby, L. T., Rhodes, J. E., \& Allen, T. D. (2007). Definition and evolution of mentoring. The Blackwell handbook of mentoring: A multiple perspectives approach, 7-20.

Flett, M. R., Gould, D., \& Lauer, L. (2012). A study of an underserved youth sports program using the Youth Program Quality Assessment. Journal of Applied Sport Psychology, 24, 275-289. 
Flett, M. R., Gould, D., Griffes, K. R., \& Lauer, L. (2012). The views of more versus less experienced coaches in underserved communities. International Journal of Coaching Science, 6(1), 3-26.

Flett, M. R., Gould, D., Griffes, K. R., \& Lauer, L. (2013). Tough love for underserved youth: A comparison of more and less effective coaching. Sport Psychologist, 27, 325-337.

Flett, M. R., Sackett, S. C., \& Camiré, M. (2016). 11 Understanding effective coaching. The Psychology of Sports Coaching: Research and Practice, 156.

Flynn, R.J. (2008). Communities that care: A comprehensive system for youth and prevention and promotion, and canadian applications to date. Institute for Crime Prevention Review, 2, 83-106.

Fraser-Thomas, J. L., Côté, J., \& Deakin, J. (2005). Youth sport programs: An avenue to foster positive youth development. Physical Education \& Sport Pedagogy, 10(1), $19-40$.

Fry, M. D., \& Gano-Overway, L. A. (2010). Exploring the contribution of the caring climate to the youth sport experience. Journal of Applied Sport Psychology, 22, 294-304.

Fry, M. D., \& Newton, M. (2003). Application of achievement goal theory in an urban youth tennis setting. Journal of Applied Sport Psychology, 15(1), 50-66.

Furstenberg, F. F., \& Kaplan, S. B. (2004). Social capital and the family. In J. Scott, J. Treas, \& M. Richards (Eds.), The Blackwell companion to the sociology of families. Oxford: Blackwell. 
Gano-Overway, L. A., Newton, M., Magyar, T. M., Fry, M. D., Kim, M., \& Guivernau, M.R. (2009). Influence of caring youth sport contexts on efficacy-related beliefs and social behaviors. Developmental Psychology, 45, 329-340.

Gardiner, H., \& Kosmitzki, C. (2008). Lives across cultures: Cross-cultural human development ( $4^{\text {th }}$ ed.). Boston: Pearson Allyn and Bacon.

Gilbert, W. D., \& Trudel, P. (2004). Analysis of coaching science research published from 1970-2001. Research quarterly for exercise and sport, 75, 388-399.

Goodstein, P. K. (2013). How to stop bullying in classrooms and schools: Using social architecture to prevent, lessen, and end bullying. New York: Routledge.

Gould, D., \& Carson, S. (2008). Life skills development through sport: Current status and future directions. International review of sport and exercise psychology, 1(1), 5878.

Gould, D., \& Carson, S. (2010). Coaching Behaviors and Developmental Benefits of High School Sports Participation. Hellenic journal of psychology, 7, 298-314.

Gould, D., Collins, K., Lauer, L., \& Chung, Y. (2007). Coaching life skills through football: A study of award winning high school coaches. Journal of applied sport psychology, 19(1), 16-37.

Gould, D., Flett, R., \& Lauer, L. (2012). The relationship between psychosocial developmental and the sports climate experienced by underserved youth. Psychology of Sport and Exercise, 13(1), 80-87.

Hansen, D. M., \& Larson, R. (2005). The youth experience survey 2.0: instrument revisions and validity testing. Urbana-Champaign, IL: University of Illinois. 
Hansen, D. M., \& Larson, R. W. (2007). Amplifiers of developmental and negative experiences in organized activities: Dosage, motivation, lead roles, and adultyouth ratios. Journal of Applied Developmental Psychology, 28, 360-374.

Harding, D. (2008). Neighborhood violence and adolescent friendships. International Journal of Conflict and Violence, 2(1), 28-55.

Hartmann, D., \& Kwauk, C. (2011). Sport and development: An overview, critique, and reconstruction. Journal of sport \& social issues,

Hartman, S., \& Manfra, L. (2016). Change in child behaviour concerns associated with childcare quality features among a sample of low-income Latino children. Early child development and care, 186, 1378-1391.

Hausenblas, H. A., \& Fallon, E. A. (2006). Exercise and body image: A meta-analysis. Psychology and health, 21(1), 33-47.

Hellison, D. (2000). Physical activity programs for underserved youth. Journal of science and medicine in sport, 3, 238-242.

Hellison, D. R., \& Cutforth, N. J. (1997). Extended day programs for urban children and youth: From theory to practice. Issues in childrens and families lives, 7, 223-252.

Higgins, K. M., \& Moule, J. (2009). “No More Mr. Nice Guy”: Preservice teachers’ conflict with classroom management in a predominantly african-american urban elementary school. Multicultural perspectives, 11, 132-138.

Higginbotham, B. J., MacArthur, S., \& Dart, P. C. (2010). 4-H Mentoring: Youth and families with promise - adult engagement and the development of strengths in youth. Journal of prevention \& intervention in the community, 38, 229-243. 
Hill, N. E., \& Herman-Stahl, M. A. (2002). Neighborhood safety and social involvement: Associations with parenting behaviors and depressive symptoms among AfricanAmerican and Euro-American mothers. Journal of Family Psychology, 16(2), 209-219.

Hirschi, T. (1969). Causes of delinquency. Berkeley: University of California Press.

Hodge, K., Danish, S., \& Martin, J. (2013). Developing a conceptual framework for life skills interventions. The Counseling Psychologist, 41, 1125-1152.

Hodge, K.P. (1989). Character building in sport: fact or fiction? New Zealand Journal of Sports Medicine, 17(2), 23-25.

Hoeve, M., Dubas, J. S., Eichelsheim, V. I., Van der Laan, P. H., Smeenk, W., \& Gerris, J. R. (2009). The relationship between parenting and delinquency: A metaanalysis. Journal of abnormal child psychology, 37, 749-775.

Holt, N. L. (2008). Positive youth development through sport. London: Routledge Holt, N. L., Kingsley, B. C., Tink, L. N., \& Scherer, J. (2011). Benefits and challenges associated with sport participation by children and parents from low-income families. Psychology of sport and exercise, 12, 490-499.

Holt, N. L., Scherer, J., \& Koch, J. (2013). An ethnographic study of issues surrounding the provision of sport opportunities to young men from a western Canadian innercity. Psychology of Sport and Exercise, 14, 538-548.

Holt, N., Sehn, Z., Spence, J., Newton, A., \& Ball, G. (2012). Physical education and sport programs at an inner-city school: Exploring possibilities for positive youth development. Physical Education \& Sport Pedagogy, 97-113. 
Huang, J. S., Norman, G. J., Zabinski, M. F., Calfas, K., \& Patrick, K. (2007). Body image and self-esteem among adolescents undergoing an intervention targeting dietary and physical activity behaviors. Journal of adolescent health, 40, 245251.

Jaime, M. C. D., McCauley, H. L., Tancredi, D. J., Nettiksimmons, J., Decker, M. R., Silverman, J. G., O’ Connor, B., Stetkevich, N. \& Miller, E. (2015). Athletic coaches as violence prevention advocates. Journal of interpersonal violence, 30, 1090-1111.

Jarrett, R. L., Brooks-Gunn, J., Duncan, G. J., \& Aber, J. L. (1997). Bringing families back in: Neighborhood effects on child development. In J. Brooks-Gunn, G. J. Duncan, \& J. L. Aber (Eds.), Neighborhood poverty. Volume 2. Policy implications in studying neighborhoods (pp. 48-64). New York: Sage.

Jarrett, R. L., Sullivan, P. J., \& Watkins, N. D. (2005). Developing social capital through participation in organized youth programs: Qualitative insights from three programs. Journal of Community Psychology, 33(1), 41-55.

Jowett, S., \& Ntoumanis, N. (2004). The coach-athlete relationship questionnaire (CART-Q): Development and initial validation. Scandinavian Journal of Medicine \& Science in Sports, 14, 245-257.

Jowett, S., \& Poczwardowski, A. (2007). Understanding the coach-athlete relationship. In S. Jowett \& D. Lavalle (Eds.), Social psychology in sport (pp. 3-14). Champaign, IL: Human Kinetics. 
Juster, F. T., Ono, H., \& Stafford, F. P. (2004). Changing times of American youth: 19812003. Institute for Social Research, University of Michigan, Ann Arbor, Michigan, 1-15.

Kane, M. J., LaVoi, N., Wiese-Bjornstal, D., Duncan, M., Nichols, J., Pettee, K., \& Ainsworth, B. (2007). The 2007 Tucker center research report: Developing physically active girls: An evidence-based multidisciplinary approach.

Kelley, B., \& Carchia, C. (2013). Hey, data data-swing!. The hidden demographics of youth sports. Retrieved from http://espn. Go.

Com/espn/story/_id/9469252/hidden-demographics-youth-sports-espn-magazine.

Kelley, M. L., Sanchez-Hucles, J., \& Walker, R. R. (1993). Correlates of disciplinary practices in working-to middle-class African-American mothers. Merrill-Palmer Quarterly, 252-264.

Lamborn, S. D., Dornbusch, S. M., \& Steinberg, L. (1996). Ethnicity and community context as moderators of the relations between family decision making and adolescent adjustment. Child development, 67(2), 283-301.

Larson, R. W., Hansen, D. M., \& Moneta, G. (2006). Differing profiles of developmental experiences across types of organized youth activities. Developmental psychology, 42, 849-863.

Larson, R. W. (2000). Toward a psychology of positive youth development. American psychologist, 55(, 170-183.

Lavoi, N. M., \& Stellino, M. B. (2008). The relation between perceived parent-created sport climate and competitive male youth hockey players' good and poor sport behaviors. The Journal of psychology, 142, 471-496. 
Lederman, R. (1991). Content analysis of word texts. The American Journal of Maternal Child Nursing, 16(3), 169.

Lerner, R. M., Lerner, J. V., Almerigi, J. B., Theokas, C., Phelps, E., Gestsdottir, S., ... \& Smith, L. M. (2005). Positive Youth Development, Participation in community youth development programs, and community contributions of fifth-grade adolescents findings from the first wave Of the 4-H study of positive youth development. The Journal of early adolescence, 25(1), 17-71.

Lerner, R. M., Lerner, J. V., von Eye, A., Bowers, E. P., \& Lewin-Bizan, S. (2011). Individual and contextual bases of thriving in adolescence: A view of the issues. Journal of adolescence, 34, 1107-1114.

Leventhal, T., \& Brooks-Gunn, J. (2000). The neighborhoods they live in: the effects of neighborhood residence on child and adolescent outcomes. Psychological bulletin, 126(2), 309-337.

Levine, L. E., \& Munsch, J. (2016). Child development from infancy to adolescence: An active learning approach. Thousand Oaks, CA: Sage.

Lisha, N. E., Crano, W. D., \& Delucchi, K. (2014). Participation in team sports as related to alcohol and marijuana use growth in youth. Drug \& Alcohol Dependence, 140, e125-e126.

Long, T., Pantaleon, N., Bruant, G., \& d'Arripe-Longueville, F. (2006). A qualitative study of moral reasoning of young elite athletes. The Sport Psychologist, 20(October 2016), 330-347. 
Mahoney, J. L., \& Stattin, H. (2000). Leisure activities and adolescent antisocial behavior: The role of structure and social context. Journal of Adolescence, 23(2), $113-127$.

Maldonado, N. L., Quarles, A., Lacey, C. H., \& Thompson, S. D. (2008). Mentoring atrisk adolescent girls: Listening to 'Little Sisters'. Mentoring and Tutoring: Partnership in Learning, 16(2), 223-234.

Martinek, T. J., \& Hellison, D. (1997). Fostering resiliency in underserved youth through physical activity. Quest, 49(1), 34-49.

Martinek, T., \& Hellison, D. (2009). Youth leadership in sport and physical education. Palgrave Macmillan.

Martinek, T., \& Schilling, T. (2003). Developing compassionate leadership in underserved youths. Journal of Physical Education, Recreation \& Dance, 74(5), 33-39.

Merkel, D. L. (2013). Youth sport: Positive and negative impact on young athletes. Open Acess J Sports Med, 4, 151-160.

McLoyd, V. C., Kaplan, R., Hardaway, C. R., \& Wood, D. (2007). Does endorsement of physical discipline matter? Assessing moderating influences on the maternal and child psychological correlates of physical discipline in African American families. Journal of Family Psychology, 21(2), 165-175.

Miles, M. B., Huberman, A. M., \& Saldana, J. (2014). Qualitative data analysis: A methods sourcebook ( $3^{\text {rd }}$ ed.). Thousand Oaks, CA: Sage Publications.

Mohan, L. (2014). Race and its impact on youth sport participation choice. International Journal of Sport Studies, 4, 1309-1316. 
Newton, M., Magyar, M., Kim, M. S., Watson, D., Gano-Overway, L., Fry, M., \& Guivernau, M. (2007). Psichometric properties of the caring climate scale in a physical activity setting. Revista de psicología del deporte, 16(1), 0067-84.

Office for the Advancement of Research. (2012, February). PYJ - Positive Youth Development. Retrieved October 09, 2016,from https://johnjayrec.nyc/pyj_pyd/

Olushola, J. O., Jones, D. F., Dixon, M. A., \& Green, B. C. (2013). More than basketball: Determining the sport components that lead to long-term benefits for AfricanAmerican girls. Sport Management Review, 16, 211-225.

Osgood, D. W., \& Anderson, A. L. (2004). Unstructured socializing and rates of delinquency. Criminology, 42, 519-550.

Pallant, J. (2013). SPSS survival manual. McGraw-Hill Education (UK).

Parsons, E. (2005). From caring as a relation to culturally relevant caring: A White teacher's bridge to Black students. Equity and Excellence in Education, 38(1), 2534.

Passmore, A., \& French, D. (2001). Development and administration of a measure to assess adolescents' participation in leisure activities. Adolescence, 36(141), 67.

Paule-Koba, A. L., Harris, O., \& Freysinger, V. J. (2013). "What Do I Think About Title IX?" Voices From a University Community. Research quarterly for exercise and sport, 84(1), 115-125.

Perkins, D. F., Borden, L. M., Villarruel, F. A., Carlton-Hug, A., Stone, M. R., \& Keith, J. G. (2007). Participation in Structured Youth Programs Why Ethnic Minority 
Urban Youth Choose to Participate—or Not to Participate. Youth \& Society, 38, $420-442$.

Petitpas, A. J., Cornelius, A. E., Van Raalte, J. L., \& Jones, T. (2005). A framework for planning youth sport programs that foster psychosocial development. The sport psychologist, 19(1), 63-80.

Pittman, K. J., Irby, M., Tolman, J., Yohalem, N., \& Ferber, T. (2011). Preventing problems, promoting development, encouraging engagement. In Washington, $D C$ : Forum for Youth Investment.

Reel, J. J., SooHoo, S., Petrie, T. A., Greenleaf, C., \& Carter, J. E. (2010). Slimming down for sport: Developing a weight pressures in sport measure for female athletes. Journal of Clinical Sport Psychology, 4(2), 99-111.

Rhodes, J. E. (2005). A model of youth mentoring. Handbook of youth mentoring, 30-43.

Rhodes, J., \& Lowe, S. R. (2008). Youth mentoring and resilience: Implications for practice. Child Care in Practice, 14(1), 9-17.

Richardson Jr, J. B. (2012). Beyond the playing field: Coaches as social capital for innercity adolescent African-American males. Journal of African American Studies, 16, 171-194.

Roth, J. L., \& Brooks-Gunn, J. (2003). What exactly is a youth development program? Answers from research and practice. Applied developmental science, 7(2), 94111.

Sabo, D. (2009). The gender gap in youth sports: too many urban girls are being left behind. Journal of Physical Education, Recreation \& Dance, 80(8), 35-40. 
Sabo, D., \& Veliz, P. (2008). Go out and play: Youth sports in america. Women's Sports Foundation. Retrieved April 15, 2015.

Scott, S., \& Palincsar, A. (2009) Sociocultural Theory. Retrieved April 19, 2016, from http://www.education.com/reference/article/sociocultural-theory/.

Smetana, J. G. (2011). Parenting beliefs, parenting, and parent-adolescent communication in African American families. African American children's mental health: Development and context, 1, 173-197.

Smith, R. E., Cumming, S. P., \& Smoll, F. L. (2008). Development and validation of the motivational climate scale for youth sports. Journal of applied sport psychology, 20, 116-136.

Smith, R.E., \& Smoll, F.L. (2002). Youth sports as a behavior setting for psychological interventions. In J.L. Van Raalte \& B.W. Brewer (Eds.), Exploring sport and exercise psychology (2 ${ }^{\text {nd }}$ ed., pp. 341-371). Washington, DC: American Psychological Association.

Smith, R. E., Smoll, F. L., \& Cumming, S. P. (2007). Effects of a motivational climate intervention for coaches on young athletes' sport performance anxiety. Journal of sport and exercise psychology, 29(1), 39-59.

Smith, R. E., Smoll, F. L., \& Curtis, B. (1979). Coach effectiveness training: A cognitivebehavioral approach to enhancing relationship skills in youth sport coaches. Journal of sport psychology, 1(1), 59-75.

Smith, R. E., Smoll, F. L., \& Hunt, E. (1977). A system for the behavioral assessment of athletic coaches. Research Quarterly, 48, 401-407. 
Staurowsky, E. J., Miller, K. E., Shakib, S., De Souza, M. J., Ducher, G., Gentner, N., ... \& Williams, N. I. (2009). Her life depends on it II: Sport, physical activity, and the health and well-being of american girls and women. Women's Sports Foundation.

Stirling, A. E., \& Kerr, G. A. (2013). The perceived effects of elite athletes' experiences of emotional abuse in the coach-athlete relationship. International journal of sport and exercise psychology, 11(1), 87-100.

Stodolska, M., Sharaievska, I., Tainsky, S., \& Ryan, A. (2014). Minority youth participation in an organized sport program: needs, motivations, and facilitators. Journal of Leisure Research, 46, 612-634.

Strachan, L., Côté, J., \& Deakin, J. (2009). An evaluation of personal and contextual factors in competitive youth sport. Journal of applied sport psychology, 21, 340355.

Strachan, L., Fraser-Thomas, J., \& Nelson-Ferguson, K. (2016). An ecological perspective on high performance sport and positive youth development. Positive Youth Development Through Sport, 57.

Theokas, C., Danish, S., Hodge, K., Heke, I., \& Forneris, T. (2008). Enhancing life skills through sport for children and youth. Positive youth development through sport, 6 , $71-81$.

Title IX and Sex Discrimination. (2015, October 15). Retrieved February 08, 2017, from https://www2.ed.gov/about/offices/list/ocr/docs/tix_dis.html. 
Trottier, C., \& Robitaille, S. (2014). Fostering Life Skills Development in High School and Community Sport: A Comparative Analysis of the Coach's Role. Sport Psychologist, 28(1) 10-21.

Veliz, P. T., Boyd, C. J., \& McCabe, S. E. (2015). Competitive sport involvement and substance use among adolescents: A nationwide study. Substance use \& misuse, $50,156-165$.

Vella, S. A., Cliff, D. P., Okely, A. D., Weintraub, D. L., \& Robinson, T. N. (2014). Instructional strategies to promote incremental beliefs in youth sport. Quest, 66, $357-370$.

Vella, S., Oades, L., \& Crowe, T. (2011). The role of the coach in facilitating positive youth development: Moving from theory to practice. Journal of Applied Sport Psychology, 23(1), 33-48.

Vella, S. A., Oades, L. G., \& Crowe, T. P. (2013). The relationship between coach leadership, the coach-athlete relationship, team success, and the positive developmental experiences of adolescent soccer players. Physical Education \& Sport Pedagogy, 18, 549-561.

Vitali, F., Bortoli, L., Bertinato, L., Robazza, C., \& Schena, F. (2015). Motivational climate, resilience, and burnout in youth sport. Sport Sciences for Health, 11(1), 103-108.

Walsh, D. (2008). Helping youth in underserved communities envision possible futures: An extension of the teaching personal and social responsibility model. Research Quarterly for Exercise and Sport, 79, 209-221.

Wang, L., Bruce, C., \& Hughes, H. (2011). Sociocultural theories and their application in 
information literacy research and education. Australian Academic \& Research Libraries, 42, 296-308.

Weiss, H. R., Little, P. M. D., \& Bouffard, S. M. (2005). More than just being there: Balancing the participation equation. New Direction for Youth Development, 105, $15-31$.

Whitley, M. A., Bean, E., \& Gould, D. (2013). On the fields of the motor city: Underserved athletes' perceptions of their coaches. Journal of Coaching Education, 4(3), 97-121.

Whitley, M. A., Hayden, L. A., \& Gould, D. (2013). Growing up in the Kayamandi Township: I. The role of sport in helping young people overcome challenges within their community. Qualitative Research in Sport, Exercise and Health, 5, 373-397.

Zarrett, N., \& Lerner, R. M. (2008). Ways to promote the positive development of children and youth. Child Trends, 11, 1-5. 


\title{
Appendix A1
}

\section{W. WesthroginiaUniversity. \\ Office of Research Integrity and Compliance

\author{
886 CHESNUT RIDGE ROAD MORGANTOWN, WV 26506
}

\section{Approval Letter Expedited}

\author{
Action Date $\quad 12 / 12 / 2016$ \\ To Marc Flett \\ From WVU Office of Research Integrity and Compliance \\ Approval Date $\quad 12 / 12 / 2016$ \\ Expiration Date $\quad 12 / 11 / 2017$ \\ Subject Protocol Approval Letter \\ Protocol Number $\quad 1611349037$ \\ Title Youth Perceptions of Their Coach and the Development of Life Skills
}

The above-referenced research study was reviewed by the West Virginia University Institutional Review Board IRB and was approved in accordance with 46 CFR 46.101b.

It has been determined that this study is of minimal risk and meets the criteria as defined by the expedited categories listed below:

- Category 7. Research on individual or group characteristics or behavior (including, but not limited to, research on perception, cognition, motivation, identity, language, communication, cultural beliefs or practices, and social behavior) or research employing survey, interview, oral history, focus group, program evaluation, human factors evaluation, or quality assurance methodologies. [NOTE: Some research in this category may be exempt from the DHHS regulations for the protection of human subjects. See Exempt Categories and 45 CFR 46.101(b)(2) and (b)(3). This listing refers only to research that is not exempt.]

Documents reviewed and/or approved as part of this submission:

Surveys for IRB.docx: 2016-11-17-05:00

Brown Ethnography IRB - Flett.docx: 2016-11-14-05:00

IRB Parental Waiver.docx: 2016-11-17-05:00

Recruitment Brochure .docx: 2016-11-17-05:00

Recruitment Brochure .docx: 2016-11-23-05:00 


\section{Appendix A2}

\section{Youth Assent Form}

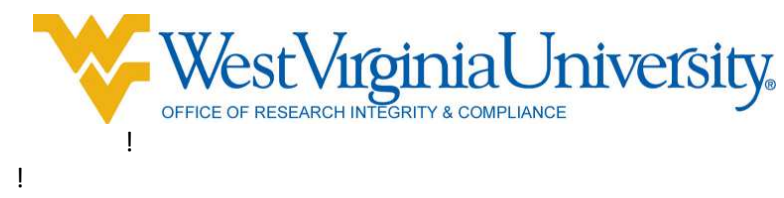

Human Research Protocol Assent Form

\section{Assent'Form'}

\begin{tabular}{|c|c|c|}
\hline \multicolumn{2}{|c|}{ Principal!!nvestigator!! } & Dr.!Ryan!Flett!! \\
\hline Department! ! & $!$ & College!of!Physical!Activity!and!Sport!Sciences! \\
\hline Protocol!Number! & $!$ & $1611349037 !$ \\
\hline Study!Title! ' & ' & Youth'Perceptions'of'Their'Coach'and'the'Development'of'Life'Skills' \\
\hline Cothnvestigator(s)' & ' & Reneé'Brown'and'Dr.'Suzanna'Hartman' \\
\hline Sponsor!(if!any)' & ' & N/A' \\
\hline
\end{tabular}

\section{Contact'Persons'}

In!the !event!you !experience !any!side !effects !or !injury!related !to!this !research, !you !should !contact!Reneé!Brown !at! (412)!980+2064. If !you !have !any !questions, !concerns, !or !complaints !about !this Iresearch, !you !can !contact! IDr. !Ryan !Flett! at!(304)!293+0844.!

!

For!information!regarding!your!rights!as!a!research !subject, !to!discuss !problems, !concerns, !or!suggestions!related !to!the! research, !to !obtain !information !or !offer !input !about!the !research, !contact!the !Office !of!Research!!ntegrity!\&!Compliance! at!(304)!293+7073.!

\section{Introduction'}

You, by Renee' Brown.' , have been asked to participate in this research study, which has been explained to you

\section{Purpose(s)'of'the'Study'}

The !purpose !of!this!study!is!threefold.!!First!it!will!provide!a!different !angle!on!the !current!literature !supporting! authoritative!coaching !styles!and!cautioning!the !use !of !authoritarian!coaching !styles. ISecond, lit!will!explore!player! perceptions !of !the!coaching!style !used !in!the !underserved !setting !and !how !it!!mpacts!their !development. !Lastly, !lt!will! examine!the!coaching!styles!used !across!the!league; !and !explore!how!to!effectively! luse lauthoritarian !coaching !styles.!

\section{Description'of'Procedures'}

The !researcher!will !have !each!coach!distribute !parental!consent !and!youth !assent!forms!to!their!players!during!practice.! The !researcher!will !emphasize!that!if !a!player!does!not!feel!comfortable, !they!can!drop!out!of !the!study!at!any!time! without!consequences.!!Consent!and !assent!will !be !completed !and !returned !to!the!coach !before!the!first!scheduled!
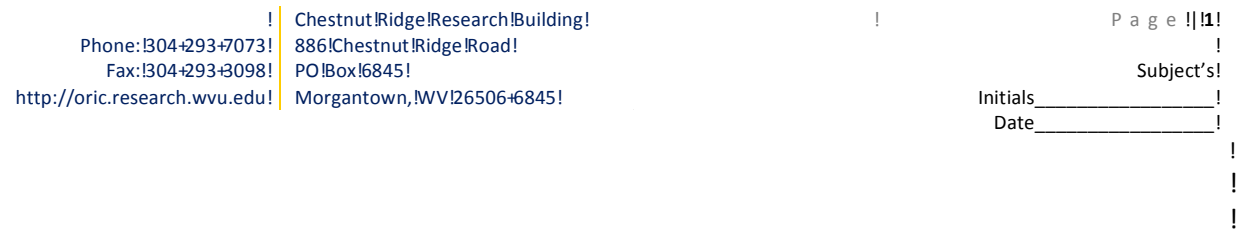


\section{Appendix A3}

\section{Information and Withdrawal Letter}

November 2016

Dear Parent/Primary Caregiver:

Hello, my name is Reneé Brown and I am a graduate student working on my doctoral degree at West Virginia University. I am asking the head coach and players of the women's basketball team to take part in my research study assessing the coaching styles and motivational climates used in the City League, and the developmental impact they have on your child (such as teaching life skills, etc.). The purpose of this letter is to inform you about a study that we hope will improve youth sports experiences in Pittsburgh. This letter is also intended to inform you that you may choose to withdraw your daughter from completing this 20 -minute survey.

The purposes of this study are to:

1. Assess the coaching style within the City League.

2. Examine the developmental outcomes that occur from participation in sport (e.g., life skills, teamwork, leadership, etc.).

3. Assess how a coach may use an authoritarian style more effectively (e.g., by combining it with humor, caring, and the right motivational climate).

If the coach and athletes at this school agree to participate in this study:

They will be asked to complete a written survey twice (once early in the season (December), and once during the last two weeks of the regular season, or shortly after the playoffs (March)). This survey will take approximately 15-20 minutes to complete, plus time for me to provide instructions before completing the surveys. Players will complete the first set of surveys by December 15.

All information provided will be kept confidential, this study is voluntary, and the coaches and players have the right to drop out at any time. A summary of the results will be provided to the team, and all other participating teams in the City League by the conclusion of my study.

However, if you do not want your daughter to participate in the study, they do not have to participate or can drop out at any time. If you do not want your daughter to participate in this study, you can email me at the address below, tell your daughter's coach, or have your daughter tell me when I visit the team to administer the surveys.

I am very grateful for you taking the time to read this letter. I can be reached at (412) 980-2064 and or email: Rrbrown@mix.wvu.edu.

Sincerely, 
Reneé B. Brown

Doctoral Candidate

\section{APPENDIX B QUALITATIVE INTERVIEW GUIDE for PARENTS/CAREGIVERS}




\section{Appendix B1}

\section{Parental/Primary Caregiver Interview Guide (45-60 minutes)}

\section{Introductory Questions:}

1.) How would you describe your parenting style?
a. Why would you describe it that way?
b. What are the benefits?
c. What are the weaknesses?

\section{Perceived Environment/Context}

1.) What are some of the challenges that your daughters face in their lives?

2.) What aspects of the environment do you think makes it harder for you to raise your daughters?

a. Are there aspects of the environment that makes it easier for you? (Environment = surroundings, sport life, school life)

3.) What are some of the personal assets/or strengths that help your daughters now, and as adults?

\section{Coaching Style}

1.) In your opinion, what is the common coaching style in the inner-city context?

2.) How would you describe the style of coaching implemented by Coach DD?

a. What are the strengths?

b. What are the weaknesses?

3.) What coaching style do you prefer for your daughter? (Authoritarian, authoritative, or a blend)?

a. Why?

4.) Do you believe this coaching style aligns with your parenting style?

a. Why?

\section{Impact of Coach (attitudes, emotional response, personal development, athlete development).}

1.) What do you believe had the biggest impact on your daughter (i.e. sport, the coach, or natural maturation)?

a. Why?

2.) What impact do you think the coach had on your daughter, throughout the season?

a. Can you provide concrete examples?

3.) Do you believe this particular coaching style is effective and aids developmental outcomes in youth living in this setting?

4.) Is there anything that I didn't ask that you would like to share? 


\section{Appendix C}

\section{Demographic Surveys}

Coach, Players, and Parental/Primary Caregivers 


\section{Appendix C1}

\section{Demographic Survey - Coach}

Please complete the following information about yourself and your coaching relative to your role as a coach in the sport of interest for this interview.

1. How many years have you coached this sport? $\rightarrow \quad$ __ years

b. How many years have you coached the majority of your current players? $\rightarrow$

c. How many years have you coached in the inner city? years

2. Do you plan to coach this sport next year? $\rightarrow \quad \square$ No $\quad \square$ Yes

3. Do you coach any other youth sports? $\rightarrow \quad \square$ No $\quad \square$ Yes

$\rightarrow$ If yes, what other sports do you coach?

4. What is your age?

Caucasian

African-American

$\square$ Hispanic-American

12. What is your race (check all that apply)?

6. What is the racial make-up of your most Actual Number current team? (Place percentages next to race) Caucasian

African-American
Hispanic-American
Asian-American
Native American
Other

7. What is your present relationship status? $\square$ Single

$\square$ Married or living with partner

$\square$ Separated or divorced

$\square$ Widowed

$\square$ Other

8. How many children do you have (if any)? Sons daughters no children

9. What was the highest degree that you earned in school:

Did not graduate from High School

High School Diploma or equivalent

Some College/Junior College Degree

College Degree

Graduate Degree

Other (specify) 
10. Have you had any formal training as a coach? $\rightarrow \square$ No $\square$ Yes

If you answered yes to question 10, please complete question a-e below. If you answered no, go to question 11.

a. Have you participated in other coaching workshops or seminars? $\square$ No $\square$ Yes

b. Do you have a physical education or recreation college degree? $\square$ No $\square$ Yes

c. Have you taken college-level courses in coaching? $\rightarrow \square$ No $\quad \square$ Yes

d. I did my training with another organization:

11. Are you a certified teacher? $\rightarrow \square$ No $\square$ Yes

12. Do you have a coaching certification? $\rightarrow \square$ No $\square$ Yes $\rightarrow$ if yes, please specify certifying agency:

13. What is your team name and what part of Pittsburgh are most of your players from?

Team Name:

Most players are from:

14. How much time do you devote to coaching and coaching-related activities for this sport?

a. Hours - The average number of hours per week when the sport is $\underline{\text { in}}$ season.

b. W__ Weeks - The number of weeks in the season (include all practice activities).

13. Hours - Estimate the total number of hours (not weekly average) you devote to coaching basketball related activities during the off season. 


\section{Appendix C 2}

\section{Demographic Survey - Players}

Instructions: Please answer the following questions about your experiences in your high school basketball program. Be sure to read the instructions carefully for each new section in the survey packet. Remember, there are no right or wrong answers; we are only interested in your honest opinion. Please take your time and be thoughtful about answering each question.

1) Team Name:

2) Your Name:

5) Race (optional):

African American

Asian/Pacific Islander

White

Hispanic

Native American

Other (Please specify?)

6) Counting this year how many years and months have you been involved in your high school basketball program? (Please include both years and months below) Years Months

7) Counting this year how many years and months have you been involved in your high school basketball program with your current head coach? (Include years and months below)

Years

Months

8) Would you play on your school's basketball team next year if you could? YES _ NO (Why? 


\section{Appendix C3}

\section{Demographic Survey - Parents/Primary Caregivers}

Please complete the following information about yourself.

1. Please circle your relationship to player:

Mother Father Primary Care Giver Other:

2. What is your age?

3. What is your race (check all that apply)

$\square$ Caucasian

African-American

$\square$ Hispanic-American

Asian-American

$\square$ Native American

$\square$ Other

4. What is your present relationship status? $\square$ Single

$\square$ Married or living with partner

Separated or divorced

$\square$ Widowed

$\square$ Other

5. How many children do you have (if any)? Sons daughters no children

6. What is the age range of your youngest to oldest

7. What was the highest degree that you earned in school:

Did not graduate from High School

$\square$ High School Diploma or equivalent

$\square$ Some College/Junior College Degree

$\square$ College Degree

$\square$ Graduate Degree

Other (specify) 


\section{Appendix D}

Questionnaires for Players 


\section{Appendix D1}

\begin{tabular}{|c|c|c|c|c|c|}
\hline $\begin{array}{l}\text { Read each statement and think about how much you } \\
\text { believe the statement describes your team. Then choose } \\
\text { the answer that shows how much you agree or disagree } \\
\text { with each statement }\end{array}$ & 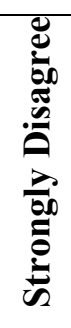 & 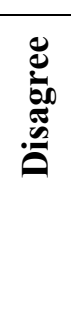 & $\begin{array}{l}\stackrel{0}{\Xi} \\
\stackrel{\Xi}{0} \\
\stackrel{0}{Z}\end{array}$ & 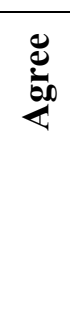 & 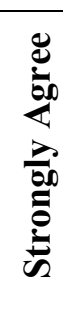 \\
\hline 1. On this team, athletes are treated with respect. & 1 & 2 & 3 & 4 & 5 \\
\hline 2. On this team, the coaches respect athletes. & 1 & 2 & 3 & 4 & 5 \\
\hline 3. On this team, the coaches are kind to athletes. & 1 & 2 & 3 & 4 & 5 \\
\hline 4. On this team, the coaches care about athletes. & 1 & 2 & 3 & 4 & 5 \\
\hline 5. On this team, athletes feel that they are treated fairly. & 1 & 2 & 3 & 4 & 5 \\
\hline 6. On this team, the coaches try to help athletes. & 1 & 2 & 3 & 4 & 5 \\
\hline $\begin{array}{l}\text { 7. On this team, the coaches want to get to know all the } \\
\text { athletes. }\end{array}$ & 1 & 2 & 3 & 4 & 5 \\
\hline 8. On this team, the coaches listen to athletes. & 1 & 2 & 3 & 4 & 5 \\
\hline 9. On this team, everyone likes athletes for who they are. & 1 & 2 & 3 & 4 & 5 \\
\hline $\begin{array}{l}\text { 10. On this team, the coaches accept athletes for who they } \\
\text { are. }\end{array}$ & 1 & 2 & 3 & 4 & 5 \\
\hline 11. On this team, athletes feel comfortable. & 1 & 2 & 3 & 4 & 5 \\
\hline 12. On this team, athletes feel safe. & 1 & 2 & 3 & 4 & 5 \\
\hline 13. On this team, athletes feel welcome every day. & 1 & 2 & 3 & 4 & 5 \\
\hline
\end{tabular}




\section{Appendix D2}

\begin{tabular}{|c|c|c|c|c|c|}
\hline $\begin{array}{l}\text { For each statement, please circle the number that } \\
\text { you feel is the most accurate. Please note that there } \\
\text { is no right or wrong answer }\end{array}$ & 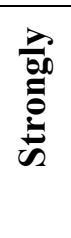 & : & 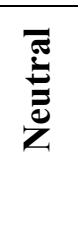 & 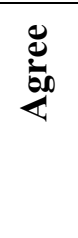 & $\begin{array}{l}\frac{a}{000} \\
\overline{0} \\
\dot{D} \\
\infty\end{array}$ \\
\hline $\begin{array}{l}\text { 1. The coach made players feel good when they } \\
\text { improved a skill }\end{array}$ & 1 & 2 & 3 & 4 & 5 \\
\hline 2. The coach encouraged us to learn new skills. & 1 & 2 & 3 & 4 & 5 \\
\hline $\begin{array}{l}\text { 3. The coach told players to help each other to get } \\
\text { better. }\end{array}$ & 1 & 2 & 3 & 4 & 5 \\
\hline $\begin{array}{l}\text { 4. The coach told us that trying our best was the most } \\
\text { important thing. }\end{array}$ & 1 & 2 & 3 & 4 & 5 \\
\hline $\begin{array}{l}\text { 5. Coach said that teammates should help each other } \\
\text { improve their skills. }\end{array}$ & 1 & 2 & 3 & 4 & 5 \\
\hline $\begin{array}{l}\text { 6. Coach said that all of us were important to team's } \\
\text { success. }\end{array}$ & 1 & 2 & 3 & 4 & 5 \\
\hline $\begin{array}{l}\text { 7. Winning games was the most important thing for } \\
\text { the coach. }\end{array}$ & 1 & 2 & 3 & 4 & 5 \\
\hline $\begin{array}{l}\text { 8. The coach spent less time with the players who } \\
\text { weren't as good. }\end{array}$ & 1 & 2 & 3 & 4 & 5 \\
\hline $\begin{array}{l}\text { 9. The coach told us which players on the team were } \\
\text { the best. }\end{array}$ & 1 & 2 & 3 & 4 & 5 \\
\hline 10. The coach paid most attention to the best players & 1 & 2 & 3 & 4 & 5 \\
\hline $\begin{array}{l}\text { 11. Players were taken out of games if they made a } \\
\text { mistake. }\end{array}$ & 1 & 2 & 3 & 4 & 5 \\
\hline
\end{tabular}




\section{Appendix D3}

REMEMBER: Make two ratings for each item. (1) rate how often your coach actually exhibited this behavior towards you as a player; and (2) What coaching style you would prefer or think is ideal for you?

MY COACH EXHIBITED THIS BEHAVIOR:

$1=$ Never

$2=$ Once In Awhile

$3=$ About Half of the Time

$4=$ Very Often

$5=$ Always

\section{PREFERED COACHING STYLE:}

$1=$ Never

$2=$ Once In Awhile

$3=$ About Half of the Time

$4=$ Very Often

$5=$ Always

\section{My Preferred}

Coach Style

1. My coach is responsive to my feelings and needs.

2. My coach uses physical punishment as a way of disciplining me.

3. My coach takes my desires into account before asking me to do something.

4. When I asked why I had to conform, my coach stated: because I said so, or I am your coach and I want you to.

5. My coach explained to me how she/he felt about my good and bad behavior.

6. My coach use exercise as punishment (e.g. run laps, push-ups, etc.) when I'm disobedient.

7. My coach encouraged me to talk about my troubles.

8. My coach encouraged me to freely express myself even when I disagreed.

9. My coach punished me by taking privileges away from me with little if any explanations.

10. My coach emphasized the reasons for rules.

11. My coach gave comfort and understanding when I was upset.

12. My coach yelled or shouted when I misbehaved.

13. My coach praised me when I was good.

14. My coach exploded in anger towards me.

15. To test that you are reading every question, please put zeros $(0)$ on both lines for this question.

16. My coach took into account my preferences in making plans for the team.

17. My coach grabbed me when I was being disobedient.

18. My coach showed respect for my opinions by encouraging me to express them.

19. My coach allowed me to give input into team rules.

20. My coach scolded or criticized me to make me improve.

21. My coach gave me reasons why rules should be obeyed.

22. My coach used threats as punishment with little or no justification.

23. My coach had warm times with me that were personally meaningful.

24. My coach punished by putting me off somewhere alone with little if any explanations. 
25. My coach helped me to understand the impact of my behavior by encouraging me to talk about the consequences of my own actions.

26. My coach scolded or criticized me when my behavior didn't meet their expectations.

27. My coach explained the consequences of my behavior.

28. My coach slapped me when I misbehaved. 


\section{Appendix D4}

Please circle how much your team has taught you to perform the skills listed below.

\begin{tabular}{|c|c|c|c|c|c|}
\hline This team has taught me to... & Not at all & A little & Some & A lot & Very much \\
\hline \multicolumn{6}{|l|}{ Teamwork } \\
\hline 1. Work well within a team/ group. & Not at all & A little & Some & A lot & Very much \\
\hline 2. Help another team/ group member perform a task. & Not at all & A little & Some & A lot & Very much \\
\hline 3. Accept suggestions for improvement from others. & Not at all & A little & Some & A lot & Very much \\
\hline 4. Work with others for the good of the team/ group. & Not at all & A little & Some & A lot & Very much \\
\hline 5. Help build team/ group spirit. & Not at all & A little & Some & A lot & Very much \\
\hline $\begin{array}{l}\text { 6. Suggest to team/group members how they can } \\
\text { improve their performance. }\end{array}$ & Not at all & A little & Some & A lot & Very much \\
\hline $\begin{array}{l}\text { 7. Change the way I perform for the benefit of the } \\
\text { team/ group. }\end{array}$ & Not at all & A little & Some & A lot & Very much \\
\hline
\end{tabular}

\section{Goal Setting}

\begin{tabular}{|c|c|c|c|c|c|}
\hline 8. Set goals so that I can stay focused on improving. & Not at all & A little & Some & A lot & Very much \\
\hline 9. Set challenging goals. & Not at all & A little & Some & A lot & Very much \\
\hline 10. Check progress towards my goals. & Not at all & A little & Some & A lot & Very much \\
\hline $\begin{array}{l}\text { 11. Set short-term goals in order to achieve long-term } \\
\text { goals. }\end{array}$ & Not at all & A little & Some & A lot & Very much \\
\hline 12. Remain committed to my goals. & Not at all & A little & Some & A lot & Very much \\
\hline 13. Set goals for practice. & Not at all & A little & Some & A lot & Very much \\
\hline 14. Set specific goals. & Not at all & A little & Some & A lot & Very much \\
\hline
\end{tabular}

\section{Social Skills}

\begin{tabular}{|l|lllll|}
\hline 15. Start a conversation. & Not at all & A little & Some & A lot & Very much \\
\hline 16. Interact in various social settings. & Not at all & A little & Some & A lot & Very much \\
\hline 17. Help others without them asking for help. & Not at all & A little & Some & A lot & Very much \\
\hline 18. Get involved in group activities. & Not at all & A little & Some & A lot & Very much \\
\hline 19. Maintain close friendships. & Not at all & A little & Some & A lot & Very much \\
\hline
\end{tabular}

\section{Problem Solving}

20. Think carefully about a problem.

21. Compare each possible solution in order to find the best one.

$\begin{array}{lllll}\text { Not at all } & \text { A little } & \text { Some } & \text { A lot } & \text { Very much } \\ \text { Not at all } & \text { A little } & \text { Some } & \text { A lot } & \text { Very much } \\ & & & & \\ & & & \end{array}$




\begin{tabular}{|c|c|c|c|c|c|}
\hline $\begin{array}{l}\text { 22. Create as many possible solutions to a problem as } \\
\text { possible. }\end{array}$ & Not at all & A little & Some & A lot & Very much \\
\hline $\begin{array}{l}\text { 23. Create as many possible solutions to a problem as } \\
\text { possible. }\end{array}$ & Not at all & A little & Some & A lot & Very much \\
\hline 24. Evaluate a solution to a problem. & Not at all & A little & Some & A lot & Very much \\
\hline \multicolumn{6}{|l|}{ Emotional Skills } \\
\hline 25. Know how to deal with my emotions. & Not at all & A little & Some & A lot & Very much \\
\hline 26. Use my emotions to stay focused. & Not at all & A little & Some & A lot & Very much \\
\hline $\begin{array}{l}\text { 27. Understand that I behave differently when } \\
\text { emotional. }\end{array}$ & Not at all & A little & Some & A lot & Very much \\
\hline 28. Notice how I feel. & Not at all & A little & Some & A lot & Very much \\
\hline
\end{tabular}

\section{Leadership}

\begin{tabular}{|c|c|c|c|c|c|}
\hline $\begin{array}{l}\text { 29. Know how to positively influence a group of } \\
\text { individuals. }\end{array}$ & Not at all & A little & Some & A lot & Very much \\
\hline 30. Organize team/ group members to work together. & Not at all & A little & Some & A lot & Very much \\
\hline 31. Know how to motivate others. & Not at all & A little & Some & A lot & Very much \\
\hline 32. Help others solve their performance problems. & Not at all & A little & Some & A lot & Very much \\
\hline $\begin{array}{l}\text { 33. Consider the individual opinions of each team/ } \\
\text { group member. }\end{array}$ & Not at all & A little & Some & A lot & Very much \\
\hline 34. For this question, please circle "A little" and "A lot" & Not at all & A little & Some & A lot & Very much \\
\hline 35. Be a good role model for others. & Not at all & A little & Some & A lot & Very much \\
\hline 36. Set high standards for the team/ group. & Not at all & A little & Some & A lot & Very much \\
\hline 37. Recognize other people's achievements. & Not at all & A little & Some & A lot & Very much \\
\hline
\end{tabular}

\section{Time Management}

\begin{tabular}{|l|lllll|}
\hline 38. Manage my time well. & Not at all & A little & Some & A lot & Very much \\
\hline 39. Assess how much time I spend on various activities. & Not at all & A little & Some & A lot & Very much \\
\hline 40. Control how I use my time. & Not at all & A little & Some & A lot & Very much \\
\hline 41. Set goals so that I use my time effectively. & Not at all & A little & Some & A lot & Very much \\
\hline
\end{tabular}

\section{Communication}

42. Speak clearly to others.

43. Pay attention to what someone is saying.

44. Pay attention to people's body language.

45. Communicate well with others.

\begin{tabular}{|lllll|}
\hline Not at all & A little & Some & A lot & Very much \\
\hline Not at all & A little & Some & A lot & Very much \\
\hline Not at all & A little & Some & A lot & Very much \\
\hline Not at all & A little & Some & A lot & Very much \\
\hline
\end{tabular}




\section{Appendix D5}

\begin{tabular}{|c|c|c|c|c|c|c|c|c|}
\hline $\begin{array}{l}\text { For each statement, please circle the } \\
\text { number that you feel most accurately } \\
\text { describe you. Please note that there is } \\
\text { no right or wrong answer. }\end{array}$ & 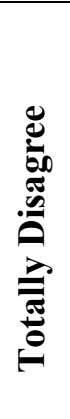 & 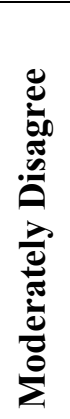 & 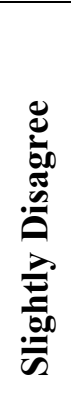 & 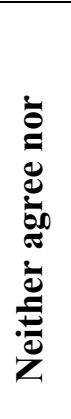 & 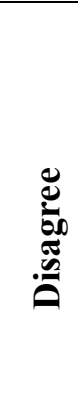 & 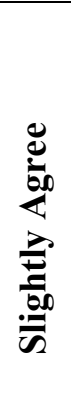 & 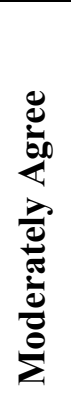 & 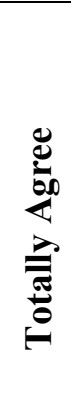 \\
\hline $\begin{array}{l}\text { 1. I usually don't laugh or joke around much } \\
\text { with other people. }\end{array}$ & 1 & 2 & 3 & & 4 & 5 & 6 & 7 \\
\hline $\begin{array}{l}\text { 2. I let people laugh at me or make fun at } \\
\text { my expense more than I should. }\end{array}$ & 1 & 2 & 3 & & 4 & 5 & 6 & 7 \\
\hline $\begin{array}{l}\text { 3. I don't have to work very hard at making } \\
\text { other people laugh-I seem to be a naturally } \\
\text { humorous person. }\end{array}$ & 1 & 2 & 3 & & 4 & 5 & 6 & 7 \\
\hline $\begin{array}{l}\text { 4. I will often get carried away in putting } \\
\text { myself down if it makes my family or } \\
\text { friends laugh. }\end{array}$ & 1 & 2 & 3 & & 4 & 5 & 6 & 7 \\
\hline $\begin{array}{l}\text { 5. I often try to make people like or accept } \\
\text { me more by saying something funny about } \\
\text { my own weaknesses, blunders, or faults. }\end{array}$ & 1 & 2 & 3 & & 4 & 5 & 6 & 7 \\
\hline $\begin{array}{l}\text { 6. I laugh and joke a lot with my closest } \\
\text { friends. }\end{array}$ & 1 & 2 & 3 & & 4 & 5 & 6 & 7 \\
\hline $\begin{array}{l}\text { 7. I usually don't like to tell jokes or amuse } \\
\text { people. }\end{array}$ & 1 & 2 & 3 & & 4 & 5 & 6 & 7 \\
\hline
\end{tabular}




\begin{tabular}{|c|c|c|c|c|c|c|c|}
\hline $\begin{array}{l}\text { 8. I often go overboard in putting myself } \\
\text { down when I am making jokes or trying to } \\
\text { be funny. }\end{array}$ & 1 & 2 & 3 & 4 & 5 & 6 & 7 \\
\hline 9. I enjoy making people laugh. & 1 & 2 & 3 & 4 & 5 & 6 & 7 \\
\hline $\begin{array}{l}\text { 10. When I am with friends or family, I } \\
\text { often seem to be the one that other people } \\
\text { make fun of or joke about. }\end{array}$ & 1 & 2 & 3 & 4 & 5 & 6 & 7 \\
\hline $\begin{array}{l}\text { 11. I don't often joke around with my } \\
\text { friends. }\end{array}$ & 1 & 2 & 3 & 4 & 5 & 6 & 7 \\
\hline $\begin{array}{l}\text { 12. Letting others laugh at me is my way of } \\
\text { keeping my friends and family in good } \\
\text { spirits. }\end{array}$ & 1 & 2 & 3 & 4 & 5 & 6 & 7 \\
\hline
\end{tabular}




\section{Appendix E}

\section{Supplemental Materials}




\section{Appendix E1}

\section{Coach-PSDQ (C-PSDQ)}

REMEMBER: Make two ratings for each item; (1) rate how often your mother [M] (coach) exhibited this behavior with you when you were a child and towards you as a player (2) how often your father $[F]$ exhibited this behavior with you when you were a child. What coaching style would you prefer or think is ideal for you?

\begin{tabular}{|c|c|}
\hline My COACH EXHIBITED THIS BEHAVIOR & PREFERRED COACHING STYLE \\
\hline MY MOTHER EXHIBITED THIS BEHAVIOR & MY FATHER EXHIBITED THIS \\
\hline \multicolumn{2}{|l|}{ BEHAVIOR: } \\
\hline $1=$ Never & $1=$ Never \\
\hline $2=$ Once In Awhile & $2=$ Once In Awhile \\
\hline $3=$ About Half of the Time & $3=$ About Half of the Time \\
\hline $4=$ Very Often & $4=$ Very Often \\
\hline $5=$ Always & $5=$ Always \\
\hline
\end{tabular}

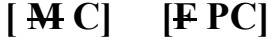

1. My parent [coach] was responsive to my feelings and needs.

2. My [coach] used physical punishment as a way of disciplining me.

3. My parent [coach] took my desires into account before asking me to do something.

4. When I asked why I had to conform, [she stated] [he stated]: because I said so, or I am your parent [coach] and I want you to.

5. My parent [coach] explained to me how she/he felt about my good and bad behavior.

6. My parent spanked [coach used exercise as punishment (e.g. run laps, push-ups, etc.) me when I'm disobedient.

7. My parent [coach] encouraged me to talk about my troubles.

8. My parent found it difficult to discipline me.

9. My parent-[coach] encouraged me to freely express myself even when I disagreed with them.

10. My parent [coach] punished me by taking privileges away from me with little if any explanations.

11. My parent [coach] emphasized the reasons for rules.

12. My parent [coach] gave comfort and understanding when I was upset.

13. My parent [coach] yelled or shouted when I misbehaved.

14. My parent [coach] praised me when I was good.

15. My parent gave into me when I caused a commotion about something.

16. My parent [coach] exploded in anger towards me.

17. My parent threatened me with punishment more often than actually giving it.

18. My parent [coach]took into account my preferences in making plans for the family [team].

19. My parent [coach] grabbed me when I was being disobedient. 20. My parent stated punishments to me and did not actually do them.

21. My parent [coach] showed respect for my opinions by encouraging me to express them. 
22. My parent [coach] allowed me to give input into family rules.

23. My parent [coach] scolded or criticized me to make me improve.

24. My parent spoiled me.

25. My parent [coach] gave me reasons why rules should be obeyed.

26. My parent [coach] used threats as punishment with little or no justification.

27. My parent [coach] had warm and intimate times with me [that were personally meaningful].

28. My parent [coach] punished by putting me off somewhere alone with little if any explanations.

29. My parent [coach] helped me to understand the impact of my behavior by encouraging me to talk about the consequences of my own actions.

30. My [coach] scolded or criticized me when my behavior didn't meet their expectations.

31. My parent [coach] explained the consequences of my behavior.

32. My parent [coach] slapped me when I misbehaved. 


\section{Appendix E2}

Table 4.2

Correlations between Time 1 and Time 2 Coaching Style Factors

Time 1

$\begin{array}{lllll}1 & 2 & 3 & 4 & 5\end{array}$

\section{Authoritarian}

2. Authoritative

3. AA-Difference

4. Caring Climate 5. Mastery Climate 6. Ego Climate

.10

$\begin{array}{ll}.10 \\ .68 & .67\end{array}$

$\begin{array}{cc}.68 & .67 \\ -.09 & 40^{* *}\end{array}$

$-.15 .43^{* *}$

$.06-.19=-.43$

$-.18$

Note. $* p<.05, * * p<.01, * * * p<.001$
Time 2

$\begin{array}{lllll}1 & 2 & 3 & 4 & 5\end{array}$

$-.03$

$-.71^{* *} \quad .72$

$-.03 \quad .43^{* *} \quad .32^{*}$

$.04 \quad .43^{* *} \quad .27^{*} \quad .48^{* *}$

$\begin{array}{lllll}.37^{* *} & -.15 & -.36 & -.10 & -.10\end{array}$ 


\section{Appendix E3}

Table 4.3

Correlations between Time 1 and Time 2 Life Skills Outcomes Total and Subscales

\begin{tabular}{|c|c|c|c|c|c|c|c|c|c|c|c|c|c|c|c|c|}
\hline & \multicolumn{8}{|c|}{ Time 1} & \multicolumn{8}{|c|}{ Time 2} \\
\hline & 1 & 2 & 3 & 4 & 5 & 6 & 7 & 8 & 1 & 2 & 3 & 4 & 5 & 6 & 7 & 8 \\
\hline 1. LS Total & & & & & & & & & & & & & & & & \\
\hline 2. Teamwork & $.74^{* *}$ & & & & & & & & $.87^{* *}$ & & & & & & & \\
\hline 3. Goal Setting & $.73^{* *}$ & $.62^{* *}$ & & & & & & & $.88^{* *}$ & $.74^{* *}$ & & & & & & \\
\hline 4. Social Skills & $.73^{* *}$ & $.56^{* *}$ & $.40^{* *}$ & & & & & & $.71^{* *}$ & $.63^{* *}$ & $.48^{* *}$ & & & & & \\
\hline 5. Problem Solving & $.81^{* *}$ & $.41^{* *}$ & $.63^{* *}$ & $.48^{* *}$ & & & & & $.79^{* *}$ & $.61^{* *}$ & $.67^{* *}$ & $.52^{* *}$ & & & & \\
\hline 6. Emotional & $.74^{* *}$ & $.43^{* *}$ & $.41^{* *}$ & $.45^{* *}$ & $.55^{* *}$ & & & & $.72^{* *}$ & $.54^{* *}$ & $.61^{* *}$ & $.36^{* *}$ & $.59^{* *}$ & & & \\
\hline 7. Leadership & $.84^{* *}$ & $.70^{* *}$ & $.57^{* *}$ & $.64^{* *}$ & $.61^{* *}$ & $.67^{* *}$ & & & $.92^{* *}$ & $.82^{* *}$ & $.77^{* *}$ & $.58^{* *}$ & $.63^{* *}$ & $.63^{* *}$ & & \\
\hline 8. Time Mgmt. & $.80^{* *}$ & $.57^{* *}$ & $.40^{* *}$ & $.53^{* *}$ & $.54^{* *}$ & $.52^{* *}$ & $.58^{* *}$ & & $.82^{* *}$ & $.62^{* *}$ & $.70^{* *}$ & $.45^{* *}$ & $.58^{* *}$ & $.60^{* *}$ & $.77^{* *}$ & \\
\hline 9. Communication & $.79^{* *}$ & $.41^{* *}$ & $.52^{* *}$ & $.48^{* *}$ & $.61^{* *}$ & $.53^{* *}$ & $.48^{* *}$ & $.77^{* *}$ & $.85^{* *}$ & $.70^{* *}$ & $.69^{* *}$ & $.58^{* *}$ & $.58^{* *}$ & $.53^{* *}$ & $.77^{* *}$ & $.79^{* *}$ \\
\hline
\end{tabular}

Note. $* p<.05, * * p<.01, * * * p<.00$ 


\section{Appendix E4}

Table 4.4

One-way Repeated Measures ANOVA of Changes in Life Skills (Outcomes) Over Time

\begin{tabular}{|c|c|c|c|c|c|c|c|}
\hline \multirow[b]{2}{*}{ Variables } & \multicolumn{2}{|c|}{ Time 1} & \multicolumn{2}{|c|}{ Time 2} & \multirow[b]{2}{*}{$\boldsymbol{F}$} & \multirow[b]{2}{*}{$R^{2}$} & \multirow[b]{2}{*}{$p$} \\
\hline & $M$ & $S D$ & $M$ & $S D$ & & & \\
\hline LS Total & 4.04 & .56 & 4.18 & .55 & 6.49 & .12 & $.01 *$ \\
\hline Teamwork & 4.30 & .63 & 4.38 & .59 & 1.45 & .03 & .24 \\
\hline Goal Setting & 4.25 & .72 & 4.33 & .62 & 1.56 & .03 & .23 \\
\hline Social Skills & 4.03 & .67 & 4.09 & .71 & .341 & .01 & .56 \\
\hline Problem Solving & 3.73 & .92 & 3.86 & .79 & 1.56 & .03 & .22 \\
\hline Emotional Skills & 3.84 & .69 & 4.02 & .81 & 2.87 & .06 & .09 \\
\hline Leadership & 4.15 & .66 & 4.22 & .67 & 1.30 & .03 & .26 \\
\hline Time Mgmt. & 4.05 & .73 & 4.09 & .73 & .15 & .00 & .70 \\
\hline Communications & 4.02 & .76 & 4.22 & .66 & 3.85 & .08 & .07 \\
\hline
\end{tabular}

Notes. $\mathrm{N}=47$. Time was the within subjects' predictor and Life Skills total and subscales scores were the dependent variables. $* p<.01$. 


\section{Appendix E5}

Table 4.5

One-way Repeated Measures ANOVA of Changes in Coaching Style (Predictors) Over Time

\begin{tabular}{lcccccccc}
\hline & \multicolumn{2}{c}{ Time 1 } & & \multicolumn{2}{c}{ Time 2 } & & & \\
\cline { 2 - 5 } \cline { 8 - 9 } Variables & $\boldsymbol{M}$ & $\boldsymbol{S D}$ & & $\boldsymbol{M}$ & $\boldsymbol{S D}$ & $\boldsymbol{F}$ & $\boldsymbol{R}^{\mathbf{2}}$ & $\boldsymbol{p}$ \\
\hline Authoritarian & 2.33 & .81 & & 2.25 & .80 & .54 & .01 & .47 \\
Authoritative & 3.48 & .80 & & 3.63 & .72 & 2.71 & .06 & .06 \\
AA-Difference & 1.13 & .1 .05 & & 1.39 & 1.10 & 2.30 & .05 & .14 \\
Caring Climate & 4.52 & .50 & & 4.54 & .42 & .20 & .00 & .66 \\
Mastery Climate & 4.61 & .56 & & 4.68 & .39 & 1.28 & .03 & .26 \\
Ego Climate & 2.63 & .90 & & 2.77 & .76 & 1.98 & .04 & .17 \\
\hline
\end{tabular}

Notes. $\mathrm{N}=46$. Time was the within subjects' predictor and the six coaching style scores were the dependent variables. ${ }^{*} p<.01$. 


\section{Appendix E6}

Table 4.6

Simple Regression Analysis of Coaching Variables Predicting Life Skills Change Scores

\begin{tabular}{lccccccc}
\hline Variables & $\boldsymbol{B}$ & $\boldsymbol{S} \boldsymbol{E} \boldsymbol{B}$ & $\boldsymbol{\beta}$ & $\boldsymbol{R}^{\mathbf{2}}$ & $\boldsymbol{t}$ & $\boldsymbol{F}$ & $\boldsymbol{p}$ \\
\hline Authoritarian & -.11 & .07 & -.23 & .05 & -1.55 & 2.41 & .13 \\
Authoritative & -.07 & .07 & -.15 & .02 & -1.03 & 1.07 & .31 \\
AA-Difference & .02 & .05 & .06 & .00 & .43 & .19 & .67 \\
Caring Climate & -.02 & .10 & -.03 & .00 & -.22 & .05 & .83 \\
Mastery Climate & .10 & .11 & .14 & .02 & .92 & .84 & .36 \\
Ego Climate & -.08 & -.06 & -.21 & .05 & -1.45 & 2.11 & .15 \\
\hline
\end{tabular}

Notes. $\mathrm{N}=47 . * p<.01$. 


\section{Appendix E7}

Table 4.7

Two-Way ANOVA Models of Coaching Factors by Time for Predicting Life Skills Scores (Wilks' Lambda Coefficients)

\begin{tabular}{lccc}
\hline Models & $\boldsymbol{F}$ & Error $\boldsymbol{d f}$ & $\boldsymbol{p}$ \\
\hline Time x Authoritarian & .01 & 44.00 & .93 \\
Time x Authoritative & 1.83 & 44.00 & .18 \\
Time x AA-Difference & .25 & 44.00 & .62 \\
Time x Caring Climate & .18 & 44.00 & .68 \\
Time x Mastery Climate & .74 & 44.00 & .39 \\
Time x Ego Climate &, 09 & 44.00 & .77 \\
\hline
\end{tabular}

Notes. $\mathrm{N}=79 . * p<.05$. 


\section{Appendix E8}

Table 4.8

Simple Regression Analysis of Coaching Variables Predicting Life Skills at Time 2

\begin{tabular}{lccccccc}
\hline Variables & $\boldsymbol{B}$ & $\boldsymbol{S E} \boldsymbol{B}$ & $\boldsymbol{\beta}$ & $\boldsymbol{R}^{\mathbf{2}}$ & $\boldsymbol{t}$ & $\boldsymbol{F}$ & $\boldsymbol{p}$ \\
\hline Authoritarian & -.15 & .11 & -.17 & .03 & -1.32 & 1.74 & .19 \\
Authoritative & .52 & .08 & .63 & .39 & 6.24 & 38.95 & $.00^{*}$ \\
AA-Difference & .36 & .06 & .59 & .35 & 5.69 & 32.39 & $.00^{*}$ \\
Caring Climate & .56 & .14 & .46 & .21 & 3.97 & 15.77 & $.00^{*}$ \\
Mastery Climate & .62 & .16 & .45 & .20 & 15.14 & 15.14 & $.00^{*}$ \\
Ego Climate & -.14 & .09 & -.19 & .04 & -1.50 & 2.24 & .14 \\
\hline
\end{tabular}

Notes. $\mathrm{N}=62 . * p<.01$. 


\section{Appendix E9}

Table 4.9

Backwards Regression of Coaching Style Factors

\begin{tabular}{|c|c|c|c|c|c|c|c|c|}
\hline & $\boldsymbol{B}$ & $S E B$ & $\beta$ & $R^{2}$ & $\operatorname{AdjR}^{2}$ & $t$ & $F$ & $p$ \\
\hline Model 1 & & & & .48 & .43 & 1.65 & 10.18 & .10 \\
\hline Authoritarian & -.17 & .79 & -.20 & & & -1.93 & & .59 \\
\hline Authoritative & .42 & .09 & .52 & & & 4.53 & & $.00^{* *}$ \\
\hline Caring Climate & .16 & .16 & .13 & & & 1.01 & & .32 \\
\hline Mastery Climate & .21 & .18 & .14 & & & 1.14 & & .26 \\
\hline Ego Climate & .01 & .08 & .01 & & & .08 & & .94 \\
\hline Model 2 & & & & .48 & .44 & 1.82 & 12.96 & .08 \\
\hline Authoritarian & -.17 & .08 & -.19 & & & -2.01 & & $.05^{*}$ \\
\hline Authoritative & .42 & .09 & .52 & & & 4.61 & & $.00^{* *}$ \\
\hline Caring Climate & .16 & .16 & .13 & & & 1.02 & & .31 \\
\hline Mastery Climate & .21 & .18 & .14 & & & 1.14 & & .26 \\
\hline Model 3 & & & & .47 & .44 & 2.28 & 16.93 & $.03^{*}$ \\
\hline Authoritarian & -.18 & .08 & -.20 & & & -2.10 & & $.04^{*}$ \\
\hline Authoritative & .44 & .09 & .55 & & & 5.08 & & $.00^{* *}$ \\
\hline Mastery Climate & .30 & .16 & .20 & & & 1.86 & & .07 \\
\hline
\end{tabular}

Notes. $* p<.05, * * p<.01$. 


\section{Appendix E10}

Table 4.10

Two-Way ANOVA Models of Authoritarian, Authoritative, and AA-Difference by Coaching Climate Factors for Predicting Life Skill Scores

\begin{tabular}{|c|c|c|c|c|c|}
\hline Models & $d f$ & $S S$ & $M S$ & $\boldsymbol{F}$ & $\boldsymbol{P}$ \\
\hline Authoritarian x Caring Climate & 3 & 2.72 & .91 & 2.29 & .08 \\
\hline Authoritarian x Mastery Climate & 3 & 1.70 & .57 & 1.37 & .26 \\
\hline Authoritarian x Ego Climate & 3 & 1.01 & .34 & .79 & .50 \\
\hline Authoritative x Caring Climate & 3 & 5.47 & 1.82 & 5.26 & $.00^{*}$ \\
\hline Authoritative x Mastery Climate & 3 & 4.80 & 1.60 & 4.47 & $.01^{*}$ \\
\hline Authoritative x Ego Climate & 3 & 4.87 & 1.62 & 4.55 & $.01^{*}$ \\
\hline AA-Differences x Caring Climate & 3 & 5.06 & 1.69 & 4.77 & $.01^{*}$ \\
\hline AA-Differences x Mastery Climate & 3 & 4.48 & 1.49 & 4.10 & $.01^{*}$ \\
\hline AA-Differences x Ego Climate & 3 & 4.11 & 1.37 & 3.70 & $.02 *$ \\
\hline
\end{tabular}

Notes. $\mathrm{N}=46 .{ }^{*} p<.05$. Only significant main effect for Authoritative and AA-Difference found. Group means reported in Results. 
Table 4.11

\section{Appendix E11}

One-Way ANOVA of Authoritarian Coaching Style by Team

\begin{tabular}{lccc}
\hline Team & $\boldsymbol{M}$ & $\boldsymbol{S D}$ & $\boldsymbol{t}$ \\
\hline Team A & 2.14 & .52 & $.00^{*}$ \\
Team B & 1.89 & .55 & $.00^{*}$ \\
Team C & 3.07 & .74 & \\
Team D & 1.86 & .73 & $.00^{*}$ \\
Team E & 2.28 & .52 & $.00^{*}$ \\
\hline
\end{tabular}

Notes. $\mathrm{N}=80 . t$-values are for Team C comparisons using Gabriel's poc hoc procedure. ${ }^{*} p<.05$. 


\section{Appendix E12}

Table 4.12

One-Way ANOVA of AA-Difference Coaching Style by Team

\begin{tabular}{lccc}
\hline Team & $\boldsymbol{M}$ & $\boldsymbol{S D}$ & $\boldsymbol{t}$ \\
\hline Team A & 1.10 & .82 & .93 \\
Team B & 1.51 & .82 & .24 \\
Team C & .68 & .86 & \\
Team D & 1.83 & 1.46 & $.02^{*}$ \\
Team E & 1.01 & .89 & .99 \\
\hline
\end{tabular}

Notes. $\mathrm{N}=80 . t$-values are for Team $\mathrm{C}$ comparisons using Gabriel's poc hoc procedure. $* p<.05$. 